\title{
Zur Aetiologie, Diagnostik und Therapie der Extrauteringravidität.
}

Von

\section{Privatdocent Dr. Richard von Braun-Fernwald.}

In den letzten Jahren hat die Lehre von der Extrauteringravidität hauptsächlich infolge der vielen operativ gewonnenen Präparate in einer sehr grossen Reihe von Arbeiten eine bedeutende Förderung erfahren und wurden die verschiedenen Erscheinungen der pathologischen Eieinnistung in vielfacher Hinsicht geklärt; doch findet sich in manchen Punkten keine volle Uebereinstimmung. Es sei mir nun gestattet, an der Hand von einzelnen beobachteten Fällen entsprechend dem gesetzten Thema die noch offenen Fragen zu erörtern.

Als häufigste Ursache für die Bildung einer Extrauteringravidität wird jetzt wohl von den meisten Autoren eine entzündliche Erkrankung der Tuben angesehen, sei es nun, dass es sich nur um eine Verminderung der Kraft des Cilienstromes der Tubenschleimhaut oder dass es sich um eine Entzündung der Schleimhaut oder endlich um tiefer in die Muskularis der Tube oder auf das Peritoneum übergreifende Processe und deren Folgezustände handelt, So sieht Dührssen in der Endosalpingitis das hauptsächlichste aetiologische Moment für das Zustandekommen einer Tubenschwangerschaft, er konnte in $68,7 \%$ feststellen, dass die geschwängerte Tube bereits vor dem Eintritt der Schwangersehaft erkrankt war. Er fand an seinen Präparaten die entzündlichen Veränderungen am uterinen Ende stärker als am abdominellen und es erklärt der Befund, dass das $E j$ noch in die Tube eindringen kann, im weiteren Verlauf aber die Kräfte lahmgelegt sind, welche 
seine Fortbewegung bewirken. Schautal) nimmt an, dass in ca. $3 / 4$ aller Fälle die Tubenerkrankung die Ursache der Extrauteringravidität ist und hebt hervor, dass als bäufigste Ursache die Gonorrhoe anzusehen ist.

Er erklärt die Entstehung der Tubargravidität infolge von salpingitischen Processen in folgender Weise: "Ein ascendirender Process des Uterus, meist ascendirende Gonorrhoe, ergreift selten beide Tubenlumina gleichzeitig . . . und befällt dem ascendirenden Charakter der Erkrankung gemäss, aus dem Uterus auf die Tube übergreifend, zunächst den Isthmus, dann erst allmählich die Ampulle und dann erst das Tubenende."

Schauta stellt sich vor, „dass durch katarrhalische Schwellung der Isthmusschleimhaut bei offener Ampulle und normaler Schleimhaut des ampullären Theiles ein Ei, befruchtet auf dem Wege des kurz vorher noch durchgängigen Isthmus oder durch äussere Ueberwanderung in die Tube geräth und trotz der Flimmerbewegung im ampullären Theil doch in letzterem stecken bleibt; weil die Continuität des durch die Flimmerbewegung angeregten Flüssigkeitsstromes, der aus der Tube in den Uterus führt, durch die Unwegsamkeit des isthmischen Theiles der Tube unterbrochen ist und also wohl die Flimmerbewegung der Cilien bestehen, von einem Flüssigkeitsstrome wegen der Rückstauung vom Isthmus her aber nicht die Rede sein kann."

Diese Errklärung passt vorzüglich für Fälle, in denen die Tubengravidität nicht allzulange nach der Infection beobachtet wird, aber weniger gut für Fälle, in denen eine langjährige Erkrankung vorangegangen ist.

Wenn bei einer Operation auch die andere Tube entzündlich erkrankt gefunden wird, so spricht dieser. Umstand wohl sehr dafür, dass eine Tubenerkrankung den Grund für die Bildung einer Extrauteringravidität abgegeben habe. So fanden wir in den in Betracht gezogenen Fällen $4 \mathrm{Mal}$ die Adnexe der anderen Seite erkrankt (I, VI, VII, VIII), und zwar wurde 2 mal eine Pyosalpinx (T und VIII) und 2 mal eine Hydrosalpinx (VI und VII) vorgefunden. Es darf aber bei Beurtheilung solcher Fälle auch nicht übersehen werden, dass besonders in Fällen, in denen es sich um das gleichzeitige Bestehen einer Hydrosalpinx auf der anderen Seite handelt, nicht immer diese vor dem Eintreten der Extrauteringravidität bestanden

1) F. Schauta, Lehrbuch der gesammten Gynäkologie. 1898. S. 88. 
haben muss. Es lässt sich sehr gut denken, dass bei einer grösseren Haematocele, die gleichzeitig die andere Tube verlagert und verschliesst, durch diese die Hydrosalpinx der andern Seite bedingt ist.

Wenn auch von den meisten Autoren Tubenerkrankungen als häufiger Grund für das Entstehen einer Extrauteringravidität angesehen werden, so wird dagegen von manchen Autoren geradezu hervorgehoben, dass solche höchst selten den Grund abgeben dürften.

So behauptet $\mathrm{Pagny}^{1}$ ) als Vertreter der Ansichten Pinard's, dass die Anamnese bei Frauen, bei denen sich eine Extrauterinschwangerschaft entwickelt hat, nur höchst selten auf ein früher bestandenes Genitalleiden hinweist (in 20 Fällen Pinard's nur $4 \mathrm{Mal}$ ).

Bouilly ${ }^{2}$ ) glanbt nicht, dass Veränderungen in der Tubenschleimhaut eine Rolle spielen, wohl aber schleichend verlaufende Endometritiden und Perimetritiden, die zu Fixationen, Verengerungen und Abknickungen führen.

A. Martin, der im Jahre 1886 dafür eingetreten war, dass die Endosalpingitis dadurch zur tubaren Schwangerschaft führe, dass sie die Cilien zerstöre und damit die Fortbewegung des Eies behindere, hat auf Grund seiner Beobachtungen seinen Standpunkt in dieser Frage wesentlich geändert; er sagt in seinem Werke "Krankheiten der Eileiter" (pag. 311): „Es erscheint unzweifelhaft, dass ebenso wie im Uterus eine nicht normale Schleimbaut jedenfalls sich nur ausnahmsweise zur Decidua entwickelt (Sterilität bei Endometritis), so auch in der Tube ein gesundes Fleckchen übrig geblieben sein muss, soll sich darin ein Ei einbetten und einen gesunden Nährboden finden. Mag also immerhin Endosalpingitis vorhergegangen sein, mag ein Theil der Tube noch die Spuren derselben zeigen - eine vielleicht partielle Heilung muss stattgefunden haben. Verursacht Endosalpingitis eine Veränderung der Secretion der Tubenschleimbaut, so wird Conception überhaupt ausgeschlossen sein" etc. - "Residuen eitriger Secretion medianwärts vom Ei sind mit grosser Wahrscheinlichkeit als nachträglich entstanden anzusehen."

Ferner hält Martin den so häufig von dem angetroffenen Befund inniger Verwachsungen der Tubenoberfläche und der ganzen

1) Pagny, E., Beitrag zum Studium der Extrauterinschwangerschaft: Ueber die Schwangerschaften, welche sich in gesunden Tuben entwickelt haben. Thèse de Paris. G. Steinheil, ref. im Centralblatt f. Gyn. 1897. No. 48. S. 1428.

2) Bouilly, La gynéc. 1899. No. 1. p. 1. 
Beckenorgane in vielen Fällen für das Product der Tubenschwangerschaft, nicht für ihre Ursache, welch' letzterer Ansicht ich mich auch anschliessen möchte.

In unserem Falle No. III, in dem wegen freier Blutung in die Bauchhöhle bei incompletem Tubarabort laparotomirt wurde, waren gar keine Prämissen für eine Tubenerkrankung gegeben, da die verheirathete Dame in ständiger ärztlicher Beobachtung stand und daher das Bestehen eines gonorrhoischen Processes mit voller Sicherheit ausgeschlossen werden muss. Es war aber auch das Puerperium nach der ersten Geburt ganz normal verlaufen, so dass von daher keine Tubenerkrankung zurüekgeblieben sein kann. Dementsprechend erschien auch grob anatomisch der uterine Antheil der das Ei beherbergenden Tube ebenso wie die ganze Tube der anderen Seite vollständig normal. In diesem Falle dürfte demnach eine. Erkrankung der Tube kaum als ätiologisches Moment in Betracht kommen. Das Ovarium wurde zurückgelassen, so dass auch nicht zu ermitteln ist, ob in diesem ein Corpus luteum gesessen war oder nicht; es lässt sich also nicht bestimmen, ob eine äussere Ueberwanderung des Eies stattgefunden hat.

Wenn wir auch im Allgemeinen eine völlig gesunde Tube für weniger geeignet zur Eieinnistung in derselben halten, so sprechen doch manche Fälle (wie unserer) dafür, dass auch in einer gesunden Tube das Ei sich implantiren kann.

Andererseits kann sich auch in einer schwer erkrankten Tube das befruchtete Ei festsetzen, und dies ist gewiss sonderbarer als die Implantation in einer gesunden Tube. So konnten Schober ${ }^{1}$ ) und Freericks ${ }^{2}$ ) je in einem Falle Tubenschwangerschaft in einer tuberkulös veränderten Tube feststellen; im ersteren Falle handelte es sich um eine lange bestehende Tuberkulose. Alexander und Moskowicz ${ }^{3}$ ) fanden an der Abtheilung Gersuny's eine Graviditas infundibulopelvica bei Tuberkulose der Tube und des Bauchfelles.

Prochownjk4) beschrieb einen Fall von Schwängerung einer noch nicht lange erkrankten Trippertube mit sicher zur Operationszeit noch virulenten Kokken im eitrigen Secret.

1) Schober, Centralblatt für Gyn. 1899. S. 662.

2) Freericks, Centralblatt für Gyn. 1897. S. 1278.

3) Alexander und Moskowicz, Centralbl. für Gyn. 1900. S. 1182.

4) Prochownik, Zur Mechanik des Tubenabortes. Dieses Archiv. 1899. S. 1049. 
Auch Küstner fand in einem Falle Eiter neben einer Schwangerschaft in der Tube.

Moskowiez ${ }^{1}$. konnte in einem Falle wohl Gonokokken und Staphylokokken im Pyosalpinx der anderen Tube nachweisen, der Inhalt der Tube, die vor dem Tubenabort das Ei beherbergt hatte, erwies sich aber als steril.

Durch die bekannte Arbeit Webster's wurde die F'rage nach der Aetiologie der Extrauteringraviditat in eine andere Bahn geleitet. Webster ${ }^{2}$ ) fand nämlich in zwei Fällen eine deciduale Veränderung der Schleimhaut der anderen Tube, welcher Befund später auch ron Mandl in einem Falle aufgenommen werden konnte. Seine Erfahrungen verwerthete M. dazu; eine Hypothese aufzustellen, „die eine befriedigende Erklärung all der wohl anerkannten Formen der ectopischen Gravidität gestattet.". Er beruft sich auf das verschiedene Verhalten der einzelnen Abschnitte der Müller'schen Gänge an verschiedenen Thieren und weist darauf hin, dass z. B. bei der Kuh sich nur ein Ei in einem der Hörner entwickelt, aber die Schleimhaut beider Hörner — das Resultat des genetischen Einflusses - deutliche deciduale Veränderungen aufweise. In ähnlicher Weise könne beim menschlichen Weibe die Tubenschleimhaut in grosser oder kleiner Ausdehnung auf den genetischen Einfluss reagiren; dies sei verursacht durch eine Art von Entwickelungsfehler, so dass ein grösserer Theil der Müllerschen Gänge deciduale Reaction zeigt; darauf beruhe es, dass das befruchtete $\mathrm{Ei}$ sich in der Tube weiter entwickeln könne."

Wenn diese Bedingungen erfüllt sind, dann bestimmen zahlreiche Faktoren, ob ein befruchtetes $\mathrm{Ei}$ in der Tube oder in Uterus zur Entwicklung gelangen soll und sei hierbei der Ort der Befruchtung von Wichtigkeit. Sippel nimmt dagegen an, dass die deciduale Reaction wahrscheinlich jeder Tube zukomme, wenn das befruchtete Orulum einen gewissen Grad der Entwicklung erreicht habe.

Mandl u. Schmit haben in ihrer werthvollen Arbeit ${ }^{3}$ ) durch Thierexperimente $\mathrm{zu}$ ergründen getrachtet, ob die Behinderung des Eintrittes des befruchteten Eies in die Gebärmutter hinreiche in

1) Moskowicz, Centralbl. für Gyn. 1899. S. 1049.

2) Webster, Die ectopische Schwangerschaft etc. Deutsch von Eiermann. Berlin. Karger. 1896.

3) Mandl und Sehmit, Beiträge zur Aetiologie und pathol. Anatomie der Eileiterschwangerschaften. Dieses Archiv. Bd. 56. S. 401. 
jedem Falle Tubenschwangerschaft zu erzeugen. Sie konnten constatiren, dass wenn sie bei ihren Versuchen am geschwängerten Kaninchen nur die Tube abbanden, sie nie eine Extrauteringravidität zu Stande kommen sahen, dass dagegen eine Schwangerschaft eintrat, wenn sie ein Uterushorn abbanden und zwar in diesem Horn. Mandl u. Schmidt ziehen aus ihren Versuchen den Schluss, dass auch beim Menschen der durch irgend welche Momente behinderte Eintritt des befruchteten Eies in den Uterus nicht die alleinige und ausschlaggebende Ursache für die Bildung einer Tubenschwangerschaft sein dürfte. Es scheine die für jede Schwangerschaft unerlässliche Bedingung Decidua zu bilden nicht jeder Tube zuzukommen: - So kommen sie auf einem andern Wege zur Erklärung der Entstehung der Extrauteringravidität Webster's.

Bei Beurtheilung der Versuche von Mandl u. Schmidt muss man, wie ich glauben möchte, doch bedenken, dass die Verhältnisse nach Abbindung der Tube nicht ganz dieselben sind, als wie wenn z. B. durch eine Adhäsion eine Knickung der Tube und auf diese Weise ein Passagehinderniss für das $\mathrm{Ei}$ zu Stande kommmt, da ja durch die Ligatur am proximalen Ende der Tube die Circulationsverhältnisse der Tube geändert werden, wenn sie auch bei Abbindung der Uterushörner ein Fortbestehen der Gravidität in den abgebundenen Hörnern beobachten konnten.

Freund machte das Stehenbleiben der Tuben auf dem infantilen Typus als aetiologisches Moment geltend. Abel hat dies für 3 Fälle als einzige Ursache feststellen zu können geglaubt, doch hatte die Frau in einem der Fälle vorher $2 \mathrm{Mal}$ uterin concipirt. Auch Patellani ${ }^{1}$ ) verficht diese Ansicht: "Wenn ein Abschnitt des Müller'schen Ganges in seiner morphologischen Entwicklung auf einem vorkergehenden phylogenetischen Stadium stehen geblieben ist (Freund's Spiralwindungen beim erwachsenen Weibe), so müsse auch die Function dieses Genitalabschnittes der beständigen Function bei dem Thier entsprechen.

Auch Moericke ${ }^{2}$ ) spricht die Ueberzengung aus, dass die Entstehung einer Tubengravidität auf atavistischen Zuständen beruhe, er macht die schlechten hygienischen Verhältnisse vielmehr verantwortlich als die Gonorrhoe, und zwar beschuldigt er das $\mathrm{Ei}$ : „das

1) Patellani, Zeitschr. für Geb. und Gyn. Bd. XXXV. H. 3. S. 373.

2) Moericke, Zur Aetiologie derTubenschwangerschaft (Graefe's Sammlung zwangloser Abhandlungen. Bd. III. H. 4 und 5, Centralbl. für Gyn. 1900. Seite 493 . 
menschliche $\mathrm{Ei}$ vermag sich eben nur dann in der Tube einzunisten, wenn demselben eine morphologische oder functionelle Disteleologie innewohnt."

Diese atavistische Theorie lässt sich nicht gut vertheidigen; denn man müsste erwarten, dass in manchen Fällen immer nur extrauterine Eiimplantationen sich ereignen. Auch ist der Umstand schwer erklärlich, wie so an einer Frau normale Eiimplantationen mit extrauterinen abwechseln. Als besonders selten ist hier der Fall Kokmann's ${ }^{1}$ ) hervorzuheben, indem nach einer operativ entfernten Tubarschwangerschaft eine normale und dann wieder eine Gravidität in der gesunden Tube auftrat.

Bekanntlich hat schon Sippel' $)$ die Ueberwanderung des Eies als Erklärung für das Zustandekommen einer Extrauteringravidität herangezogen und Gottschalks) hat später 3 derartige Fälle veröffentlicht. Je einen Fall von äusserer Ueberwanderung des Eies hat. Hofmeier ${ }^{4}$, Martin ${ }^{5}$ ) und Mamurovsky ${ }^{6}$ ) publicirt. Schrenck ${ }^{7}$ ) führt in einer Zusammenstellung von 610 Fällen von Extrauteringravidität in 11 Fällen äusserer Ueberwanderung und in einem Falle sogar innere Ueberwanderung als aetiologisches Moment an.

Die Entstehung der Extrauteringravidität in Folge äusserer Ueberwanderung wird in der Weise erklärt, dass durch den aus der Ueberwanderung erwachsenen Zeitverlust das ki schon zu sehr verändert sein und deshalb in der Tube stecken bleiben soll. Küstner ${ }^{8}$ ) hält dagegen die Ueberwanderung des Eies für recht häufig, will aber diese Thatsache nicht obne weiteres im Sinne der gestörten Wanderungsmechanik des Eies aetiologisch verwerthet wissen.

Durch die Untersuchungen Hasse's wissen wir, dass nur die überwiegende Stärke des Flimmerschlages der einen Tube die

1) Kokmann, Centralbl. f. Gyn. 1897. S. 1221. Mon. f. Geb. u. Gyn. 1897. Bd. 5.

2) Sippel, Deutsche med. Wochonsehr. 1892.

3) Gottschalk, Centralbl. f. Gyn, 1898. S. 393.

4) Hofmeier, Ges. für Geb. u. Gyn. Berlin. 12. I. 1900. Centralb. f. Gyn. 1900. S. 233.

5) Martin, Zur Kenntniss der Tubenschwangersehaft. Mon. f. Geb. u. Gyn. 1897. H. 1.

6) Mamurovsky, Centralbl. f. Gyn. 1896. S. 1342.

7) Schrenck, Ueber ectop. Gravidität. In'-Dissert. Dorpat. 1890.

8) Küstner, Ueber Extrauterinschwangerschaft. Volkmann's Sammlung klin. Vorträge. No. 244/245. 
Aufnahme eines Eies aus einem anderen Eierstock ermöglichen. Die experimentellen Untersuchungen von Knauer und Grigorieff über Eierstocktransplantation brachten den Beweis, dass auch von transplantirten Ovarien aus die Eichen in die Tube gelangen, da Schwangerschaft eintreten kann. Wir können daher mit Küstner den Schluss ziehen, dass auch der physiologischen uterinen Gravidität eine äussere Ueberwanderung des Eies vorhergehen kann. Dagegen scheint uns der von Küstner citirte (l. c.) Fall nicht so zwingend die äussere Ueberwanderung zu beweisen, wie er es annimmt.

„Frau S. wurde am 13. März 1894 wegen rechtsseitiger Tubengravidität operirt und zugleich ein linksseitjger hühnereigrosser cystischer Ovarientumor entfernt, die Frau behielt also die linke Tube und das rechte Ovarium. Zu bemerken ist, dass bei der Operation nirgends peritonitische Stränge entdeckt wurden und dass die Konvalescenz völlig glatt verlief. Etwa 2 Jahre später wurde die Frau uterin gravid und am normalen Ende spontan entbunden."

Es ist in diesem Falle gewiss möglich, ja vielleicht sogar wahrscheinlich, dass es sich um eine äussere Ueberwanderung des Eies gehandelt hat, bewiesen ist dies aber durchaus nicht, da ja ebensogut das Ei durch den wieder wegsam gewordenen Tubenstumpf in das Uteruscavum eingetreten sein konnte. Wissen wir doch aus den Publicationen Pissemsky's ${ }^{1}$ ), Gordon's ${ }^{2}$ ). 0 . Schmidt's ${ }^{3}$, dass die unterbundene Tube wieder wegsam werden kann und so Gravidität eintreten kann, fèrner haben die Untersuchungen von $\mathrm{Ries}^{4}$ ) ergeben, dass in $3 \mathrm{Fällen} \mathrm{von} \mathrm{Uterusexstir-}$ pation nach vorausgegangenen Adnexexstirpationen die Tubenstümpfe durchgängig und bis zum offenen Ostium mit Epithel überkleidet waren.

Gordon ${ }^{5}$ ) berichtet sogar über 2 Fälle von Schwangerschaft nach Entfernung beider Tuben und Eierstöcke. Ebenso hat Abel ${ }^{6}$ ) die an der Klinik Zweifel gewonnene Erfahrung mitgetheilt, dass

1) Pissemsky, Verh. d. gyn. G. in Kiew. Centralbl. f. Gyn. 1897. 18.

2) Gordon, Centralbl. f. Gyn. XXI. S. 143.

3) 0. Schmidt Centralbl. f. Gyn. XXI. S. 117.

4) Ries, Centralbl. f. Gyn. XXI. S. 901.

5) Gordon, Verh. d. nordam. Ges. f. Gyn. Mai 1896. Centralbl. f. Gyn. 1896. S. 1052.

5) Abel, Dieses Archiv. Bd. 58. H. 2. S. 364. 
trotz Abbindung und Durchschneidung der Tuben gelegentlich eines Kaiserschnittes diese wieder sich vereinigen können und Schwangerschaft eintreten kann.

Endlich hat Fraenkel') experimentell nachgewiesen, dass der unterbundene Tubenstumpf wieder wegsam wird.

Dass der Tubenstumpf nicht nur das Ei durchtreten lassen kann, sondern sogar das befruchtete Ei beherbergen kann, beweist der folgende Fall Morfit's:

Morfit ${ }^{2}$ (St. Louis) musste 2 Jahre und 4 Monate, nachdem er einer Frau wegen Pyosalpinx rechterseits die Anhänge entfernt hatte, wegen geplatzter Tubenschwangerschaft die Laparotomie ausführen; dabei fand er zu seiner Ueberraschung, dass der Sitz des geplatzten Eisackes der Stumpf der Tube war, d'as rechte 0va'rium fehlte. In der Beschreibung des Präparates fehlt eine nähere Angabe, ob das. Tubenlumen an der Stelle der bei der ersten Operation erfolgten Abbindung durchgängig war. Morfit nimmt nun an, dass das Ei sich nur durch innere Ueberwanderung in dem Tubenstumpf eingenistet haben kann. Dies geht aus der Beschreibung des Falles durchaus nicht hervor, so dass es viel wahrscheinlicher erscheinen muss, dass nach Analogie der citirten Fälle das Lumen des Tubenstumpfes durchgängig war und so durch äussere Ueberwanderung des Eies die Extrauteringravidität zu Stande kam.

Eine innere Ueberwanderung des Eies erscheint viel unwahrscheinlicher, man kann sich doch schwer erklären, wieso das Ei in den Tubenstumpf befördert worden sei. Wenn Morfit auch nicht die Durchgängigkeit des Tubenendes aufgefallen ist, so konnte er es ganz leicht übersehen haben, da der Douglas durch Blutcoagula, „durch die er sich erst durcharbeiten musste", erfüllt war, also ein Verschluss der Oeffnung sehr leicht erst secundär erfolgt sein kann. Es wäre auch noch möglich, dass bei der Exstirpation des Ovarium ein Ovarialrest zurückgeblieben ist und das befruchtete Ei von diesem stammte, so dass es sich dann wieder um keine äussere Ueberwanderung handeln würde.

Dieser Fall ist auch deshalb interessant, weil er die Befürchtungen, dass in einem Tubenstumpf nach einfacher Unterbindung ohne Uebernähung des Stumpfes mit Peritoneum in der einen oder

3) Fränkel, Dieses Archiv. Bd. 58. H. 2.

1) Morfit, Stump pregnancy. Medical news. Jane. 1900. S. 870. 
der anderen Weise eine Tubengravidität sich bilden kann, als gerechtfertigt erweist.

Sippel') ist in jüngster Zeit von Nenem für seine Hypothese eingetreten und hat die von Martin (Krankheiten der Eileiter) gegen sie ausgesprochene Ansicht, dass das Ei im Verlauf der äusseren Ueberwanderung nicht zu gross geworden sein kann, um den engen Kanal der Tube zu passiren, dahin rectificirt, dass er nicht von der Grösse des Eies gesprochen habe, sondern „dass es bereits jenen Entwickelungsgrad erlangt hat, der einmal seine Oberfläche rauh macht und somit sein Weitergleiten erschwert und der ihm ferner die Eigenschaft giebt, den specifischen Reiz auf die Tubenschleimhaut auszuüben, welcher vom befruchteten Ei ausgehend dieselbe anregt, ihre Umwandlung in Decidualgewebe durchzumachen."

Er glaubt nicht, dass die Folgerungen, welche Mandl und Schmidt an ihre schönen und interessanten 'Versuche ohne weiteres knüpfen, ohne weiteres Geltung haben können, denn einmal ist es nicht sicher, $a b$ die in Betracht kommenden Thiere überhaupt Tubenschwangerschaft produciren können und zweitens fehlte immerhin der exacte Nachweis wirklich stattgehabter Befruchtung der in der ligirten Tube zu Grunde gehenden Ovula.

Derzeit kann man die Frage, ob die äussere Ueberwanderung des Eies bei der Entstehung der Extrauteringravidität eine Rolle spielt, nach alledem noch nicht entscheiden. Für Fälle, in denen kein anderes aetiologisehes Moment $z u$ finden ist, wird man wohl diese Erklärung als sehr glaubhaft annehmen müssen. Ich konnte eine äussere Ueberwanderung in 3 Fällen, No. I, VIII, XI constatiren. In den Fällen I und VIII fand sich auf der anderen Seite ein Pyosalpinx, im Falle XI im Ovar derselben Seite eine kleine Cyste. An der Klinik Schauta wurde sie unter 28 Fällen, an denen ein Corpus luteum nachgewiesen wurde, 2 mal beobachtet.

Küstner fand unverhältnissmässig häufig chronisch entzündete Ovarien bei Extrauterinschwangerschaft, und zwar waren es nicht nur die Einbettung des Ovariums in perimetritische Processe und perioophoritische Schwarten, sondern auch Processe, welche sich mit mehr Berechtigung in ihren Anfängen weiter zurück, wie die Entstehung der Extrauteringravidität, datiren liessen, also Oophoritis

1) Sippel, Ueber äussere Ueberwanderung des Eies, deciduale Reaction der Tube und Tubenschwangerschaft. Centralbl. f. Gyn. 1901. No. 12. 
corticalis, Hydrops folliculi, Entwickelung von serösen Cysten; doch hat auch Küstner Fälle gesehen, in denen keine Entzündungsspuren, weder tubare noch peritubare oder ovarielle, wahrnehmbar waren.

Küstner wies auch auf die Aeusserung Kossmanns ${ }^{1}$ ) hin, dass nämlich die pathologischen Ovarien pathologische Eier produciren und dass diese eine Prädisposition für die fehlerhafte Eieinnistung in der Tube abgeben.

Es will mir aber dünken, dass wir dann noch mehr Extrauteringraviditäten beobachiten würden.

Nicht gar so selten wird Extrauteringravidität bei gleichzeitig vorhandener Ovarialcyste beobachtet, und es ist nicht ausgeschlossen, dass diese einen Einfluss auf die Bildung einer Extrauteringravidität haben kann, sei es, dass der erkrankte Eierstock pathologische Eier producirt, was weniger wahrscheinlich ist, da ja relativ häufig eine uterine Gravidität bei entarteten Eierstöcken beider Seiten bebeobachtet wird, oder sei es, dass durch die Cyste der Verlauf der Tube alterirt wird und die Tube geknickt oder das Lumen comprimirt wird. Wir haben das gleichzeitige Bestehen einer Cyste in zwei Fällen beobachtet ( $X$ und $X I$ ), und in einem von diesen Fällen (XI) hat es sich zugleich um eine äussere Ueberwanderung des Eies gehandelt. In beiden Fällen spricht in der Anamnese nichts für eine überstandene Tubenerkrankung.

In früherer Zeit war vielfach die Ansicht vertreten, dass Tumoren in der Tube oder Schleimbautpolypen den Grund für das Fintreten einer Extrauteringravidität abgeben; diese Ansicht wurde in letzter Zeit dahin rectificirt, dass wohl in seltenen Fällen Schleimhautpolypen der Tube (Fälle von Beck, Breslau, Dührssen, Leopold, Olshausen, Wyder etc.), oder Tumoren (Petit, Roth, Olshausen, Webster, Marshall etc.) oder endlich Divertikel in der Tubenwand (Th. Landau and Rheinstein, Williams, Henrotin und Herzog, Schrenck) den Grund abgeben können, dass aber diese pathologischen Verändérungen bei der Entstebung der Tubengravidität keine allgemeine Geltung haben.

Was speciell die Divertikelbildung anlangt, hat C. Goebel²) aus seinen Untersuchungen entnommen, dass, obwohl er eine

1) Kossmann, Zeitschr. f. Geb. und Gyn. Bd. XXVII. S. 214.

2) C. Goebel, Dieses Arch. Bd. LV. H. 3. S. 658. 
Divertikelbildung an seinem Präparat nachweisen konnte, dem mikroskopischen Befunde nach nicht diese die Schuld an der extrauterinen Eieinnistung trage, sondern neigt der Ansicht zu, dass hier eine abnorme Beschaffenheit des Eies oder Befruchtung desselben an abnormer Stelle das Zustandekommen der Tubargravidität bewirkt habe.

Von Doktorl) wurde in zwei Fällen die Atrophie während der Lactation für die Entstehung der Extrauteringravidität verantwortlich gemacht.

Es wurde auch auf die Möglichkeit einer physiologischen Antiperistaltik der Tube bei der Entstehung der ectopischen Schwangerschaft von Manchen ein grosses Gewicht gelegt (Wendeler, Rumpf). Schon früher war von manchen Autoren (Astruc, Ramsbotham, Baudelocque und Freund) die Hypothese aufgestellt worden, dass eine ectopische Schwangerschaft ihre Entstehung einem Schreck oder einer excessiv geschlechtlichen Erregung verdanke. Auch der Coitus interruptus wurde von mancher Seite verantwortlich gemacht.

Die vielen Hypothesen über die Entstehung einer Extrauteringravidität zeigen, dass nicht alle Fälle auf gleiche Weise erklärt werden können. Wahrscheinlich ist, dass verschiedene Ursachen eine Extrauteringravidität herbeiführen können. Unaufgeklärt bleibt, warum diese Erkrankung stetig zuzunehmen scheint, wenn man nicht, wie viele Autoren es thun, die Gonorrhoe dafür verantwortlich macht.

Der häufigste Ausgang der Extrauteringravidität ist wohl die vorzeitige Unterbrechung mit Blutung aus der Eihaftstelle. Es kann das Ei zu Grunde gehen und in der Tube liegen bleiben und sich um dasselbe ein Mantel aus Blutcoagulis bilden (Blutmole resp. Fleischmole). Wenn das Ei ganz aufgesogen ist, bleiben nur die Reste der Blutmole zurück. Es kann ferner das Ei aus der Tube durch das Fimbrienende vollständig ausgestossen werden (completer Tubenabort), oder es können Eitheile zurückbleiben (incompleter Tubenabort). Meistens kommt es in allen diesen Fällen zur Bildung einer bald grösseren, bald kleineren Hämatocele. Die Grösse derselben hängt einerseits ab von der Dauer der Schwangerschaft, andererseits von der Art der Ausstossung, ferner davon, ob der

1) Doktor. Centralbl. f. Gyn. 1898. S. 625. 
Tubenabort complet oder incomplet, und endlich von deu eventuellen Nachschüben der Blutung.

Viel seltener als der Tubenabort ist die Tubenruptur (nach Fehling ${ }^{1}$ ) 8:1). Küstner fand 16 Rupturen auf 75 Aborte, an der Klinik Schauta wurden 18 Rupturen und 81 Aborte beobachtet (Lindenthal2). Wieso es in dem einen Falle zum Tubenabort und in dem andern zur Tubenruptur kommt, ist durchaus nicht aufgek]ärt. Es dürfte dabei die Beschaffenheit der Tubenwand (Durchwucherung derselben durch Chorionzotten) und auch der Grad der intratubaren Blutung am meisten in Betracht kommen. Dass eine Ruptur der Tube nur dann zu Stande kommen kann, wenn bei gewöhnlich noch lebendem Ei Contractionen der Tube einsetzen, während das abdominale Tubenende verschlossen ist (Law son Tait, Fehling), diese Ansicht ist durch neue Forschungsergebnisse überholt. Auch der Sitz des Eies kommt, wie Lindenthal entgegen der Ansicht Thorn's nachgewiesen hat, nicht in Betracht; es ist für das Eintreten einer Ruptur oder eines Abortes gar nicht massgebend, ob das Ei im ampullären oder im isthmischen Theil der Tube sitzt.

Gewöhnlich kommt es bei einer Ruptur zur freien Blutung in die Bauchhöhle. Die Menge des in diese ergossenen Blutes hängt, abgesehen von der Zeit, die seit dem Bersten verstrichen ist, ab von der Grösse des sogenannten „Risses", ferner davon, ob ein grösseres Gefäss eröffnet wurde, und endlich davon, ob das Ei noch in der Tube sitzt oder nicht. Doch kann auch bei einer ganz kleinen Lücke in der Tubenwand und in der Tube sitzendem Ei eine tödtliche Blutung erfolgen (Wasten). Ich glaubte constatiren zu können, dass die Blutung weniger stürmisch war, wenn das $\mathrm{Ei}$ noch in der Tube sass, unsere 3 Fälle I, IV, V scheinen mir diese Annahme zu rechtfertigen. Besonders im Falle IV war die Ruptur schon um 11 Uhr Vormittags eingetreten und es war so viel Zeit (bis 12 Uhr Nachts) verstrichen und ein weiter Transport im Wagen durch 2 Stunden rom Lande in die Stadtwohnung der Pat. und dann wieder in das Sanatorium überstanden und trotzdem war der Puls kurz vor der Operation nicht so besonders schlecht. Es ist wohl anzunehmen, dass in diesem Falle

1) Fehling: Zeitschr. f. Geb. u. Gyn. XXXVIII. H. 1.

2) Lindenthal, Beiträge zur Therapie der Extrauteringravidität. Mon. f. Geb. u. Gyn. 1900. Bd. I. 
die Blutung nicht fortwährend gedauert hat, sondern dass öfters ein Stillstand eingetreten war, oder vielleicht dass sich der Beginn einer Hämatocele gebildet hatte, die durch den Transport wieder zerstört wurde. Ich hatte aus unseren Fällen I und IV den Eindruck gewonnen, dass es sich nicht in allen Fällen von Tubenruptar um eine wirkliche Ruptur handelt, sondern dass es sich, wie in den angezogenen Fällen, um Usur der Tubenwandung beziehungsweise um ein Durchwachsenwerden der Tubenwand durch die Chorionzotten handle. Besonders bei der Betrachtung des frischen Präparates kommt man auf diesen Gedanken, aber auch bei der Besichtigung des gehärteten Präparates findet man eine runde Oeffnung in der Tubenwand, an deren Rand viele bald grössere, bald kleinere Läppchen zu sehen sind.

Dieses langsame, wenn ich so sagen darf, Durchdrücken der Tubenwand durch das wachsende Ei schien mir auch von Bedeutung für die Erklärung, dass es, wenn auch selten, aber doch auch bei sogenannter Tubenruptur zur Bildung einer Hämatocele kommt, wie aus den früher citirten Statistiken hervorgeht. Auch in unserem Falle $V$ war es zur Bildung einer Hämatocele gekommen und die freie Blutung in die Bauchhöhle trat erst nach mebreren Tagen auf. Mandl und Schmit suchten in 3 von den 14 an der Klinik Schauta beobachteten Fällen die Bildung einer Hämatocele damit zu erklären, dass bereits vor Eintritt der Ruptur eine Blutung in den Fruchthalter stattgefunden hatte, so dass zur Zeit der Ruptur in Folge der bereits bestehenden theilweisen Thrombosirung der Gefässe die Blutung nicht mehr stürmisch war, sondern successiv erfolgte.

In meinem Fall I ist eine Entscheidung über das Entstehen der Ruptur recht schwer. Es ist nämlich sehr interessant, dass das Ei intact in der Tube gesessen hatte und besonders, dass das Ei relativ sehr gross war und dass die Frucht schon längere Zeit abgestorben'gewesen sein musste, da sie deutlich im Zustande der Colliquescenz war. Es ist in diesem Falle, wenn man die Grösse des Eies mit der Grösse der colliqueseirenden Frucht vergleicht, ein, wio ich glaube, begründeter Verdacht vorhanden, dass das Ei trotz des erfolgten Absterbens der Frucht weiter wuchs. Es drängte sich mir daher die Vermuthung auf, dass auch in diesem Falle die Tubenwand durch den Druck, oder wie wie wir jetzt wissen, durch das Einwachsen der Zotten des Eies langsam usurirt wurde. 
Dafür, dass nach dem Absterben der Frucht die Placenta weiter wachsen könne, scheinen in ähnlicher Weise wie in unserem Falle auch zwei von Bozeman ${ }^{1}$ ) veröffentlichte Fälle zu sprechen. Er beobachtete einen Fall von Tubenruptur, in dem der Fötus resorbirt war, in einem zweiten Falle war der Fötus kleiner als er der Schwangerschaftsdauer entsprach, dagegen befanden sich nach seiver Ansicht die Placenten noch im Wachsthum begriffen und drohten eine Ruptor des Fruchtsackes herbeizuführen.

Wenn wir ferner einen Analogieschluss aus dem Verbalten des Eies in manchen Fällen von intrauteriner Gravidität bei abgestorbener Frucht ziehen dürfen, muss unbedingt zugegeben werden, dass trotz Absterbens der Frucht sich das Ei weiter entwickeln und ein starkes Wachsthum zeigen kann; so habe ich in der letzten Zeit ein gänseeigrosses $\mathrm{Ei}$ gesehen, das durch Monate getragen worden war: ap einer Stelle der Wand fand sich ein kaum $1 \mathrm{~cm}$ langer Embryo, der in seinem Aussehen dem 1. Schwangerschaftsmonate entsprach. In diesem Falle muss also sicher das. Ei weiter gewachsen sein, nachdem die Frucht schon lange abgestorben war: Das Merkwürdige an diesem Falle war, dass der Embryo nicht aufgesogen war, obwohl es sich um einen so kleinen Embryo gehandelt hatte. Ferner wissen wir von den zuerst von Breus richtig gedeuteten subchorialen Haematomen, dass. die Eihäute nach dem Fruchttode weiter wachsen und sich bei gleichzeitigem Auftreten on Blutungen gegen das Eicavum in grösserem oder geringerem Grade vorstülpen. Es ist naheliegend auch für ein in der Tube sitzendes $\mathrm{Ej}$, die Möglichkeit eines weiteren Wachsthums trotz des Abgestorbenseins der Frucht anzunehmen, da ja die Ernährungsverhältnisse des Eies in der Tube keine wesentlich anderen sind als im Uterus.

Es kann sich aber auch noch eine Ruptur der Tube ereignen, wenn sich schon eine Mole in derselben gebildet hat oder wenn es schon zur Bildung einer Hämatocele gekommen ist. Auch nach incompletem Abort kann noch eine Ruptur eintreten.

Sänger ${ }^{2}$ ) hat schon im Jahre 1894 auf eine besondere Art secandärer Ruptur bei Abortus tubarius incompletus und tubarer Mole hingewiesen, die seines Wissens noch nicht beschrieben

1) Bozeman, N. G., Two cases of tubal pregnaney, operation in the praerupture stage.' The Americ. gyn. and obstet. journ. Vol. XIII. No. 2.

2) Sänger, Sitzung der Ges. für Geb. in Leipzig. 19. 4. 1894. Centralbl. für Gyn. 1894. S. 656. 
worden sei, nämlich auf multiple Fissuren der Tubenwand. Manche Blutung nach anscheinender Abkapselung der primären Hämatocele dürften nach S. auf diese Fissuren zurückzuführen sein.

Veit) hat in seiner Sammlung auch ein Präparat von einer Ruptur der schwangeren Tube, in der das $\mathrm{Ei}$ abgestorben, in eine Blutmole verwandelt ist. Zwischen dem $\mathrm{Fi}$ und dem abdominalen Ende war in den Tubencanal Blut ergossen, als Beweis dafür, dass hier während des Abortus noch Ruptur erfolgte. Veit glaubt demnach, dass eine Ruptur der Tube in den ersten Monaten auch nach dem Tode der Frucht noch möglich ist. Die Erklärung dafür sei relativ ènfach, wenn man an einzelnen Präparaten die sehr starke Verdünnung der Wand beobachtet. Hier brauche nur ein Hinderniss für den weiteren Austritt des der Placentarinsertionsstelle entstammenden Blutes einzutreten, um durch die Ansammlung. desselben zur Ruptur zu führen. Veit's Fall lässt sich gewiss auf diese Weise sehr gut erklären; bei-meinem Fall No. I dagegen möchte ich das Fortbestehen des Wachsthums des Eies als Erklärung für die Ruptur heranziehen.

Ein ähnlicher Fall wurde von Schauta in der Sitzung der geb. gyn. Ges. in Wien vom 7: Mai 1901 vorgestellt. Es hatte sich um eine peritubare Hämatocele gehandelt und war nachträglich eine Ruptur der Tube mit freier Blutung in die Bauchhöhle aufgetreten, weshalb die früher eingeschlagene conservative Therapie der Hämatocele aufgegeben ünd zur abdominellen Coeliotomie geschritten werden musste. In der Discussion erwähnte Chrobak einen ähnlichen Fall, den er vor Jahren erlebte. Ein Fall von Ruptur nach incompletem Abort wurde von Lindenthat (l. c.) aus der Klinik Schauta mitgetheilt.

Es ist bekannt, dass die Ruptur gewöhnlich aus einer Gelegenheitsursache auftritt; so wissen wir, dass sie häufig in Folge des gesteigerten intraabdominellen Druckes gelegentlich der Entfaltung der Bauchpresse oder gelegentlich des sexuellen Verkehres eintritt. Hat sich nun durch vorangegangene Usur ein Loch in der Tubenwand gebildet, so kann man sich ganz gut vorstellen, dass durch dieses schon präformirte Loch, wenn ich mich so ausdrücken darf, ein Abortus eintretenkann.

1) J. Veit, Zur Behandlung früher Extrauteringraviditäten. Zeitschr. f. Geb. u. Gyn. Bd. XL. H. 1. 
Es wären dann für die Bildung einer Hämatocele ganz ähnliche Verhältnisse gegeben wie bei einem wirklichen Tubenabort.

Ich habe schon angeführt, dass mich auf diese Erklärungsweise mancher Fälle von Tubenruptur schon vor Jahren die Fälle hingewiesen hạben, in denen eine runde Lücke in der Tubenwand vorgefunden wurde, aus der es blutete, das Ei aber in toto unverletzt in der Tube gesessen war. Es ist ja nicht ganz von der Hand zu weisen, dass auch in einem solchen Falle die Blutung in die Eihüllen das Primäre war und die Tubenwand in Folge des dadurch gesteigerten Innendrucks rupturirte. Dagegen erscheint es sonderbar, dass das Ei nach dem Platzen des Fruchtsackes nicht ausgestossen wurde.

Wenn auch an der der rupturirten Stelle gegenüber liegenden Stelle eine Verdickung der Wand durch Blutcoagula gefunden wird, so bleibt es immerhin schwer zu entscheiden, ob diese Blutung der Grund für die Ruptur oder ob sie erst in Folge der Ruptur oder Usur durch ảie Lockerung des Eies von seiner Einnistungsstelle entstanden ist.

Die histologischen Untersuchungen der neueren Zeit haben eine Erklärung für die in Besprechung stehende eigenthümliche Erscheinung in manchen Fällen von Tubenruptur gegeben.

Ein Eiudringen von Zotten in die Muskelschicht ist in einzelnen Fällen schon längst beobachtet worden. So beschreibt Poppel schon 1868 ein ähnliches Bild. Langhans, Leopold, Recklinghausen und Freund besehrieben Fälle, in denen die Zotten sogar die Tubenwand perforirten. Ein ähnlicher Fall von multipler Perforation der Tubenwand durch die in die Bauchhöhle hineingewachsenen Zotten wurde von Beckmann ${ }^{1}$ ) in der Petersburger geb. Gesellschaft schon am 24.11.96 besprochen. "Ausser der Oeffnung in der Tubenwand, die durch Ruptur entstand und profuse intraperitoneale Blutung bewirkte, waren noch 4 Oeffinungen vorhanden. Die regelmässige Form dieser Oeffnungen, ihre dünnen Ränder, die Menge der Zotten und ihr Verhältniss zu den Rändern können nicht anders gedeutet werden, als dass die Oeffnungen durch die Einwucherung der Zotten in die Tubenwand entstanden, was B. schon vor 3 Jahren vorausgesagt habe." Seite 1138 .

1) Beckmann, Monatsschrift für Geburtshülfe u. Gynäkologie. Bd. XI. 
Füth ${ }^{1}$ ) hat auch aus seinem Präparat (in einem Vortrag der Ges. für Geb. in Leipzig am 18. October 1897 besprochen) entnommen, "dass das Ei die an einer Stelle vorhanden gewesene Muskulatur bei Seite gedrängt, rareficirt, ausgefressen hat, wie man sich ausdrücken will, und diesen Sitz des Eies innerhalb der Muskulatur, sowie den ausgeprägten Schleimhautcharackter des Eiüberzuges glaubt Herr Geheimrath Werth im Hinblick auf das jugendliche Stadium des Eies sich nur durch die Annahme erklären zu können, dass das Ei sich selbst seinen Weg in die Tiefe der Wand gebahnt hat."

Füth hat auch des Weiteren den von Muret beschriebenen Fall, nach diesen Anschauungen, wie wir jetzt zu wissen glauben, richtig zu deuten versucht und die Ansicht Muret's, dass ein am Rande der Insertionsstelle des Eies befindlicher Deciduawall verhütet habe, dass eine an der Insertionsstelle erfolgte Blutung diese überschritt, allerdings nicht sehr bestimmt angefochten.

Aschoff ${ }^{2}$ ) hat durch seine Untersuchungen diese Ansicht Füth's kräftig gestützt, er vertritt wie dieser die Ansicht, dass die Zerstörung der Tubenwand zu den Einbettungseigenthümlichkeiten des Eies in der Tube gehört. Er stellte auch, wie jch glaube, als erster fest, dass an der Placentarstelle die Mehrzahl aller Tuben mit Abort aus dem 2. und 3. Monat eine durch organisirte Blutgerinnsel verdeckte Ruptur der eigentlichen Tubenwand besitzen, die als Folge der langsamen Zerstörung der letzteren aufzufassen sind. Dies organisirte Blutgerinnsel bilde dann eine schützende Decke, die freilich später von Neuem durchbrochen werden könne.

Ulesko Stroganowa ${ }^{3}$ ), der die Arbeiten Füth's u. Ascboff's offenbar nicht bekannt waren, da; diese Autoren von ihr nicht genannt wurden, überzeugte sich durch Untersuchungen einer Reihe von Tubenschwangerschaften, dass die Erscheinung einer Durchwucherung der Tubenwand durch Chorionzotten eine gewöhnliche ist und sich durch die Entwicklungsbedingungen leicht erklärt.

1) Füth, Studien über die Einbettung des Eies in die Tube. Mon. f. Geb. u. Gyn. Bd. VIII. S. 684.

2) L. Asch off, Beiträge zur Anatomie der Schwangerschaft. Beiträge zur pathol. Anatomie und allgemeinen Pathologie. Bd. 25. 1899. S. 276.

3) Ulesko-Stroganowa, Anatomische Veränderungen der schwangeren Tube im Bereiche der Eiinsertion. Mon. f. Geb. u. Gyn. 1900. XII. H. 6. Seite 710. 
In einigen Fällen konnte U. S. das microseopische Durchdringen der Zotten durch die Serosa beobachten, so dass sie in die Bauchhöhle hervorragten. Nicht selten sah man Bilder, in denen der Defect der Tubenwand durch einen Thrombus verstopft war. Bei der Operation fand sich dann keine Oeffnung in der Tube. -

In Berücksichtigung soleher Bilder müsse man folgern, dass eine Eróffnung der Tubenwand ziemlich häufig zu Stande komme. Doch machen die Blutungen aus kleinen Oeffnungen in dem Placentarabschnitt keine schweren Erscheinungen, da sie vor Bildung von Thromben schnell zum Stehen kommen. Sie waren auch klinisch nicht bemerkt. -

Unter den von U. untersuchten Fällen giebt es solche, wo die klinischen Erscheinungen auf wiederholte innere Blutungen hinweisen, bei der Eröffnung der Bauchhöhle fand man alte Blutgerinnsel und frisehes Blut. Trotzdem erwies sich die Ampullenöffnung der Tube als verwachsen, so dass eine Blutung aus dem freien Ende der Tube nicht angenommen werden konnte.. (Der Verschluss konnte aber auch durch eine Blutung aus dem Fimbrienende secundär erfolgt sein. Der Verfasser.) Microscopisch wurden hier dureh Thromben verschlossene Defecte nachgewiesen.

"Auch der Stillstand der Schwangerschaft schützt die Tube nicht vor einer Ruptur, da die Zotten noch eine Zeitlang weiter leben können, selbst nach dem Tode der Frucht."

Die Folgerungen U. S.'s widersprechen den in der Jiteratur circulirenden Anschauungen, denen zufolge die Ruptur der schwangeren Tube relativ selten ist.

Nach Stroganowa sollen die Rupturen am häufigsten an der Placentarstelle zu Stande kommen, aber nur selten einen solchen Umfang erreichen, dass dureh sie die Frucht austreten kann und zwar aus sehr verständlichen Gründen: 1. dank der Dicke der Placenta selbst, 2. weil die sich in diesem Bezirk bildenden Spalten gewöhnlich keinen grossen Umfang erreichen und leicht thrombosiren. Die Gefahr solcher Rupturen besteht hauptsächlich in der Möglichkeit der grossen Blutverluste, die sogar tödtlich sein können. (Wasten.)

Es kann bei einem Riss der Tube an der Placentarinsertionsstelle die Blutung dadurch stehen, dass die Placenta die Rissstelle direct verstopft, wie Shoemakerly in einem. Falle beobachtet haben will.

1) Shoemaker, Centralbl. für Gyn. 1899. S. 91. 
In jüngster Zeit haben diese Untersuchungen wieder ihre Bestätigung durch F üth und Krönig ${ }^{1}$ ) gefunden, beide haben ein Hineinwuchern der Langhans'schen Zellen in die Blutgefässe und ein Auseinanderdrängen der Tubenmuskulatur und der Bindegewebszüge der Tube durch die Zotten constatirt.

Krönig bemerkt ganz zutreffend, dass es dahin gestellt bleiben muss, ab diese neven anatomischen Auffassungen von der Tubengravidität im Stande sind, unsere klinische Indicationsstellung bei Tubengravidität zu beeinflussen. Er hebt hervor, dass nach diesen neuesten Forschungsergebnissen die Bildung einer Haemotocele noch keineswegs als ein genügendes Zeichen erscheine um weiter expectativ verfahren zu können und er glaubt, dass nach den neueren anatomischen Untersuchungen zu urtheilen, auch bei tubarem Abort immerhin noch die Möglichkeit einer Tubenruptur gegeben ist.

Diese Vermuthung Krönig's haben, wie wir gesehen haben, schon die früher citirten Fälle bestätigt.

Im Gefolge der neuen Forschungsergebnisse müsste man in der Therapie der Extrauteringravidität demnach einem activeren Vorgehen huldigen, und dies zu einer Zeit, wo, wie wir hören werden, von den meisten Autoren, so auch von den früher Radicalen, viel conservativere Principien befolgt wurden und für die Haematocelentherapie ein Zuwarten als berechtigt erklärt wurde. Ohne der Besprechung der Therapie der ectopischen Gravidität vorgreifen zu wollen, muss ich schon hier im Anschluss an das eben Besprochene erklären, dass in weiterer Vervollständigung der in dieser Richtung angebahnten Forschung eine neuerliche Umwälzung in der Indicationsstellong wohl kaum Platz greifen wird. Wenn auch in einzelnen, gewiss seltenen Fällen trotz Haematocelenbildung noch eine Ruptur oder richtiger gesagt, eine weitere Durchwucherung der Tubenwand mit consecutiver freier Blutung in die Bauchhöhle eintreten kann, so dürfte für die Indicationsstellung doch die practische Erfahrung maassgebend bleiben, die eine conservative Therapie bei Haematocele vollauf berechtigt erscheinen lässt, es wäre denn, dass sich ähnliche Beobachtungen wie die citirten häufen würden.

In allerjüngster Zeit ist eine ausführiche Arbeit $\mathrm{F} u ̈ \mathrm{uh}^{\prime} \mathrm{s}^{2}$ ) erschienen, die schon dem früher citirten Vortrage zu Grunde

1) Füth u. Krönig, Centralbl. für Gyn. 1901. No. 12.

2) Füth, H., Ueber die Einbettung des Eies in der Tube. Dieses Archit. 63. Bd. S. 97 . 
gelegen war. In dieser tritt er an der Hand von sehr fleissig und instructiv durchgearbeiteten Präparaten für seine schon früher (1897) geäusserte Ansicht über das nahezu Physiologische des Durchwucherns, der Zotten durch die Tubenwand ein und macht seine Prioritätsrechte gegenüber Uleska-Stroganow a geltend.

Die Untersuchungen Füth's, Aschoffs und Ulesko-Stroganova's decken sich mit unsern klinischen Erfahrungen und haben die auch von uns schon früher angenommene Entstehung mancher Rupturen in vorzüglicher Weise geklärt.

Eine Tubenruptur mit freier Blutung in die Bauchhöhle zeigt sich gewöhnlich in folgenden Erscheinungen: plötzlicher Schmerz im Bauche, als wie wenn etwas gerissen wäre und im Anschluss daran ein schwerer, sich stetig steigernder Collaps und Zunahme der Anämie als Zeichen des Fortbestehens einer inneren Blutung. In seltenen Fällen kann die Blutung so stark werden, dass in kurzer Zeit der Tod erfolgt, so konnte Fehling (1. c.) in einem Falle den Tod 3/4 Stunden nach den ersten Symptomen beobachten.

Bei freier Blutung in die Bauchhöhle beobachtet man meist einen leichten Meteorismus, der die bimanuelle Untersuchung, die ohnehin (wegen vielleicht in Blutung begriffener Hämatocolen) sehr vorsichtig ausgeführt werden soll, noch erschwert; recht häufig tritt Erbrechen auf, bei hochgradiger Blutung ist die Temperatur subnormal. Die freie Flüssigkeit in der Bauchhöble lässt sich bei starker Blutung durch Schallwechsel bei Lageveränderung deutlich nachweisen (in den Fällen I, III, IV). Dass, wie Robson ${ }^{1}$ ) beobachtet haben will, bei Lageveränderung die Dämpfungsgrenze sich zum Unterschied von anderen Flüssigkeiten sehr langsam verschiebt, konnte ich nicht beobachten.

Ausser den zur Genüge bekannten Symptomen der Tubenruptur oder besser gesagt der freien Blutung in die Bauchhöhle möchte ich die Aufmerksamkeit auf Eines lenken, das ich im Falle IV zu beobachten Gelegenheit hatte, dass die Patientin besonders über die in der Brust und in die Achsel ausstrahlende Schmerzen klagte. Diese Angabe über die Localisation der Schmerzempfindung kann man auch in Fällen von Hämatocelenbildung beobachten, wie in unserem Falle XII. Wieso es zu dieser Localisation kommt, lässt sich kaum erklären.

1) Robson, Ref. Centralbl. f. Gyn. 1899. No. 13. 
Die Dauer der tubaren Schwangerschaft, somit die Grösse des Eies, ist bei Tubenruptur nicht immer massgebend für die Intensität der inneren Blutung. So konnten wir im Falle II eine sehr starke innere Blutung bei einer sehr frühen Extrauteringravidität von ca. 2 Wochen constatiren. Die Tubenanschwellung an der rupturirten Stelle war nur haselnussgross, es spritzte aber an der Rupturstelle eine zerrissene Arterie in vollem Strahle. Es fand sich eine grosse Menge Blutes in der Bauchhöhle, obwohl die Ruptur um $1 / 28$ Uhr Morgens eingetreten war und die Patientin schon um 11 Uhr operirt wurde.

Es karn die Ruptur auch in anderer Weise erfolgen. Es kann, wie sich schon Veit (1. c. p. 161) ausdrückte, „in Absätzen" erfolgen, wie auch unser Fall No. I sehr schön zeigt. Es ist diese Ruptur in Absätzen durchaus nicht zu verwechseln mit einer Ruptur; im Gefolge deren sich eine. Hämatocele gebildet hatte, die dann im weiteren Verlaufe platat. In letzterem Falle müsste man die Reste der Hämatocele bei der Operation finden. In unserem Falle I traten am 22. März Morgens beim Gehen plötzlich heftige Bauchschmerzen auf, die Patientin wurde ohnmächtig, konnte aber bàld nach Hause gehen. (Ich möchte diesen Anfall auch in der Weise erklären, dass die Tubenwand schon an einer Stelle durchwuchert war und dass durch den beim Gehen gesteigerten intraabdominellen Druck aus dieser Stelle eine freie Blutung in die Baushhöhle eintrat, die dann wieder aufhörte.) Dann war Pat. während des Tages und dor Nacht wieder ganz wohl, bis am 23. dieselben Zustände, aber nur in höherem Grade, auftraten. Trotzdem wurde Patientin erst am Abend in die Klinik gebracht. Bei der Operation fand sich nur freies Blut in der Bauchhöhle und keine Andeutung einer Hämatocele, die den Stillstand in den bedrohlichen Erscheinungen hätte genügend erklären können.

In den drei von Veit beobachteten Fällen, in denen die Ruptur in Absätzen enfolgte, erwies es sich mit Sicherheit, dass es sich nicht um eine Ruptur einer Hämatocele gehandelt hat, sondern um eine freie Blutung in die Bauchhöhle bei starker älterer Adhäsivbilding der schwangeren Tube im Douglas'schen Raume. In diesen Fällen war aber zweimal von dem behandelnden Arzte, einmal von Veit die Diagnose auf Hämatocele gestellt worden.

Ein mit diesen ähnlicher Fall ist unser Fall V, doch ist es viel wahrscheinlicher, dass es sich in diesem um die Bildung einer 
kleinen Hämatocele gehandelt hatte. Es war 5 Tage vor der Operation von einem hervorragenden Specialisten die Diagnose auf perfecten Tubenabortus gestellt worden. Es dürfte damals ein Tumor neben. dem Uterus gefühlt worden sein, der offenbar als Hämatocele aufgefasst wurde, denn sonst wäre sicher ein operativer Eingriff vorgeschlagen worden. Bei der Operation zeigte sich nun im ampullären Theile der 'Tube ein wallnussgrosser Tumor, an dem Darmschlingen adhärent waren und der von Blutcoagulis umgeben war. Bei Besichtigung des Präparates fand man einen Tubentumor von Wallnussgrösse; die Tube zeigt auf einer Seite ein etwa kreutzergrosses L_och, aus dem Reste der Eihäute heraushängen. Am frischen Präparat war an der Rupturstelle ein etwa nussgrosses Blutcoagulum, das mit der Tubenwand verbunden war. An dem gehärteten Präparat findet man dieses Blutcoagulum in Verbindung mit dem grössten Theil des Chorions getrennt von dem Tubentumor. Intra operationem war aber das Chorion noch in dem Tubentumor und das Blutcoagulum vor der Tubenrupturstelle gelagert.

Es ist in diesem Falle zweierlei möglich, entweder es hat sich um alte Verlöthungen des Darmes mit der Tube gehandelt, oder es waren die Adhäsionen jüngeren Datums und gebildet durch die Blutung. Da die Adhäsionen leicht zu lösen waren, ist letztere Annahme wahrscheinlicher. Dann hat es sich um eine Hämatocele gehandelt, die durch eine geringe Blutung aus einer Tubenruptur entstanden war und erst durch die stärkere Blutung wurden die Adhaesionen getrennt und es konnte sich das Blat in die Bauchhöhle ergiessen. Aber es kann auch die Tubenwand über die Stelle hinaus von den Chorionzotten durchwuchert worden sein, die von der Haematocele bedeckt war.

Ich glaube, man muss beim Ueberblicken der Krankengeschichte sich mehr zu der Auffassung hinneigen, dass sich eine kleine Hämatocele gebildet hatte. Jedenfalls kann man, wie ich gJaube, mit Recht annehmen, dass es sich um kein plötzliches Einreissen der Tubenwand gehandelt haben kann.

Man könnte noch annehmen, dass es sich um einen beginnenden Tubenabort gehandelt hat mit Hämatocelenbildung und dann plötzlich eingetretener Tubenruptur. Dagegen spricht aber das Präparat, da das Fimbrienende frei von Blutcoagulis war.

Es wäre vielleicht möglich, die angezogenen 3 Fälle Veit's in ähnlicher Weise wie diesen zu.. deuten, doch sagt Veit ans- 
drücklich, dass es sich in seinen Fällen um alte Adhäsionen gehandelt hat.

Unser Fall spricht, wie schon erwähnt, auch dafür, dass trotz ausgebildeter Hämatocele noch eine Blutung in die freie Bauchhöhle unter Umständen zu fürchten ist.

Seltener als bei Tubenruptur wird bei Tubarabort eine freie Blutung in die Bauchhöhle beobachtet, und dann handelt es sich in der Regel um incompleten Abort. Ein derartiger Fall ist der Fall No. II, in welchem die Placenta halb aus der Tube geboren war und es nicht zur Bildung einer Hämatocele kam.

Küstner beobachtete in 5 Fällen unter 59 Fällen von Tubarabort eine ausserordentlich starke Blutung.

Dass auch bei completem Tubarabort eine lebensgefährliche Blutung in die freie Bauchhöhle stattfinden kann, beweisen der Fall Piering's und 2 aus der Klinik Schauta von Mandl1) publicirten Fälle.

Im Falle Piering' ${ }^{2}$ ) wurden an der fast pulslosen Frau die Laparotomie mit gutem Erfolge ausgeführt. Es handelte sich um einen completen Tubarabort im Beginn der zweiten Woche, wie die microscopische Untersuchung der Tube und des im Douglas unter Blutgerinsel gefundenen ganz unversehrten Eies bewies. In dem ersten der von Mandl publicirten Fälle schien die Wandung beider Tuben vollkommen intact, beide Tuben erschienen stark geschwellt, nirgends war eine Erweiterung des Tubenrohres zu sehen, aus welcher man schliessen könnte, welche von beiden die gravide ist. Die Fimbrienenden, besonders das linke, stark gewulstet, ectropionirt. Es entleerte sich aus dem Ostium abdominale beider Tuben Blut, so dass es während der Operation ganz unmöglich war, zu bestimmen, welche Seite die gravide ist; daher Exstirpation beider Tuben. Bei der mikroskopischen Untersuchung wurden an einer Stelle in der linken Tube in dem ampullären Antheile Chorionzotten nachgewiesen.

In dem zweiten Falle war der Uterus faustgross, antevertirt, weich, zu seinen beiden Seiten undeutliche, weiche Resistenzen, die nicht scharf abgegrenzt sind. Ein besonderer Tumor ist nicht zu tasten. Zur Sicherung der Diagnose wurde das hintere Scheiden-

1) Piering, Verhandl, der deutsohen Ges. für Gyn. 1895. Centralbl. für Gyn. 1895. S. 782 .

2) Mandel, Klinische und anatomische Beiträge zur Frage des completen Tubarabortes. Monatsschrift f. Geb. u. Gyn. 1900. Bd. I. 
gewölbe eröffnet, worauf sich nach Eröffuung des Douglas massenhaft Blut entleert. Die Palpation ergiebt undeutlich eine Verdickung der linken Tube, welche vorerst für den Sitz der Gravidität gehalten wurde. Vorderer Scheidenbauchschnitt, Stürzung des Uterus, nachdem um seinen Fundus einige zarte Adhäsionen stumpf gelöst werden. Er ist faustgross, in Bezug auf Consistenz und Aussehen einem graviden Uterus ähnlich. In Anbetracht der Grösse des Organes gelingt es nicht, die Adnexe einzustellen und zu entwickeln, daher Totalexstirpation. Nach der Operation werden die Coagula durchmustert und da findet sich inmitten eines faustgrossen Blutcoagulums das Ei. Ein circa $1 \mathrm{~cm}$ langer Embryo in der unversehrten Amnioshöhle mit dem etwas zerfetzten Chorion. In der linken Tube fand sich in einem dem Fimbrienende entnommenen Stücke das Stroma der Tubenfalten in einer Schnittserie von circa 100 Schnitten decidual verändert. Makroskopisch an beiden Tuben nichts zu finden.

Es hat sich also auch in diesem Falle um eine schwere Blutung bei completem Tubarabort gehandelt, und es war von diesem Standpunkte die Operation durchaus indicirt. Es lässt sich aber die Frage aufwerfen, ob in diesem Falle die Blutung nicht schon gestanden hat. Es würde dafür die Angabe sprechen, dass bei der Untersuchung zu beiden Seiten des Uterus undeutlich weiche Resistenzen getastet wurden, und ausserdem der Umstand, dass das $\mathrm{Ei}$ in einem faustgrossen Coagulum gelegen war. Es ist immerhin möglich, dass dieses Coagulum neben dem Uterus gelegen war nnd als solches getastet wurde. Das wäre dann der Beginn einer Hämatocele gewesen. Es ist ja immer sehr schwer zu entscheiden, ob die Blutung steht oder fortdauert, sobald sich einmal eine Andeutung einer Hämatocele im Douglas gebildet hat.

Ist letzteres der Fall, so kann der Patientin noch in mehrfacher Weise eine Gefahr drohen. Es kann neben der Hämatocele eine Blutung in die freie Bauchböhle stattfinden, wie in dem Falle ron Hollstein, oder es kann die Abkapselung der Hämatocele eine unvollständige sein und durch eine Oeffnung die Blutung in die freie Bauchhöhle sich fortsetzen oder es kann nach Durchbruch der Kapsel eine Nachblutung erfolgen, wie in den Fällen von Gräfe, v. Frank, Gusserow, Leopold, Schwartz, Thorn oder es kann, wenn sich schon eine Hämatocele an einer Stelle gebildet hat, wo die Tubenwand von Chorionzotten durehwuchert wurde, eine weitere Durchwucherung 
der Tubenwand neben der von der kleinen Hämatocele gedeckten Stelle stattfinden und dadurch eine freie Blutung in die Bauchhöhle bedingt sein.

Es kann aber auch nicht zur freien Blutung in die Bauchhöhle kommen, sondern es können sich acute Nachschübe der Hämatocele ereignen. Es tritt eine Blutung neben der Hämatocele auf und es bildet sich so neben der alten eine neue, die Hämatocele ist durch Apposition gewachsen. Warum es in dem einen Fall zur freien Blutung in die Bauchhöhle, in einem andern Falle zu letztbeschriebenem Ereigniss kommt, ist nicht aufgeklärt, doch dürfte dies von der Intensität der Blutung abhängen, auch ist es möglieh, dass die Beschaffenheit des Blutes oder des Peritoneums hierbei eine Rolle spielt.

Im Falle IX meiner Beobachtungen traten auch, wie aus der Krankengeschichte ersichtlich, wiederholte Nachschübe auf; es hatte sich um eine Lücke in der Wand der Hämatocele gehandelt. Der Fall ist auch deshalb von besonderem Interesse, weil an einer Stelle eine Partie ganz frisch coagulirten Blutes bei der Laparotomie aufgefunden wurde, welches Coagulum nur mit einem ganz dünnen Häutchen überzogen war. In diesem Falle hatte sich das ausgestossene Ei weiter entwickelt.

Wiewohl die Lehre von der Bildung der Haematocele schon so ziemlich abgeschlossen ist und es fast allgemein anerkannt ist, dass sich die Haematocele in zweierlei Weise bilden kann, entweder so, dass Adhäsionen vorhanden sind und die Blutung in einen abgekapselten Raum erfolgt, wie dies Schroeder für alle Fälle angenommen hatte (primäre Haematocele nach Schauta oder diffuse Haematocele nach Saenger), oder dass die Blutung das Erste ist und die Abkapselung das Zweite (solitäre Hämatocele nach Saenger oder die secundäre Hämatocele nach Schauta, welchen Ausdruck ich bevorzugen möchte), so dürfte in der grossen Mehrzahl der Fälle die Bildung der Hämatocele in letzterer Weise zu Stande kommen. Mein Fall erläutert in ganz besonders instructiver Weise die Art der Bildung der secundären Hämatocele. Je nach dem Alter der Nachschübe weist die Wand der Hämatocele verschiedene Dicke auf.

Im Falle XII traten wiederholte Nachschübe (im Ganzen 6) mit mehr oder minder schwerem Collaps auf. Es hatte sich um eine im Aussenrande der Tube sitzende Blutmole gehandelt; in der stark wallnussgrossen Mole war ein kleines $\mathrm{Ei}$ von kaum 
Haselnusskerngrösse mit gallertigem Inhalt eingebettet. Obwohl die Schwangerschaft bis zum ersten Anfall über 6 Wochen bestanden hatte, findet sich ein relativ kleines Ei vor. Wohl muss man bedenken, dass es zur Zeit der Operation zum Mindesten 14 Tage abgestorben gewesen sein dürfte, da vermuthlich bald nach dem ersten Anfall das Ei zu Grunde ging. Dass bei ausgebildeter Tubenmole und Haematocele trotz Ruhelage und Anwendung des Eisbeutels schwere Nachschübe der Blutung auftraten, dürfte nicht zu den häufigen Beobachtungen gehören.

Die Diagnose der Extrauteringravidität kann in jedem Stadium die grössten Schwierigkeiten bieten.

Die Diagnose der intacten Tubengravidität in den ersten Monaten ist nur dann zu stellen, wenn bei Vorhandensein von anderen Symptomen einer Schwangerschaft eine Vergrösserung und wahrscheinlich auch Erweichung des Uterus und ein weicher Tumor im Verlaufe der Tube sich vorfindet. Zieht aber eine normale Tube über eine Ovarialcyste hinweg, so kann dies eine Extrauteringravidität vortäuschen. Da der Uterus bei einer Extrauteringravidität vergrössert ist, so ist zur Unterscheidung, ob er ein Ei beherbergt oder nicht, das Zeichen der Frühdiagnose, auf das ich seinerzeit (Wiener klinische Wochenschrift 1899, No. 1) aufmerksam gemacht habe, zu verwerthen: Consistenz und Grössendifferenz der Hörner, zu tastender, längs verlaufender Sulcus zwischen den Hörnern.

Aber auch dann begegnet man oft Schwierigkeiten, wenn schon längere Zeit eine Blutung aus dem Uterus besteht. Dann kann der Uterus eben leer getastet werden, weil die Frucht schon ansgestossen wurde, und der als Extrauteringravidität angesprochene Tubentumor zeigt sich bei der Operation als Ovarialcyste. Dieses Verhältniss illustrirt besonders deutlich folgender Fall:

Eine 28jährige Frau, die viermal geboren hatte, hatte seit November 1898 unregelmässige, fast fortwährend andauernde Blutungen. Trotz dieser Blutungen konnte sie die Zeit der Periode durch die zunehmende Stärke genau erkennen; die letzte Periode hatte sie angeblich am 21. December. Seit einiger Zeit klagte Pat. über subjective.Schwangerschaftssymptome. Bei einer Untersuchung am 6. Februar fand ich eine weite, aufgelockerte Vagina sowie eine weiche Portio vor; in das orificium ext. konnte die Fingerkuppe eindringen. Der anscheinend vergrösserte Uterus lag retroflectirt, und rechts hinter ihm konnte man einen weichen Tumor tasten. Nach vorsichtiger Aufrichtung des Uterus fand ich denselben vergrössert, die Consistenz etwas weicher als am normalen Uterus; ich konnte aber bei genauer Untersuchung die 
besprochenen Symptome der Frühgravidität nicht finden, weshalb ich mich zur Annahme berechtigt hielt, dass der Uterus kein Ei beherberge. Rechts hinter dem Uterus lag num, durch das hintere Scheidengewölbe sehr leicht zu tasten, ein schwach gänseeigrosser, weicher, im Douglas fixirter Tumor, zu dem sich die etwas verdickte, aber ganz weich sich anfühlende Tube, auf eine Strecke von $4 \mathrm{~cm}$ hinziehend, verfolgen liess. Es machte den Eindruck, als wie wenn die Tube in den Tumor übergehen würde. Die linken Adnexe wurden normal getastet. Wenn ich die Anamnese berücksichtigte und diesen Befund mit der Erkenntniss, dass der Uterus leer sein dürfte, zusammenreimte, so musste ich mit der grössten Wahrscheinlichkeit die Diagnose auf rechtsseitige Tubargravidität stellen.

Bei der vaginalen Coeliotomie stellte sich aber heraus, dass es sich um ein weiches Ovarialkystom handelte. Die unregelmässigen Blutungen hatten von einer Endometritis post abortum hergerührt (vergl. Wiener klin. Wochenschr. 1899. No. 10).

Bisweilen werden, wie ich in Consiliarfällen wiederholt erfahren habe (ich habe darüber 5 Fälle notirt), frühe Graviditäten mit einem einseitigen Adnexentumor mit Extrauteringravidität verwechselt. Es muss zugestanden werden, dass eine sichere Differentialdiagnose in der ersten Zeit auf sehr grosse Schwierigkeiten stösst. Die genaue Beachtung der Anamnese und weitere Beobachtung der Patientin, die natürlich Ruhelage einhalten muss, wird meistens eine Entscheidung treffen lassen.

Aber auch bei weiter vorgeschrittener Schwangerschaft (von $4 \frac{1}{2}$ Monaten) habe ich eine derartige Verwechselung an einer Patientin gesehen, die ein gewandter College untersucht hatte. Es war die Wahrscheinlichkeitsdiagnose einer intrauterinen und gleichzeitig einer extrauterinen ins Auge gefasst worden.

Die 29jährige Frau hatte ein lebendes Kind spontan geboren. In der zweiten Schwangerschaft vor $1 \frac{1}{2}$ Jahren trat ein Abortus ein, danach durch 4 Wochen ein Puerperalprocess. For $4 \frac{1}{2}$ Monaten letzte Periode. Als die Schwangerschaft $11 / 2$ Monate gedauert hatte, hob die Patientin eine schwere Last, verspürte dabei einen rissartigen Schmerz, der sie von da ab stets quälte; es trat auch Erbrechen ein, das vorher nicht bestanden hatte. Diese Zustände dauerten mit wechselnder Intensität bis zum Tage der Untersuchung. Bei der bimanuellen Untersuchung fand ich eine aufgelockerte ulcerirte Portio in einer der Schwangerschaftsdauer entsprechenden Stellung. Der Uterus schwach manns-kopfgross, das rechte Horn sehr stark ausgebaucht, sehr weich, das linke Horn viel resistenter und kleiner, so dass der Uterus eine unregelmässige Gestalt aufweist; die ligamenta rotunda dieser Gestalt entsprechend zu tasten, die ganze Untersuchung sehr schmerzhaft, das linke Hypogastrium besonders schmerzhaft, doch lässt sich in genügender Entspannung der Bauchdecken constatiren, dass Adhäsionen, die von einem offenbar schon früher bestandenen Adnextumor herrühren, diese starken Schmerzen bedingen.

Nach alledem war trotz der eigenartigen Anamnese die Diagnose 
doch nur mit intrauteriner Gravidität und Adnexaffection zu stellen. Die Frau bat auch am normalen Termin spontan entbunden und ein normales Wochenbett durchgemacht.

Es ist aber auch die Möglichkeit vorhanden, dass der Uterus ein $\mathrm{Ei}$ beherbergt und zugleich sich ein $\mathrm{Ei}$ in der Tube entwickelt. Diese Diagnose wird besonders in der ersten Graviditätszeit recht schwer zu stellen sein und immer eine Wahrscheinlichkeitsdiagnose bleiben.

Strauss) glaubt, dass der von ihm beobachtete Fall von Extra- nod gleichzeitig Intrauteringravidität der erste ist, wo in dem früben Stadium der 12. Schwangerschaftswoche die Diagnose vor der Operation mit grosser Wahrscheinlichkeit, nach der Operation mit Sicherheit gestellt wurde.

Herme $\mathrm{s}^{2}$ ) beschrieb einen hierher gehörigen Fall, den ich deshalb besonders hervorheben möchte, weil der Uterus im späteren Verlauf der Gravidität das von mir beschriebene Graviditätssymptom zeigte. Koeliotomie wegen linksseitiger, in einer Hämatocele liegender Tubengravidität. Uterus vergrössert. Spontane Geburt am richtigen Termin, H. fiel bei dem fortschreitenden Wachsthum des Uterus der Befund auf, dass sich die linke Hälfte desselben erheblich derber und härter anfühlte als die rechte, weit stärker ausgedehnte und eine weiche, pseudofluctuirende Consistenz darbietende. In der vorgeschrittenen Zeit der Gravidität verschwand dieser Unterschied. Hermes hat somit meine angezogenen Erfahrungen über die Gestaltsveränderung und Consistenzdifferenz unbewusst bestätigt, obwobl er - wie ich sagen zu können glaube, irrthümlich diesen Unterschied auf die Abtragung der linken Adnexe und die durch sie bedingten Aenderungen in der Bluteirculation zurückführte.

H. weist darauf hin, dass es in gleichen Fällen wie in dem vorliegenden unmöglich sein wird, bei der Operation die Diagnose "intrauterine Schwangerschaft" zu stellen, da in so früher Schwangerschaft die Vergrösserung des Uterus keine derartige ist, dass sie zur Diagnose verwerthet werden könnte.

Dieser Ansicht wöchte ich nicht beipflichten, sondern ich möchte aus meinen Erfahrungen als höchst wahrscheinlich annehmen,

1) Strauss, Tubargravidität bei gleichzeitiger Intrauteringravidität. Zeitschr. für Geb. und Gyn. XLIV. H. 1. S. 26.

2) Hermes, Ein seltener Fall von gleichzeitiger Extra- und Intrauteringravidität. Deutsche med. Wochenschr. 1900. No. 10. Centralbl. für Gynäk. 1900. S. 974 . 
dass man in diesem Falle zur Zeit, als die Operation ausgeführt wurde (2 Monate nach der letzten regelmässigen Periode) schon eine Grössen- und Consistenzdifferenz der Uterushörner hätte finden können, wenn man darnach gesucht hätte und wenn man anf diese Untersuchungen der Frühgravidität eingeübt ist. Gerade der Umstand, dass im weiteren Verlauf der. Gravidität das beschriebene Graviditätssymptom beobachtet wurde, spricht nach meinen Erfahrungen dafür, das man wahrseheinlich dies Symptom schon am Ende des 2. Monates bätte finden können. Ich kamn mich demnach durchaus nicht seinem Urtheile anschliessen, dass die Diagnose nicht durch bimanuelle Untersuchung gestellt werden kann. Um so mehr würde iẹh glauben, dass bei genauer directer Betastung bei einer Laparotomie eine Gravidität von 2 Monaten zu constatiren ist.

Schwieriger scheint es mir zu sein, zu entscheiden, ob ein neben einem frühgraviden Uterus getasteter Adnextumor durch einen entzündlichen Process oder durch eine Extrauteringravidität bedingt ist.

Schroeder, Kleinwächter, Brown und Parry gaben die Resultate von 38 Fällen gleichzeitiger extra- und intrauteriner Gravidität bekannt. Dazu kämen noch die Fälle Boyster, Mond, Hermes, Mathewson. Von allen beobachteten Fällen ist nur in einem einzigen Falle (Ludwig) die Mutter und beide Kinder am Leben erhalten worden.

Ich habe auch einen hierher gehörigen Fall beobachtet, in dem es sich aber um intrauterinen und extrauterinen Abortus handelte. Fr. v. P., 28 Jahre alt, war vor 2 Jahren am Ende der 1. Schwangerschaft durch Forceps entbunden worden, das Puerperjum unter meiner Controlle normal verlaufen. Im Jahre 1896 war die Periode durch 2 Monate ausgeblieben. Es traten Schmerzen und Blutungen ein und es erfolgte trotz Ruhelage der Abortus, nach der Ausstossung des Eies ergab die Untersuchung das Vorbandensein eines rechtsseitigen etwa hühnereigrossen, wenig beweglichen Adnexentumors, in den die normale Tube, deren Verlauf sich circa $3 \mathrm{~cm}$ vom Uterus entfernt verfolgen liess, sich verior.

Einige Tage nach dem stattgehabten Abortus empfand Pat. plötzlich Schmerzen auf der rechten Seite, erbrach wiederbolt und collabirte. Es wurde absolute Ruhelage angeordnet und ein Eisbeutel aufgelegt. Pat. erholte sich von diesem Collaps. Kein Fieber. Nach 2 Tagen wurde nun eine sehr vorsichtige Unter- 
suchung vorgenommen und dabei rechts und hinter dem Uterus ein gut mannesfaustgrosser Tumor gefunden, der den Uterus etwas elevirt und dessen Fundus nach links verdrängt hatte. Unter conservativer Therapie (Ruhelage von 7 Wochen) schwand der Tumor. In diesem Falle ist die Diagnose zwar nicht sicher erwiesen, aber doch im höchsten Grade wahrscheinlich.

Aehnlich unserem Falle sind die 2 Fälle von Desguin ${ }^{1}$ ) and und ein Fall von Wells ${ }^{2}$.

In den ersten 2 Fällen handelte es sich um Bildung grosser Haematocelen in Folge von Ruptur und Tubengravidität wenige Tage nach erfolgtem Abortus eines intrauterin entwickelten Eies. In beiden Fällen ist die Diagnose aber auch durch die Laparotomie bestätigt worden. In letzterem Fall wurde wegen Erscheinungen der inneren Blutung die abdominale Koeliotomie ausgeführt, die anf Tubenruptur gestellte Diagnose bestätigt. Nach 24 Tagen Entfernung eines abgestorbenen uterinen Eies durch Ausschabung.

In dem mit letzterem ähnlichen Fall M ond $\left.{ }^{3}\right)$ trat bei bestehender intrauteriner Gravidität ein Tubarabort ein, der durch die Laparotomie bestätigt wurde. Die Frau wurde 5 Monate hiernach leicht von einem kräftigen Kinde entbunden. Wochenbett normal.

Sehr grosse Schwierigkeiten kann in manchen Fällen die Differentialdiagnose zwischen intrateriner und extrauteriner Gravidität schon in der ersten Schwangerschaftshälfte bereiten. Diese Schwierigkeit kann dadurch hervorgerufen werden, dass es sich um eine Lateroflexion oder um eine Torsionsstellung des Uterus handelt, die lange Cervix wird für den leeren Uterus und das gravide Corpus uteri für den extrauterinen Fruchtsack gehalten (Martin). Fälle von Martin, Howitz, Handfield, Jones, Engelmann, Gusserow, Olshausen, Wenninga). So erwähnt auch Küstner zwei Fälle, in denen eine uterine Gravidität für eine extrauterine angesehen wurde. Jedesmal lag eine Torsionsstellung des Uterus vor, wodurch das vergrösserte Organ

1) Desguin, Deux observations de grossesse extrautérine coincident avec une grossesse normale. Soc. med. chir. d'Anvers. Septbr. 1898. Ref. La Gyn. III. No. 5.

2) Wells, Ein Fall gleichzeitiger intra- und extrauteriner Schwangerschaft. N.-Y. med. journ. 26. Mai 1898. Ref. Soc. gynaecol. III. No. 5.

3) Mond, Ref. Wiener klinische Wochenschr. 1900. No. 14. S. 330.

4) Vergl. Muret, Zur differentialdiagnose der intrauterinen und der extrauterinen Gravidität eto. Ref. Centralbl. für Gyn. 1899. S. 1422. 
exquisit seitlich neben die hypertrophische, dann meist noch besonders lang ausgezogene supravaginale Cervixpartie zu liegen gekommen war. Die lang nach hinten verzogene Cervix war für den leeren Uterus, das gravide Corpus für den extrauterinen Fruchtsack gehalten worden.

LöhIein ${ }^{1}$ ) macht auch darauf aufmerksam, dass bei Schwangeren die normale Rechtstorsion des Uterus nicht selten besonders deutlich ausgeprägt ist und dann, wie es den Giessner Assistenzärzten $2 \mathrm{mal}$ passirte, fälschlich eine ektopische Schwangerschaft vermuthet werden kann. K. glaubt, dass diese Verwechslung leichter geschehen kann, wenn die Anamnese Schmerzen und Blutungen ergiebt. Desgleichen führt Muret ${ }^{2}$ ) drei persönliche Beobachtungen an, die in differentialdiagnostischer Hinsicht von Bedeutung sind, in denen es sich um Schlaffheit des Isthmus des graviden Uterus obne Collumbypertrophie handelte. Ebenso erwähnte Schauta in der Geb. Gyn. Ges. in Wien eines hierhergehörigen Falles, in dem die richtige Diagnose auf intrauterine Gravidität erst nach wiederholter Untersuchung gestellt werden konnte.

Drei einschlägige Fälle hat v. Dittel ${ }^{3}$ ) publicirt. Im dritten dieser Fälle wurde unter der Diagnose einer Extrauteringravidität die Laparotomie ausgeführt und es zeigte sich, dass es sich nicht um eine extrauterine Gravidität handle, sondern um eine intrauterine mit Lateroflexion des Uterus, allerdings fand sich rechts und hinter dem Uterus die über daumendicke erweiterte Tube, die mit altem Blut erfüllt war und im kleinen Becken zahlreiche Blutcoagula älteren und jüngeren Datums. Patientin soll nach 4 Wochen abortirt haben. In diesem sehr interessanten Falle war die Anamnese sehr verrätherisch.

Ich habe auch vor 9 Jahren an der Klinik einen derartigen Fall beobachtet; es handelte sich um eine Frau, die wiederholt geboren und in der letzten Zeit wiederholt eine Pelveoperitonitis überstanden hatte. Es imponirte der dextroflectirte, durch Adhäsionen fixirte Uterus als eine Graviditas extrauterina. Eine wiederholte Untersuchung ergab die Unrichtigkeit der Diagnose. Es ist überhaupt in ähnlichen Fällen eine grosse Vorsicht am Platze und wird es gut sein, einen derartigen Fall vor dem Stellen

1) Löhlein. Deutsche med. Wochenschrift. 1897. No. 16.

2) Muret, l.c.

3) v. Dittel, Geb. gyn. Ges. in Wien. Sitzung am 26. April 1899. Centraibl. für Gyn. S. 1299. 
einer stricten Diagnose wiederholt zu untersuchen. In solch' zweifelhaften Fällen wird es vortheilhaft sein, den Abgang der Tuben (eventuell in Narkose) aufzusuchen, um die Diagnose stellen za können; auch kann die bimanuelle Untersuchung per rectum in unklaren Fällen Aufschluss geben.

Häufiger als eine Torsion des Uterus wird die eigenthümliche Gestalt des Lterus in den ersten Monaten der Schwangerschaft, die bei der Untersuchung zu tasten ist, auf die falsche Diagnose der Extrauteringravidität leiten. Ich habe in der früher citirten Arbeit über die Frühdiagnose der Schwangerschaft auf die eigenthümliche Gestalt hingewiesen, die der schwangere Uterus bei der Untersuchung zeigt. Nun kann die Vergrösserung oder die Ausbuchtung des einen sich weicher anfühlenden Hornes so hochgradig sein, dass das kleinere härtere Horn für den Uterusfundus und das grössere weichere Horn für den extrauterinen Fruchtsack gehalten wird. Piskacek ${ }^{1}$ ) bat diesen Befund auf Grund selbstständiger, von meinen Untersuchungen unabhängiger Untersuchungen bestätigt, so zwar, dass seine Zeichnungen besonders markanter Fälle mit der Zeichnung genau stimmen, die ich seinerzeit bei meinem Vortrage in der geb. gyn. Gesellschaft2) entworfen habe. Herr Hofrath Schauta hat schon früher vier Fälle publiciren lassen (vergl. Herzfeld: Klinischer Bericht über 1000 Bauchhöhlenoperationen. Deuticke, 1895. Citirt von Schauta in der Discussion über meinen Vortrag in der erwähnten Sitzung), in denen wegen der auf Graviditas extrauterina gestellten Diagnose die Laparotomie ausgeführt wurde, bei der sich aber herausstellte, dass es sich nur um die in Besprechung stehende eigenthümliche Gestalt des Uterus bei intrauteriner Gravidität gehandelt hat, wie Herr Hofrath Schauta in der Discussion erklärte.

$\mathrm{Bar}^{3}$ ) beschrieb in letzter Zeit in der Societé obstetrique de Paris auch einen Fall, in dem durch das in Besprechung stehende Symptom eine Extrauteringravidität vorgetäuscht wurde, und Budin ${ }^{3}$ ) bespricht in derselben Sitzung zwei Fälle, in denen aus der gleichen Ursache eine falsche Diagnose auf Extrauteringravidität gestellt wurde.

1) Piskacek, Ueber Ausladungen umschriebener Gebärmutterabschnitte als diagnostisches Zeichen im Anfangsstadium der Schwangerschaft. Braumüller. Wien und Leipzig. 1899.

2) Sitzung 24. 5. 1899. Centralbl. f. Gyn. 1899. S. 488.

3) Bar, Budin, Ref. Centralblatt für Gyn. 1901. No. 11. S. 282. 
Hierher dürfte auch der Fall Martin's') zu rechnen sein, in dem die unrichtige Diagnose trotz Austastung des Uterus gestellt wurde: Als tubarschwanger im 6. Monat übersendet; kindliche Theile auffallend fühlbar in einem Gebilde, welches aus dem Becken in die Bauchhöhle emporragte. Rechts daneben lag eine Masse, welche einem durch stark chronische Metritis veränderten oder aber etwa im dritten Monate schwangeren Uteruskörper entsprach. Dieser vermeintliche Uteruskörper erschien an dem Fruchthalter, dessen untere Peripherie von der Scheide aus sehr leicht zu bestreichen war, deutlich beweglich. In der Narkose drang der Finger leicht ein bis an das obere Ende der Körperhöhle. Die Koeliotomie ergab, dass der Eisack in utero lag. Schluss der Bauchhöhle, normale Entbindung am Termin.

Auch der Fall Pollosson's') scheint mir durch dieses Symptom erklärlich. „Bei einer Ausräumung wegen Hyperemesis erwies sich der Uterus als leer, dagegen gelangte der Finger in eine vor dem Uterus gelegene Höhle, welche das Ei enthielt. Dies wurde leicht entfernt, und die Frau genas. Die Diagnose war falsch; es hatte sich um eine vor dem Uterus placirte Tubargravidität gehandelt; die Communication war gelegentlich der Erweiterung durch Hegar'sche Stifte entstanden." Diese Erklärung erscheint mir nieht recht plausibel. Eine Extrauteringravidität vor dem Uterus bätte man vor der Operation wahrscheinlich tasten müssen. Ausserdem ist es kaum glaublich, dass durch die Erweiterung der Cervix durch Hegar'sche Stifte das Tubenostium sich so sehr erweitert, dass man in die Tube mit dem Finger (!) eindringen kann. Ich glaube daher, dass es sich viel eher um die in Rede stehende eigenthümliche Gestalt des Uterus mit Ausbauchung einer Wand gehandelt habe.

Ferner referirte in der Geb. Gesellschaft in New-York U c Lean ${ }^{3}$ ) über einen Fall, in dem interstitielle Schwangerschaft eine Beckengeschwulst bez. Tubenschwangerschaft vortäuschte; bei der Koeliotomie zeigte sich, dass der Theil der Geschwulst, der für den Uteruskörper angesehen wurde, ein dünner Sack war, in dem sich eine Frucht von ca. 4 Monaten befand. Nach rechts von demselben

1) Martin, Krankh. der Eileiter. 1898. S. 375.

2) Pollosson, Tubenschwangerschaft unstillbares Erbrechen, künstlicher Abort, Heilung. Lyon. med. 1899. 15. Centralbl. f. Gyn. 1899. S. 1420.

2) M c. Lean, Centralb. für Gen. 1898. S. 1248. 
fand sich der grössere Theil des Uterus durch Adhäsionen im Becken fixirt. Nachdem letztere durchtrennt und die ganze Masse aus dem Becken herausgehoben wurde, zeigte sie die normale Form eines im 4. Nonate graviden Uterus.

Nach dieser Beschreibung dürfte es sich in diesem Falle um eine Ausbuchtung der Uteruswand gehandelt haben, die durch die Fixation des Uterus mehr zur Geltung kam. Desgleichen theilt Vineberg ${ }^{\mathbf{1}}$ ) einen ähnlichen Fall mit, in dem von anderer autorativer Seite die Diagnose auf ectopische Schwangerschaft gestellt worden war und wo es sich nur um eine unregelmässige Entwicklung des schwangeren Uterus gehandelt hatte. Einen ähnlichen Fall will auch Currier ${ }^{2}$ ) beobachtet haben.

Es wird bei der Differentialdiagnose auf diese Erfahrungen über die eigenthümliche Gestalt des frühgraviden Uterus besonders geachtet werden müssen. Aber auch in Fällen vorgeschrittener Gravidität, im 4.-6. Monat, findet man Befunde, die den Verdacht auf Extrauteringravidität nahe legen. So konnte ich wiederholt die eine Partie des Uterus härter finden, sie imponirte zuerst allein als der ganze gravide Uterus, nur entsprach die Grösse nicht der Graviditätsdauer. Erst nach längerem Untersuchen findet man, dass zu dieser Hälfte des Uterus noch eine andere viel grössere gehört, die man wegen der besonders weichen Resistenz zu Beginn der genauen Untersuchung oder bei einer oberflächlichen Untersuchung gar nicht gemerkt hatte. In einem solchen Falle ist die falsche Diagnose auf Tubengravidität sehr naheliegend, oder es wird von dem Mindergeübten eine Gravidität früherer Zeit angenommen, weil die weiche Hälfte ganz übersehen wird. So wurde mir im verflossenen Jahr von einem befreundeten Collegen seine Frau, die im 6. Monate schwanger war und diese Erscheinung darbot, in der Sorge vorgestellt, dass es sich um eine Extrauteringravidität handle. Meine Untersuchung deckte sich vollkommen mit seinem Befund, nur deutete ich den Befund (das linke Horn war kleiner, fester, das rechte Horn, das man erst nach längerer Untersuchung in seiner Contur abtasten konnte, war sehr weich und grösser und überragte das andere Horn) anders, nämlich als.

1) Vineberg. Ibidem.

2) Currier, Centralbl. für Gyn. 1895. S. 1284. 
sicher normale Gravidität, die auch durch eine spontane Geburt ad terminum ihr Ende fand.

Da der Befund in. solchen Fällen ein constanter ist, dürfte, wie ich schon seinerzeit erwähnt, für diese Erscheinung vielleicht auch der Sitz der Placenta massgebend sein.

Dührssen hat in seiner bekannten Arbeit') anch Fälle von Aussackungen der Seitenkanten des anteflectirten Uterus gesammelt, diese Aussackungen waren aber durch perimetritische Verwachsungen des Uterus bedingt. Diese Fälle gehören daher strenge genommen nicht zu der in Rede stehenden Erscheinung am schwangeren Uterus, doch könnten, auch durch sie selbstredend falsche Diaguosen auf Extrauteringravidität verursacht werden. Der von mir citirte Fall Mc Lean's kann auch in diese Rubrik gezählt werden.

Es ist mir aber fraglich, ob diese Verwachsungen die Aussackung des Uterus bedingen, ich möchte eher glauben, dass die Verwachsungen etwas zufälliges sind und die Aussackung schon durch die Gravidität allein hervorgerufen wird, wie ich früher besprochen habe.

Dübrssen hat des Weiteren, pag. 178, „im kleinen Becken liegende Aussackungen der hinteren Corpuswand des schwangeren anteflectirten Uterus" in Besprechung gezogen und constatirt, dass bei dieser Erscheinung fünfmal die Diagnose auf Tubarschwangerschaft gestellt wurde.

Die im kleinen Becken liegende Aussackung muss nicht eine solche der hinteren Wand sein. Sie lässt sich auch in der Weise erklären, dass bei der früher besprochenen, durch die Ungleichmässigkeit der Uterushörner bedingten asymmetrischen Gestalt des Uterus der kleinere Uterusantheil sich gegen die Aushöhlung des Beckens hindreht, dadurch dass der sich rascher vergrössernde Antheil über die Beckeneingangsebene hinaufsteigt (Schauta). Es kann diese Torsion des unregelmässig gestalteten Uterus auch dadurch bedingt sein, dass eine Retroflexion des nicht graviden Uterus ohne oder mit Fixation bestanden hat. Da ist :es bei dem ungleichen Wachsthum der beiden Uterushälften ja ganz naheliegend, dass der stärker wachsende Uterusantheil sich mehr nach vorne dreht als der kleinere Antheil. Gerade der von

1) Dührssen, Ueber Aussackungen, Rückwärtsneigungen und Knickungen der schwangeren Gebärmutter etc. Dieses Arch. Bd. LVII. S. 211. 
Dührssen citirte Fall Sperber zeigte nach seiner spontanen Aufrichtung die Gestalt, die wir häufig an graviden Uteri finden.

Ich halte nun dafür, dass wir durchaus nicht berechtigt sind, einen solchen Uterus einen bicornis zu nennen.

Nach Sperber „lag der Uterus breit und beweglich mit seinem grössten Theil in der rechten Abdominalhälfte, um seine verticale Axe von rechts nach links gedreht, der Fundus in Nabelhöhe, Corpus stark in die Quere gezogen, rechtes Horn stark vorspringend, etwas böher stehend als das weniger prominirende linke Horn, Frucht lag quer, Kopf links, Steiss rechts, kleine Theile vorn, fötale Herztöne in der Mittellinie."

Das ist nicht die Beschreibung eines Uterus bicornis.

Man könnte ja auch sagen, dass die Fälle von früher Gravidität, die das von mir besprochene Symptom in besonderer Deutlichkeit aufweisen, lauter Uteri bicornes sind. Dazu haben wir aber, wie ich glaube, kein Recht. Denn nach unseren und fremden Beobachtungen verschwindet die Differenz in den beiden Hörnern im weiteren Verlaufe der Schwangerschaft und das Ei wächst auch in das andere Horn hinein. Der Ausdruck "Uterus bicornis" erscheint mir daher für solche Fälle unpassend gewählt.

Da ein in der Schwangerschaft so gestalteter Uterus kein Uterus bicornis der üblichen Bezeichnung zu sein braucht, so fällt auch der Schluss fort, den Dührssen aus der Eigenthümlichkeit des bicornen Uterus gezogen hat, dass er stets anteflectirt liegt und dass die Aussackung nicht aus einer, oder besser gesagt, bei bestandener Retroflexion hervorgegangen sein kann. Ein Fall von Gravidität, den jch eben in Beobachtung habe, beweist, dass trotz bestehender Retroflexion die stärkere Ausbauchung eines Hornes bei der weiteren Entwicklung der Gravidität beobachtet werden kann, oder dass ein sogenannter Uterus bicornis gravidus nach Dührssen bei früher bestandener Retroflexion möglich ist:

Frau Sc., 21 Jahre alt, seit 8 Wochen verheirathet, stets gesund, die Periode war stets regelmässig, seit der Ehe ausgeblieben. Bei der ersten Untersuchung am 14. August fand ich die Portio etwas aufgelockert, den vergrösserten Uterus retroflectirt, das Corpus tief im Douglas liegend, die Portio hoch an der hinteren Symphysenwand stehend. Unsichere Schwangerschaftszeichen von Seite des Magens, Wahrscheinlichkeitsdiagnose der Gravidität. Ich ordnete für die nächsten 14 Tage wiederholte Seitenlage mit erhöhtem Steiss an, was von der jungen lebenslustigen Dame kaum befolgt worden sein dürfte. Da die Retroflexion so hochgradig war, dass ich bei weiterer Vergrösserung 
des Uterus eine Incarceration befürchtete, entschloss ich mich am 29. August $\mathrm{zu}$ einer vorsichtigen Massage and einer Aufrichtung in wiederholten Sitzungen; nach 5 Sitzungen konnte ich unter sehr geringen Schmerzen das Corpus uteri über die Beckeneingangsebene heben und es blieb im weiteren Verlaufe in dieser Lage. Am 19. 1X. habe ich folgenden Befund notirt: Uterus anteflectirt, der Schwangerschaftszeit entsprechend vergrössert, auffallend unregelmässige Gestalt, rechtes Horn viel grösser als das linke, es macht den Eindruck, als ob ein breit gestielter ''umor am fundus uteri (linkes Horm) hängen würde, tiefer Sulcus links, rechtes Horn fast praller als linkes.

Die Patientin befand sich nun vollkommen wohl.

Am 12. October liess sie mich wegen Scbmerzen, über die sie auf der linken Seite klagte, rufen. Ich fand dieselbe Gestalt des Uterus, nur letzteren entsprechend vergrössert, das rechte Horn oder besser gesagt den rechten Uterusantheil viel mehr nach vorne stehend und jetzt auffallend weicher als den linken, die Palpaltion des linken Antheils etwas schmerzhaft; es machte mir den Eindruck, als wenn der Uterus eine Torsion nach links gemacht hätte ${ }^{1}$ ).

In diesem Falle dürfte es sich wohl um eine Schwängerung eines früher retroflectirten Uterus gehandelt haben, da in der Schwangerschaft keine Gelegenheitsursache für das Eintreten einer Retroflexion beobachtet wurde und auch nicht anzunehmen ist, dass der Uterus allein in Folge der Schwangerschaft sich nach rückwärts gebeugt habe.

Auch durch die unregelmässige Gestalt des Uterus durch Uterustumoren (Myome) bei intrauteriner Gravidität kann leicht die Diagnose fälschlich auf Extrauteringravidität gestellt werden: Einen hierher gehörigen Fall beschreibt Schauta in seinem Lehrbuch II. pag. 94. Es handelte sich um ein Myom von der Grösse und Form des Uteruskörpers bei intrauteriner Gravidität. Oft wiederholte Untersuchungen führten zur sicheren richtigen Diagnose. Noch schwerer kann die Diagnose in früher Schwangerschaftszeit bei dem Vorhandensein von Myomen sein.

Ganz besondere Schwierigkeiten bietet die Differentialdiagnose zwischen Extrauteringravidität und Gravidität in einem verkümmerten Nebenhorn, ja es können diese Zustände, wie Kussmaul gezeigt hat, auch an der Leiche leicht verwechselt werden, nur der Abgang des Ligamentum rotundum kann darüber entscheiden.

Die Diagnose einer intacten Tubengravidität unterliegt auch dann besonderen Schwierigkeiten, wenn sich das Ei in einer erkrankten Tube eingenistet hat.

1) Anmerkung bei der Correctur: Pat. wurde am 5. IV. durch Forceps entbunden. 
Sehr schwierig kann es unter Umständen sein, diê Differentialdiagnose zwischen Extrauteringravidität bez. Hämatocele und Retroflexio uteri gravidi fixata zu stellen; es werden bisweilen wiederholte? Untersuchungen erforderlich sein; prima vista lässt sich nicht immer so ohne Weiteres das Richtige treffen. Wenn der Fundus uteri bei bestehender Extrauteringravidität nicht deutlich getastet werden kann, ist eine Verwechselung dieser zwei pathologischen Zustände lehr leicht möglich; als Ultimum refugium bleibt, wenn auch eine Untersuchung in Narkose keine Aufklärung gegeben hat, ein vorsichtiger Aufrichtungsversuch, während aber gleichzeitig zu einer etwa nothwendig werdenden Laparotomie Alles hergerichtet sein muss. Weniger zu empfehlen wäre eine vorsichtige Sondirung des Uterus, da, wenn es sich um eine Retroflexion des graviden Uterus handelt, doch sehr leicht die Schwangerschaft unterbrochen wird und man andererseits auch durch eine Sondirung nicht immer die richtige Diagnose zu ermitteln vermag. Es kańn bei einer scharfwinkeligen Abknickung des Uterus eine Sondirung des Cavums unmöglich sein und so zur falschen Diagnose führen, wie - in den Fällen von Bailly') und Semmelweiss'). In letzterem Falle wäre der Kaiserschnitt gemacht worden, wenn nicht die spontane Geburt eingetreten wäre. Die Sonde hatte sich in einer Ausbuchtung der hinteren Wand des Mutterhalses verfangen.

Im Falle Schwartz ${ }^{2}$ ) war auch sondirt worden, und es hatte sich eine Sondenlänge von $91 / 2 \mathrm{~cm}$ ergeben; hinter dem vermeintlichen Uterus lag ein fluctuirender, sehr schmerzhafter Tumor, der ganz unabhängig vom Uterus erscheint. Erst die Laparotomie ergab, dass der Fundus gegen den Uteruskörper und das Collum unter spitzem Winkel retroflectirt war. Reposition gelang lejcht. Normale Entbindung.

Die Schwierigkeit der Diagnose zeigen auch die zwei Fälle ${ }^{3}$ ) aus der Greifswalder Klinik. In beiden Fällen wurde die Diagnose irrthümlich auf Tubengravidität bei anteflectirtem Uterus gestellt. Die Täuschung wurde dadurch veranlasst, dass nach Ablassen des Urins die stark hypertrophirte und contrahirte Blase der

1) Dührssen, l. c. S. 101 u. 102.

2) Schwartz, Annales de gynéc. 1894. October.

3) Grauert, Ueber Retrofexio uteri gravidi cum incareeratione mit besonderer Berücksichtigung von zwei in der Greifswalder Univ.-Frauenklinik behandelten Fällen. Inaug.-Diss. Ref. Centralbl. f. Gyn. 1900. S. 383. 
Portio fest auflag und den Uteruskörper vortäuschte, während der das Becken ausfüllende gravide Uterus für den tubaren Fruchtsack gehalten wurde.

Der 2. Fall zeigt ausserdem die Fruchtlosigkeit der Sondirung. Es wurde sondirt und scheinbar eine normale Länge der Gebärmutterhöhle festgestellt, während die Sonde thatsächlich nur die Länge des Canales der hypertrophirten Cervix angab. In beiden Fällen Laparotomie, Aufrichtung des Uterus, boide Fälle endeten mit Abort.

Dagegen räth Dührssen ${ }^{1}$ ) zum Stellen der Differentialdiagnose "vor einer Koeliotomie oder einem Repositionsversuch die Sondirung vorzunehmen." "Ist es nun Tubenschwangerschaft, so schadet eine lege artis ausgeführte Sondirung nichts - ist es eine Retroflexio uteri gravidi, so schadet sie meistens auch nichts."

Dührssen glaubt auch, dass in dem citirten Falle Bailly die richtige Diagnose zu stellen gewesen wäre, wenn man die Sondenspitze auch nach hinten gedreht hätte. D. verlangt ferner zur Vermeidung von Irrthümern die Verwendung einer recht dicken Sonde, die nach den verschiedenen Richtungen vorgeführt werden soll.

Es kann auch umgekehrt eine Extrauteringravidität irrthümich als Retroflexio angesprochen werden.

Letztere Verwechslung characterisiren die Fälle Giles's ${ }^{2}$ ) Es wurde in 2 Fällen die Diagnose fälschlich auf Retoversio uteri gravidi gestellt, Repositionsversuche gemacht und bei einer der Kranken später der Uterus zwecks Einleitung des künstlichen Abortus sondirt. Tod am nächsten Tage, nachdem man auf die Diagnose "Extrauteringravidität" zurückgekommen war. Im zweiten Falle wurde offenbar durch die Reposionsversuche die Tube rupturirt, wie bei der am nächsten Tage gewonnenen Laparotomie gefunden wurde. Genesung.

Gerade bei der Differentialdiagnose zwischen Retroflexio uteri gravidi und Extrauteringravidität dürften auch hervorragenden Gynaekologen bie and da Irrthümer unterlaufen. Wenn in der Literatur nicht allzuviele Fälle publicirt sind, so spricht dieser Umstand nicht dagegen, da Fehldiagnosen nicht so häufig publicirt werden; und wenn solche publicirt werden, gesehieht dies doch nur

1) Dührssen, l. c.

2) Giles, Transart. of the obst. soc. of London. Yol. XXXIX. p. 232. 
von Seite solcher Autoren, die über jeden Zweifel einer mangelhaften Untersuchungstechnik erhaben sind.

In einem Falle machte mir die Differentialdiagnose zwischen einer Extrauteringraviditat und einer Blasenmole einige Schwierigkeiten.

Es hatte sich um eine junge Patientin gehandelt, die vor 2 Jahren einmal normal geboren hatte (Eine genauere Anamnese kann ich nicht bringen, da ich sie leider nicht aufgezeichnet habe und sich dieser Vorfall vor 7 Jahren ereignete). Nachdem die Periode durch 4 Monate ausgeblieben war, traten plötzlich starkes Erbrechen und Blutungen ein, die in weehselnder Stärke andauerten. Es gingen dunkelrothe Massen gestockten Blutes von üblem Geruch ab, gleichzeitig bestanden krampfartige Schmerzen im Abdomen. Nachdem dieser Zustand durch 6 Wochen angehalten hatte, entschloss sich die Patientin einen Arzt zu Rathe zu ziehen, auf dessen Verlangen ich die Patientin sah. Sie sah recht herabgekommen aus, und klagte über öfters wiederkehrende Schmerzen im Bauch. Ich fand bei der äusseren Untersuchung desselben einen Befund, der in Rücksicht auf die Anamnese nicht leicht zu deuten war: nämlich in der rechten regio hypogastrica einen gänseeigrossen Körper, der sehr stark ballotirte, sehr deutlich durch die Bauchdecken getastet wurde. Er machte den Eindruck eines ballotirenden kindlichen Schädels; in der linken regio hyprogastrica fand sich gleichfalls eine sebr bewegliche kleinere Geschwulst, die für einen kleinen Kindestheil angesprochen werden konnte. Ueber die Symphyse ragte etwa $1^{1 / 2}$ Handbreit ein aus dem Becken aufsteigender Tumor von unregelmässiger Form (der Uterus) empor. Bei der combinirten Untersuchung fand man eine weite Scheide, deren Wand aufgelockert, blutiges Secret aus der Vagina, die Portio hoch oben und vorne an der Symphyse stehend, aufgelockert, der Yuttermund für die Fingerkuppe zugängig, der Cervicalcanal geschlossen. Der Douglas war herabgedrängt durch einen weichelastischen Tumor, dessen obere Grenze ca. 11/2 Handbreit über den Symphysenrand reichte. $\mathrm{Da}$ das Abdomen aufgetrieben, war die die Untersuchung recht erschwert. Der Palpationsbefnnd des Bauches konnte sebr leicht zur Diagnose einer Abdominalgravidität verleiten, ebenso war das starke Herabgedrängtsein des Douglas sehr verdächtig; doch hatte ich die Vermutbung, dass es sich auch um eine intrauterine Gravidität mit Retroflexion des Uterus und Molenbildung handeln könne und dass die in der Bauchhöhle getasteten frei beweglichen Gebilde entweder Ovarialtumoren oder gestielte Myome sein könnten. Ich liess die Patientin zur Sicherheit in ein Sanatorium iüberführen und entschloss mich, zur Sicherstellung der Diagnose den Cervicalcanal durch Hegar zu dilatiren. Die Kornzange förderte nun Theile einer Blasenmole heraus. Nun wurde die Gebärmutterhöhle theils digital, theils instrumentell (mit der Löffelzange) ausgeräumt; dabei bereitete die Ausräumung des im Douglas liegenden Antheiles einige Schwierigkeiten. Hierauf exacte Excochleation der Uteruswand, intrauterine Irrigation und Tamponade mit Jodoformgaze. Glatter Verlauf nach der Operation. Patientin wurde nach 14 Tagen sehr gekräftigt entlassen. Der Entlassungsbefund wies neben dem involvirten Uterus jederseits einen Adnexentumor und zwar rechts einen grösseren gut apfelgrossen, links einen kleineren auf. Im weiteren Verlauf wurden diese Adnexentumoren 
in conservativer Weise behandelt und sie versehwanden im VerIaufe von einigen Monaten vollständig und Patientin befand sich in den nächsten Jahrèn andauernd wohl. Vor 2 Jahren babe ich die letzten günstigen Nachrichten über sie geleg*entlich der Trennung ihrer Ehe erhaiten.

Nach meiner Ansicht dürte es sich in diesem Falle nur um eine oedematöse Sehwellung der Ovarien oder vielleicht auch der Tuben gehandelt haben.

Unwahrscheinlich ist es für mich, dass es sich um alte Adnextumoren und zufällig gleichzeitige Molenbildung gehandelt habe, sondern ich balte nach der Beobachtung des Ealles die Molenbildung als die Ursache der Anschwellung der Adnexe bezw. der Ovarien. Jedenfalls ist es bemerkenswerth, dass so geformte und so bewegliche Geschwülste bei gleichzeitiger Molenbildung zu einer falschen Diagnose verleiten können.

Da der eine Antheil des Uterus den Douglas herabdrängte, der andere Theil aus dem Becken herausgewachsen war, hat es sich um eine Retroflexio uteri partialis oder um eine Aussackung der hinteren Corpuswand im Sinne Dührssen's gehandelt. Auffallend ist dabei jedenfalls, dass es zu. keinen Incarcerationserscheinungen gekommen ist. Man kann sich dies nur so erklären, dass schon frühzeitig ein Theil des Uterus in das grosse Becken gewachsen war, wie es Dührssen (l. c.) für seinen Fall auch angenommen hat, in dem sich Patientin bis zum Anfang des 5. Monats ganz wohl gefühlt hatte.

Es dürten auch in unserem Falle Verwachsungen den Grund für das Ausbleiben der spontanen Aufrichtung abgegeben haben, da der Uterus auch später retroflectirt lag. Es wird für das Zustandekommen einer Incarceration ganz abgesehen von den bestehenden Verwachsungen gewiss auch der Grad der Retroflexion von Einfluss sein, da ja bei geringeren Graden einer Retroflexion ein grösserer Theil der vorderen Uteruswand die Möglichkeit hat, über die Beckeneingangsebene hinauszuwachsen.

Grosse Schwierigkeiten in der Diagnosenstellung können in der späteren Schwangerschaftszeit auch Fälle von hochgradiger Hypoplasie der Uteruswand verursachen. So hatten wir in der Klinik einen Fall aufgenommen, bei dem die Kindestheile so deutlich durch die Bauchdecken durchgetastet wurden, dass die Differentialdiagnose erst nach wiederholten Untersuchungen und nach Auffindung der auch sehr zarten, kaum tastbaren ligamenta rotunda gestellt wurde. 
In einem Falle ${ }^{1}$ ) von vorgeschrittener Bauchhöhlensehwangerschaft, den wir in der Klinik beobachteten, fand man ganz deutlich den Contour des extrauterinen Eruchtsackes durch eine deutliche Furche geschieden von den Umrissen des Uterus. Wir sahen an dem Fruchtsacke ganz deutliche Contractionen, so dass es bei einer oberflächlichen Untersuchung den Eindruck machen konnte, als handle es sich um die Contractionen in einem Horn eines Uterus bicornis. Der Fruchtsack entsprach in seiner Grösse einem graviden Uterus von 7 Monaten. Das Präparat konnte die Entstehung der Contractionen im Sacke auch nicht ganz klären. Obwohl in dem extrauterinen Fruchtsacke muskuläre Elemente gefunden wurden, kann man nicht sagen, dass der Sack aus der Tubenwand gebildet wurde, sondern es entschied sich der Obducent (Hofrath Weichselbaum) für die Diagnose Tuboovaicalgravidität. Aber auch ohne dass contraetile Elemente in dem Fruchtsack gefunden werden, kann dieser die Erscheinung von Contractionen aufweisen, wenn der Fruchtsack innig mit dem Uterus verbunden ist, so dass sich die Contractionen des letzteren ersterem mittheilen. Die wirklich getasteten Contractionen des Fruchtsackes sind streng auseinander zu halten yon wehenartigen Schmerzen, die von den Contraetionen des Uterus herrühren dürften. So hat Martin in einem Falle von Ovarialschwangerschaft heftige wehenartige Schmerzen beobachtet. Es war der Fruchttod am normalen Ende der Schwangersehaft unter heftigen Wehen eingetreten.

Es mag ein Zufall sein, dass ich in keinem Falle eine intacte Tubengravidität mit normalem Ei gefunden habe; überhaupt wurde in der Klinik des Herrn Hofrathes Gustav v. Braun seit dem Jahre 1892 kein derartiger Fall beobachtet. In 2 Fällen hatte ich eine intacte Tubengravidität angenommen, die Diagnose entsprach aber nicht der Wirklichkeit. Es ist dies der früher citirte Fall, in dem ich die Cyste für einen extrauterinen Fruchtsack hielt und ferner der Fall XI, in welchem ich im Verlauf der Tube einen deutlichen Tumor vorfand; es zeigte sich bei der Operation, dass ich mit der Diagnose einer Extrauteringravidität Recht hatte. Es handelte sich aber um eine Tubenmole, nicht um eine intacte Tubengravidität.

1) G. Braun, Centralbl. für Gyn. 1899. S. 485. 
War im letzteren Falle Reste der Blutung aus dem Tubenende (Adhaesionen, Verlagerung der Tube etc.) oder eine ausgesprochene Haematocele vorhanden; so wurde öfters darauf hingewiesen, dass zur Differentialdiagnose zwischen eirem auf Extraateringravidität beruhenden Tumor und entzündlichem Adnexentumor der Befund der Adnexe der anderen Seite berücksichtigt werden soll, indem das Vorfinden eines Tumors auf beiden Seiten mehr für eine entzündliche Adnexenerkrankung spreche. Diese Regel ist nach meiner Ansicht von sehr geringem diagnostischen Werth. Es wird wohl ein einseitiger Adnexentumor mehr für eine Extrauteringravidität, dagegen wird der Befund von beiderseitigen Adnexentumoren nicht gegen das Bestehen einer extrauterinen Gravidität auf einer Seite sprechen. Es sind ja recht häufig die Adnexe der anderen Seite entzündlich erkrankt, da ja wohl in manchen Fällen die beiden Adnexe, vielleicht in verschiedenem Grade, aus einer gemeinsamen Ursache heraus (Gonorrhoe, Puerperalprocess) erkrankt waren und sich in einer Tube das Ei angesiedelt hat.

Es kann die andere Tube auch einen blutigen Inhalt aufweisen. Wenn das Fimbrienende geschlossen ist, kommt es zur Bildung einer Hämatosalpinx; es kann sich sogar ein Blutgerinnsel bilden, das irrthümlich für ein Abortivei gehalten werden könnte (Küstner). Während r. Ott in dieser Blutung in der andern Tube einen consensuellen Prozess der Extrauterinschwangerschaft sieht, erblickt Küstner in diesem Prozesse einen pathologischen Zustand der Tube, welcher in irgend einer Form bereits zur Zeit der Entstehung der Extrauteringravidität vorhanden war. Ich möchte mich auch letzterer Ansicht ansehliessen.

Es kann aber auch in allerdings sehr seltenen Fällen, vorkommen, dass in jeder Tube sich eine Extrauteringravidität vorfindet.

Martin ${ }^{1}$, der einen solchen Fall beobachtet hat, konnte aus der Literatur nur acht einschlägige Fülle zusammenstellen. In seinem Falle wurden die linksseitigen Adnexe abgetragen, der rechtsseitige tubare Fruchtsack gespalten, entleert und vernäht.

Endlich ist es bei ausgebildeter Hämatocele häufig ganz unmöglich, die Adnexe der andern Seite abzutasten, da sie mit der Hämatocele verbacken sein können oder es kann die retrouterine Hämatocele den Uterus, besonders dessen Fundus, so verschieben bezw. eleviren, dass die Adnexe der andern Seite nicht abgetastet

1) Martin, Zeitschr. für Geb, und Gyn. Bd. XXXVIII. H. 1. S. 144. 
werden können. Dagegen hat gerade die erwähnte Dislocation des Uterus eine gewisse differentialdiagnostische Bedeutung, doch lässt sich die Differentialdiagnose zwischen Hämatocele und entzündlichen Adnexentumor hänfig überhaupt nicht stellen, wie alle Autoren zugeben. Wir können in beiden Fällen den gleichen Befund aufnehmen: Seitlich und hinter dem Uterus ein Tumor, der den Douglas herabdrängt, die Grenzen des Tumors nach oben sind wegen der Darmadhäsion nicht zu tasten. Die Anamnese kann zur Differentialdiagnose in derartigen Fällen herangezogen werden. Doch ist auch sie sehr trügerisch, so kann sie für ektopische Schwangerschaft sprechen, bei der Operation findet man dann einen eitrigen Adnexentumor, wie in unseren Fallen XVI, XVII. Andrerseits muss man bedenken, dass eine ectopische Schwangerschaft vorliegen kann, ohne dass die Anamnese damit stimmt.

Das Verhalten der Periode ist bei Extrauteringravidität überhaupt recht unverlässlich. Es giebt recht häufig Abweichungen von der typischen Anamnese in Bezug auf die Blutungen, die durch Wochen ausgeblieben sein sollen, dann unerwartet, meistens unter Kolikerscheinungen wiedergekommen sein und mit wechselnder Stärke anhalten sollen. In vielen Fällen von ektopischer Schwangerschaft war die Periode überhaupt nicht ausgeblieben. So war unter 77 der von Martin beobachteten Fälle die Periode in 25 Fällen, nach Franz ${ }^{1}$ ) unter 70 Fällen 24 Mal nicht ausgeblieben. An der Klinik Schauta war die Periode unter 81 Fällen von Tubarabort $24 \mathrm{Mal}$ und unter 18 Fällen von Tubenruptur $2 \mathrm{Mal}$ nicht ausgeblieben (vergl. Lindenthal, l. c.).

Auch bei Rupturen kann den Unerfahrenen das Verhalten der Periode irreführen, es kann nämlich eine Ruptur der schwangeren Tube in sehr früher Schwangerschaftszeit sich ereignen, so berichtet Dawsson ${ }^{2}$ ) über eine Ruptur am 16. Schwangerschaftstag, ebenso demonstrirte $\mathrm{H}_{0}\left(\mathrm{fmeier}{ }^{3}\right.$ ) eine kaum $1 \mathrm{~cm}$ Durchmesser haltende, geplatzte linke Tubenschwangerschaft. Desgleichen ist in unserm Fall II die Ruptur des Tubensackes in sehr früher Zeit erfolgt.

1) Franz, Centralbl. für Gyn. 1890. S. 1290.

2) Deurson, Transact of the obst. Soc. of London. Vol. XL. p. 155. Frommel. 1898.

3) Hofmeier, Ges. für Geb. u. Gyn. in Berlin. Sitzung 12. I. 1900. Centralbl. f. Gyn. 1900. S. 233. 
Füth hat in seiner schon eitirten Arbeit (dieses Arch. LXIII. B.) 2 Fälle von besonders früh geborstener Tubengravidität besehrieben and will für den Fall II die Graviditätsdauer auf 10-11 Tage bestimmt: wissen, im Falle I nimmt er eine Graviditätsdauer von 10 Tagen an.

Das gleich frisch in natürlicher Grösse gezeichnete Präparat (Fig. 7 auf Tafel IV) kommt mir für eine Gravidität von 10 bis 11 Tagen etwas gross vor; jedenfalls muss ich sagen, dass unser Präparat kleiner war, es dürfte beiläufig dasselbe Graviditätsalter wie das Präparat I Füth's haben.

Dass man sich auf das Verhalten der Periode gar nicht verlassen kann, zeigen auch unsere Fälle IV, VI und VIII.

Im Falle IV von Tubenruptur war vor 3 Wochen die letzte Periode etwas verspätet aufgetreten, zu welcher Zeit die ektopische Schwangerschaft schon bestanden haben musste.

Im Falle VI ist die Anamnese auch schwer zu denten. Anfangs November soll die letzte regelmässige Periode beobachtet worden sein, und schon Mitte November scheint sich die Hämatocele gebildet zu haben. Entweder es handelt sich um eine sehr frühzeitige Unterbrechung der ektopischen Schwangersehaft durch Tubenabort oder, was mir wahrscheinlicher dünkt, hat die Patientin bei schon bestehender Tubengravidität noch einmal regelmässig menstruirt.

Im Falle VIII ist die Anamnese ganz unverständlich: angeblich wurde die letzte regelmässige Periode vor 2 Monaten beobachtet, und von dieser Zeit erst fühlt sich Patientin leidend, giebt aber nicht an, dass sie za dieser Zeit einen collapsähnlichen Zustand zu überstehen hatte. Da die Frucht in ihrer Entwicklung dem 5. Monat entsprach, so muss die Patientin trotz schon bestehender ektopischer Schwangerschaft zweimal die Periode regelmässig gehabt haben. Dass trotz der grossen Hämatocele die Patientin nie in einen Collapszustand verfiel, ist gewiss auch sehr auffallend.

Weindler ${ }^{1}$ ) ist in letater Zeit für die Benutzung der Menstruationscurven zur Diagnostik der Extrauteringravidität eingetreten, wie sie an der Klinik Leopold entsprechend der in dieser Richtung von Kaltenbach ${ }^{2}$ gegebenen Anregung stets verwerthet

1) Weindler, Zur Diagnose der frühzeitigen Extrauteringravidität etc. Dieses Archiv. Bd. LXI. H. 3.

2) IIaltenbach, Lehrbuch der Geburtshülfe. 1890. S. 222. 
wurden. Diese Verwendung der Menstruationscurven hat gewiss einen ganz vorzüglichen didactischen Werth. Weindler hebt in dieser Arbeit auch drei an der Klinik beobachtete Fälle hervor, in denen die Menses in nabezu normaler. Weise verliefen. Besonders interessant ist der dritte von diesen Fällen: Periode war nicht ausgeblieben. Seit der Entbindung der Patientin im Januar hielten die Blutungen jedoch länger als früher ân, und im Juni sei ein Ohnmachtsanfall, verbunden mit einem Schüttelfrost, aufgetreten. Nachdem ist die Frau zweifelsohne sofort nach ihrer Entlassung aus der Anstalt wieder gravid geworden. Der bei der Kranken gefühlte rechts seitige Tumor wurde als starre abgekapselte Exsudatmasse aufgefasst, eine Annahme, die durch das fast sechs Wochen andauernde fieberhafte Wochenbett volle Berechtigung hatte. Bei der Laparotomie fand sich eine Graviditas tubaria med. dextra iünssten Datums mit Hämatocelenbildung.

Das Eintreten bezw. Andauern einer uterinen Blutung spielt bei der Diagnose auf Extrauteringravidität eine Rolle, doch ist es auch möglich, dass eine Tubenruptur oder ein Tubenabort sich ereignet, ohne dass eine Blutung beobachtet wird, sie kann erst einige Tage nach dem Anfall eintreten. Gewöhnlich ist die Blutung nicht stark, jedenfalls niemals so stürmisch wie bei einem uterinen $\mathrm{Ab}$ ort, und dies kann bei einer Differentialdiagnose allerdings auch mit Vorsicht verwendet werden. Hat sich eine Haematocele gebildet, so dauern die uternen Blutungen an und es ändert sich nach einiger Zeit die Farbe der Ausscheidung. Während sie anfangs gewöhnlich dunkelroth ist, wird sje nach einigen Wochen braunroth und dies halte ich für ein gutes Zeichen der beginnenden Resorption der Haematocele. Eine so starke plötzliche uterine Blutung, dass man wegen Lebensgefahr in Folge dieser die Vagina hätte tamponiren müssen, habe ich noch in keinem Falle beobachtet.

Ich möchte aber doch auch nicht glauben, dass man aus der Beschaffenheit und dem Fliessen des Blutes bei der Differentialdiagnose zwischen ektopischer Gravidität und uterinem Abort zu viel sollte herauslesen wollen. Nach Cullingworth ${ }^{1}$ ) soll das entleerte Blut bei Extrauteringravidität stets besonders dunkel, von mässiger Menge, geruchlos, dicklich sein und im stetigen Fluss

1) Callingworth, Ueber Eileiterschwangerschaft mit besonderer Berüchsichtigung ihrer frühzeitigen Diagnose und Behandlung. Clinical journ. Dec. 8. Centralbl. für Gyn. 1898. S. 942. 
abfliessen. Bei uterinem Abort dagegen soll die Blutung öfters sistiren, um von Neuem zu beginnen.

Die Differenz im Geruch, sowie das Charakteristische des stetigen Fliessens der Blutung ist mir durchaus nicht aufgefallen und halte ich daher diese Merkmale nicht für verwendbar.

Der Abgang einer Decidua sichert wohl die Diagnose auf Extrauteringravidität, doch kommt man nicht häufig in die lage, sie zu Gesicht zu bekommen, da sie häufig schon früher unbemerkt abgegangen ist, bevor der Arzt befragt wurde; man wird also in den meisten Fällen auf dieses die Diagnose stützende Symptom verzichten müssen.

Martin ${ }^{1}$ ) hat 5 Fälle beobachtet, in denen bei Tubengeschwulst, nachdem die Menstruation ausgeblieben war, neben dem nicht schwangeren Uterus bei wehenartigen Schmerzen und blutigem Ausfluss, auf die Vermuthung eines tubaren Abortus hin die Koeliotomie gemacht wurde und nur eine Sactosalpinx purulenta angetroffen wurde mit chronisch exsudativer Peritonitis, welche ebenfalls fieberlos verlaufen war.

Es ist naheliegend, dass ebenso wie eine entzündliche Adnexenaffection mit Extrauteringravidität verwechselt werden kann, dies mit einer Appendicitis möglich ist, da es ja bekanntlich in manchen Fällen auch sehr schwer ist, eine Adnexenerkrankung von einer Appendicitis zu unterscheiden. Von einem derartigen Fall berichtet Walther ${ }^{2}$ ); er diagnosticirte eine Appendicitis, es hatte sich aber die schwangere Tube hinter dem Coecum entwickelt.

Besondere diagnostische Schwierigkeiten besitzen auch jene Fälle, in denen es sich um Extrauteringravidität, combinirt mit einer Ovarialcyste, handelt, wie in dem Falle von Martin und in meinem Falle No.X. Auch in meinem Falle wurde die Ovarialcyste als Hämatocele angesprochen, und es zeigte sich bei der Uperation allerdings das Vorhandensein einer Extrauterinschwangerschaft in der Tube; das aber, was als Hämatocele angesprochen worden war, war die Ovarialcyste.

Eine Sondirung des Uterus vermeiden wir principiell bei Verdacht auf Extrauteringravidität. Desgleichen halten wir eine Probe-

1) Martin, Krankheiten der Eileiter. 1898.

2) C. Walther, Ein Fall ron retrocoecaler Tubenschwangerschaft. Revue de gyn. et de chir. abdom. 1897. Novbr.-Decbr. Centralbl. für Gyn. 1898. S. 597. 
excochleation (v. Ott etc.) für gefährlich, da bei intacter Tubenschwangerschaft ein Tubarabort resp. eine Tubenruptur hervorgerufen und bei frisch gebildeter Hämatocele dieselbe zum Platzen gebracht werden kann. In einem Consiliarfalle in einem Orte der Umgebung Wiens wurde von dem Arzte wegen vermeintlichen Abortus eine Excochleation ausgeführt; die Frau collabirte unmittelbar post operationem; die Section ergab das Geplatztsein einer Tubengravidität.

Löhlein') warnt auch vor der vorsichtigen Herausnahme kleiner. Schleimhautpartikelchen für die mikroskopische Untersuchung.

Von manchen Autoren wird zur Differentialdiagnose die Probepunction von der Vagina aus (Küstner u. A.) angerathen. Wir haben diese Punction niemals ausgeführt und möchten dieselbe auch nicht befürworten, da, wie der aus der Klinik Schauta publicirte Fall (Lindenthal, l. c. p. 185), in dem eine so heftige innere Blutung eintrat, dass trotz sofort ausgeführter Laparotomie der Tod in Folge Anämie erfolgte, beweist, dass die Probepunction unter Umständen gefährlich sein kann, und ausserdem durch die Punction Irrthümer involvirt werden können. So publicirt Küstner einen Fali, in welchem er die Wahrscheinlichkeitsdiagnose auf Extrauteringravidität gestellt hatte, aber ein umfängliches Ovarialhämatom angetroffen hat. In einem anderen Falle ergab die Punction eine klare, strohgelbe Flüssigkeit. Er hielt eine doppelseitige Salpingo-Oophoritis mit kleincystischer Ovarialdegeneration für nicht ausgeschlossen, tral aber eine Extrauterinschwangersehaft, allerdings combinirt, mit der vermutheten Ovarienaffection, an. In dem schon citirten Falle von Martin hätte man bei der Punction sicher den Inhalt der Ovarialcyste entleert, und trotzdem handelte es sich zugleich auch um eine Extrauteringravidität, ebenso in unserem schon erwähnten Fall X. In unseren Fällen Vl und VII handelte es sich um eine Extrauteringravidität und Hydrosalpinx der anderen Seite, und man hätte sicherlich zufällig in den Hydrosalpinx kommen können und hätte so eine falsche Diagnose stellen müssen.

Ferner hätte man in dem Falle No. XV, in dem es sich um Blutungen in eine torquirte, adhärente Ovarialeyste handelte, bei einer zu stellenden Differentialdiagnose zwischen Hämatocele anteuterina und Ovarialcyste gewiss nach Punction fälschlich die erste

1) Löhlein, Deutsche med. Wochenschr. 1895. No. 33. 
Diagnose gestellt. Dieser Fall ist überhaupt in differentialdiagnostischer Beziebung gewiss interessant, da der Pathologe, der das Präparat begutachtete, die Diagnose makroskopisch erst auf Kystom stellen konnte, als er an einer Stelle des Präparates Cystthen mit colloidem Inhalt fand, und verweise ich daher auf die Krankengeschichte.

Auf die Beschaffenheit der Portio darf man als differentialdiagnostisches Zeichen nicht allzu viel geben. Da ja sogar bei früher intrauteriner Gravidität die Portio ganz hart sein kann, so kann dies ebenso der Fall sein bei intacter Tubengravidität. Noch weniger werden wir eine Erweichung der Portio bei ausgebildeter Hämatocele, besonders einige Zeit nach dem Fruchttod, erwarten können. Es lehrt auch die Erfahrung, dass bei ausgebildeter Hämatocele die Portio häufig gar nicht im Sinne der Erweichung verändert ist. Je länger eine. Hämatocele besteht, um so wahrscheinlicher dürfte eine Auflockerung der Portio fehlen.

Das Vorbandensein von Colostrum in der Brust hat für die Diagnose sehr wenig Bedeutung.

Den besonderen Werth der Pulsation der Uterina auf einer Seite für die Differentialdiagnose konnte jch durch meine Untersuchungen nicht bestätigt finden.

Wenn es schon manches Mal schwer ist, einen entzündlichen Adnexentumor von einer Extrauteringravidität zu unterscheiden, so kann auch in der Diagnose einer inneren Blutung sehr leicht ein Irrthum unterlaufen. Es kann nämlich ein ganz ähnlicher Collapszustand bedingt sein durch das Austreten von Eiter in die Bauchhöhle, wie die Fälle XVI und XVII zeigen. In ersterem Falle trat der Collaps bei Pyosalpinx unmittelbar nach einer vorsichtigen bimanuellen Untersuchung auf. Im zweiten Falle waren spontane Collapszustände aufgetreten. Ich hatte mich nach einer achttägigen. Beobachtung für die Diagnose einer Extrauteringravidität entschieden; bei der Laparotomie zeigte es sich aber, dass es sich um eine Eiterhöhle im Becken handle. Da die Fimbrienenden der Tuben frei in die Abscesshöhle eintanchten, hat dies die Vorstellung in mir wachgerufen, dass es sich hier um einen ähnlichen Vorgang gehandelt habe wie bei der Entstehung einer Hämatocele, dass nämlich der aus der Tube ausgeflossene Eiter durch den Reiz des Peritoneums den Collapszustand bedingte und dass der Eiter sich in der Beckenhöhle abkapselte. Der 
Analogie nach wäre dies als Pyocele peritubaria $z u$ bezeichnen.

In einem Falle der Klinik Schauta musste zur Differentialdiagnose zwischen freier Blutung in die Bauchhöhle und Peritonitis zuerst die vaginale Koeliotomje ausgeführt werden.

Es kann ferner manchmal unüberwindliche Schwierigkeiten bereiten, eine Differentialdiagnose zwischen eine: Extrauteringravidität und acutem Ileus zu stellen. In dem Falle Mackenrodt's ${ }^{1}$ ) war vom Arzte die Diagnose auf Extrauteringravidität gestellt worden.

Eine 35jährige Frau erkrankte plötzlich unter Leibschmerzen und grosser, rasch zunehmender Erschöpfung. Keinerlei Menstruationsanomalien; Darm durchgängig, Stuhl und Blähungen normal. M. fand die Patientin verfallen, 100 Pulse, Leib wenig gespannt, kaum druckempfindlich, zwischen Nabel und Symphyse ein kindskopforosser, schlaffer, verschieblicher Tumor, der Uterus retrovertirt, im Douglas eine weiche Masse, der Tumor dem Uterus anliegend, Adnexe nicht zu tasten. Vor wenigen Stunden war reichlicher Stubl erfolgt. M. glaubte an eine innere Blutung aus einer strangulirten Cyste. Beim Hervorziehen des kugeligen, schlaffen, blauschwarzen Tumors bei der Laparotomie dreht er sich um mehr als eine Tour nach rechts, war also am Stiel strangulirt. Der Stiel war aber die Radix mesenterii und der Tumor war das zu einem glatten Tumor verklebte Iejunum. Resection. des Darmes, dieser war völlig durchgängig und enthielt mit Blut vermengte Kothmassen und Schleim.

Steffeck ${ }^{2}$ ) beschreibt einen Fall, der insofern noch bemerkenswerth ist, als es sich um eine sterile Frau handelte, die plötzlich nach 3 monatlicher Amenorrboe unter sehr heftigen Schmerzen im Leibe erkrankte. Die Patientin war fast pulslos und sehr anaemisch, der Leib ganz wenig aufgetrieben, vorne schmerzhaft. Bei der Laparotomie drängte sich ein Convolut dunkel gefärbter, verwachsener Darmschlingen aus der Wunde heraus. Nach Lösung der allenthalben im Banchranm vorhandenen Adhaesionen fanden sich in der Tiefe 2 feste Stränge, die vom Dünndarm zur Flexura sigmoidea zogen. Durch den Spalt zwischen diesen Adhaesionen war der ganze übrige Dümndarm hindurchgeschlüpft und völlig abgeklemmt. Nach Durchschneidung des einschneidenden Ringes wurde sofort freie Passage geschaffen. Am 3. Tage Exitus unter zunehmender Schwäche.

Steffeck stimmt mit Mackenrodt darin überein, dass die Differentialdiagnose zwischen geplatzter Tubensehwangerschaft und acutem Ileus unmöglich sein kann.

Wenn es sich aber thatsächlich um eine Extrauteringravidität handelt, lässt sich die Differentialdiagnose zwischen Tubenruptur und Tubenabort unmöglich mit Sicherheit stellen, denn es verläult

1) Mackenrodt, Centralbl. für Gyn. 1901. S. 898.

2) Steffeck, Ibidem. 
letztere in manchen Fällen ganz nach dem Bilde, das wir beim Letzteren zu sehen gewohnt sind und umgekehrt; wohl kann man im Allgemeinen sagen, dass ein Abortus meist weniger stürmisch und mit Bildung einer Haematocele verläuft; während wir bei Ruptur viel häufiger eine freie Blutung in die Bauchhöhle antreffen.

Fehling hat hervorgehoben, dass eine tödtiche Blutung bei vollständigem Tubarabort nicht bekannt sei; durch den Fall Piering's und durch die in jüngster Zeit von Mandl publicirten Fälle aus der Erfahrung Schauta's scheint, wie schon hervorgehoben, die Möglichkeit bewiesen zu sein.

Die Schmerzempfindung im Bauche spielt bei der Diagnose der Extrauteringraviditä, nach meiner Ansicht auch mit vollem Recht, eine grosse Rolle. Zwei Hauptarten von Schmerzen kann man da unterscheiden, die natürlich nicht immer stricte geschieden sind. Entweder es wird angegeben, dass plötzlich ein heftiger Schmerz im Abdomen verspürt wurde (dieser Schmerz überrascht die $\mathrm{Pa}$ tientinnen häufig im vollsten Wohlbefinden und haben die Patientinnen nicht selten auch keine Ahnung, dass sie schwanger sind), dann handelt es sich meist um Ruptur oder plötzlichen completen Abort, oder es beginnen einseitig oder auch unbestimmt im Bauche wehenartige Schmerzen, die für längere Zeit aufhören können and wieder mit erneuter Heftigkeit einsetzen, dann handelt es sich gewöhnlich um Tubenabort.

Eine Frage, die immer wieder aufgeworten und verschieden beantwortet wird, ist die, wodurch die Schmerzen beim verschiedenen Verlauf der ektopischen Schwangerschaft bedingt sind. Bei plötzlich eintretender Ruptur der Tube ohne Vorboten scheint ihn wirklich das Zerreissen der Tubenwand oder das Durchtreten des Eies durch das durch Usur wenigstens theilweise präformirte Loch zu bedingen; es wird wenigstens in den meisten Fällen das Verspüren eines Rejssens oder Platzens von den Patientinnen angegeben. Es lässt sich nicht annehmen, dass der Beginn der Blutung. in die Bauchböhle diesen charakteristischen Schmerz hervorruft.

Handelt es sich um Blutungen um das in der Tube sitzende Ei, ohne dass es zur Ruptur oder zum Abort kommt, so dürfte der Schmerz dureh die Erhöhung des Druckes in der Tube bedingt sein. Wohl könnte es sich auch um Contractionen der Tubenwand (Tubenwehen) handeln, die in Folge des Reizes durch die stärkere Ausdehnung der Tubenwand auftreten.

In den Fällen von completem Tubarabort, in denen wie bei 
Ruptur auch das Fühlen eines plötzlichen Schmerzes angegeben wird, könnte dieser durch die Contractionen der Tubenwand oder auch durch die plötzliche Ausdehnung des Tubenabschnittes, den das aus der Tube heraustretende Ei passirt, bedingt sein, eine Erklärungsweise, welche wohl die naheliegendste ist. Dass eine plötzliche starke Blutung durch das Fimbrienende in die Bauchhöhle den Schmerz bedingt, ist auch hier nicht wahrscheinlich.

Die wiederkehrenden wehenartigen Schmerzen bei tubarem Abort können damit erklärt werden, dass blutige Nachschübe in die Tube erfolgen, oder damit, dass die Schmerzen der Ausdruck von wirklichen Tubenwehen, i. e. Zusammenziehung der Tubenwand sind. Es wird hauptsächlich gegen letztere Auffassung meistens vorgebracht, dass die Tubenwand sehr gedehnt und daher dünn sei. Daher sei es nicht wahrscheinlich, dass sie die Kraft habe, sich genügend ausgiebig zu contrahiren. Es hat mir den Eindruck gemacht, dass in manchen Fällen doch Tubencontractionen anzunehmen sind, so in unserm Fall III ron incompletem Abortus, in dem die Eihäute halb in der Ampulle der Tube zurückgehalten, halb geboren waren. So hat auch Fehling (l. c. p. 88) dies für manche Fälle im Beginn für richtig gehalten. Thorn ${ }^{1}$ ) glaubt bei der Erklärung bleiben zu müssen, dass in dem von ihm beschriebenen Falle Contractionen der Tube stattgefunden haben und an der Elimination des Ovulums Theil genommen haben. Strauch ${ }^{2}$ ) hat die Contractionen der Tube, die mit grossen. Schmerzen verbunden waren, sogar tasten können.

Es ist ja auch die Tubenwand nicht immer so dünn, dass man ihr eine Contractionsfähigkeit ganz absprechen kann, auch bleibt zu berücksichtigen, dass bei weit vorgeschrittener Tubengravidität deutliche Contractionen beobachtet wurden.

Endlich könnten auch die Contractionen des Uterus zur Erklärung der Schmerzen herangezogen werden.

Bei Hämatocelenbildung lassen sich die Schmerzen aneh dureh blutige Nachschübe in den Hämatocelensack oder damit erklären, dass sich Darmschlingen an der Hämatocele angelöthet haben und durch gestörte Peristaltik die Schmerzen verursachen. Diese letztere Erklärung trifft vollinhaltlich für den Fall zu, wenn Schmerzen bei

1) Thorn, Zur Frage der Tubenwehen. Centralbl. f. Gyn. 1899. S.534.

2) Strauch, Zur Frage der Tubenwehen. Centralbl. für Gyn. 1899. Seite 1295 . 
vollkommen ausgebildeter Hämatocele bestehen. Diese Schmerzen gehören strenge genommen nicht hierher.

Die wiederholten Schmerzen bei einer schubweisen Ruptur können durch schubweises Bluten in den Tubensack oder durch schubweises Reissen erklärt werden. Es bleibt aber noch die Möglichkeit, diese Schmerzen als Wehen aufzufassen, welche das Ei durch die Oeffnung auszutreiben trachten, welche in der Tubenwand durch die Durchwucherung der Zotten entstanden ist. Es wird jedenfalls immer schwer sein, eine richtige Erklärung über die Entstehung des Schmerzes zu geben.

Veit hat in letzter Zeit darauf hingewiesen, dass die Diagnose des Fruchttodes bei genügender Beobachtung meist zu machen sei, und hat die Therapie davon abhängig gemacht. Er sagt (l. c. p. 189), ndass bei todter Frucht regelmässig, bei lebender Frucht höchstens manchmal Zeichen (Blutungen oder Schmerzanfälle) vorausgehen, während ganz unerwartet nur bei lebender Frucht Ruptur erfolgt. Es kann sich um das Bild dor ganz unvorhergesehenen Gefahr nur in diesen letzteren seltenen Fällen handeln, während bei Ruptur nach dem Fruchttode immer infolge der Symptome eine Therapie wenigstens möglich gewesen wäre, wenn die Patientin auf die Erscheinurgen geachtet und ein Arzt die Diagnose gestellt hätte. Damit ist die Gefahr einer Ruptur, die ganz unerwartet eintreten kann, aus dem Bereich der Gründe für die Operation jeder abgestorbenen Tubenschwangerschaft ausgeschieden und die Möglichkeit gegeben $z$ u warten, bis die deutlichen Zeichen des Drohens der Ruptur eintreten. Es ist sogar nicht zu verkennen, dass, wenn die Patientin nach dem Fruchttod ruhig im Bett liegt and alle Schädlichkeiten von ihr ferngehalten werden, das Vorkommen einer Ruptur nach dem Fruchttode zum mindesten zweifelhaft ist.".

Es will mir aber dünken, dass man mit den conservativen Principien doch zu weit gehen wärde, wenn man nach dieser Ansicht Veit's handeln und eine Operation bei der Palpation nach intacter Tubengravidität und (doch nur wahrscheinlich) abgestorbener Frucht unterlassen würde.

Die Diagnose, ob die Frucht abgestorben ist, scheint mir nämlich durchaus nicht so verlässlich zu sein und kann man sich wohl an einer Klinik, wo stets Alles für einen operativen Eingriff parat ist, zu einem Zuwarten entschliessen. Im Privathause wäre, wie ich glaube, das Zuwarten doch recht unbeimlich und es ist eine 
vaginale Koeliotomie bei intacter Tubengravidität besonders in den ersten 10 Wochen in der That kein so schwerer Eingriff.

Am meisten diagnostischen Werth möchte Winter ${ }^{1}$ ) auf langandauernde uterine Blutungen legen, welche er bei lebender Frucht niemals beobachtet hat; andererseits können sie aber auch bei todter Frucht fehlen.

Der Abgang einer Dccidua, der früher als ein diagnostisches Zeichen für den Tod der Frucht galt, kann nach den Beobachtungen mehrerer Autoren (so von Schauta, Hofmeier, Czempin; Olshausen, Martin, Webster) nicht mehr als solches angesehen werden.

Veit hat allerdings ausdrücklich gesagt, dass kein eiliger Beschluss zur Operation geboten sei, ohne die Operation ganz abzulehnen.

Meistens wird aber die erste Bedingung für die Erfüllung des Vorschlages Veit's fehlen, dass nämlich von dem behandelnden Arzte bei etwas versehleierten Symptomen die Diagnose auf Extrauteringravidität überhaupt gestellt wird.

Wenn wir die Frage nach der Therapie bei Extrauteringravidität ins Auge fassen, so sind wohl bei der Behandlung der unveränderten Tubengravidität, sowie der secundären Bauchhöhlenschwangerschaft (eine primäre ist derzeit noch durchaus nicht sicher nachgewiesen) und bei der freien Blutung in die Bauchhöhle fast alle Operateure einig, dass ein operativer Eingriff unbedingt erforderlich ist.

Bei diagnostirter intacter Tubengravidität in früher Zeit hat bekanntlich nach Friedrech $v$. Winckel Morphiuminjectionen in den Fruchtsack behufs Tödtung des Embryo's angerathen (ebenso Bandl, Stumpf, Kowalewicz). Da eine solche Injection wegen einer Blutung, die dadurch erzeugt werden kann, nicht ganz ungefährlich und die Wirkung doch eine unsichere ist, so verzichten wohl die meisten Gynäkologen auf diese Therapie.

Uebrigens genügt es gar nicht, die Frucht zum Absterben zu bringen, wie auch unser Fall No. I von Ruptur der Tube bei schon in einem hohen Grade von Colliquescenz befindlicher Frucht beweist. Trotz des Absterbens der Frucht ist also immer noch die Gefahr einer Ruptur, nicht nur die Gefahr eines gewöhnlich doch milder Seite 91.

1) Winter, Lehrbuch der gynäkologischen Diagnostik. Leipzig. 1896 . 
verlaufenden Tubenabortes vorhanden. Allerdings darf man nicht untersehätzen, dass nach Morphiuminjectionen Ruhelage eingehalten werden muss und dadurch die Gelegenheit für das Eintreten einer Ruptur der Tube sehr verringert ist. Uebrigens dürfte man nur sehr selten in die Lage kommen, diese Methode zu üben, da man intacte Tubengraviditäteu so selten antrifft, weil sie den Patientinnen gar keine Beschwerden zu machen brauchen. Ferner kann man bei der Benutzung der Morphiumtherapie nie wissen, ob die Diagnose richtig war. Hätte ich zum Beispiel in den 2 von mir früher citirten Fällen von fälschlich supponirter intacter Tubengravidität diese Therapie eingeleitet, so hätte ich ein Stationärbleiben der Geschwulst wahrscheinlich für eine Wirkung der Morphiumtherapie gehalten.

Auch die Anwendung der Elektricität zur Tödtung der Frucht, die eine Zeit lang befürwortet warde, und auch jetzt noch in einzelnen amerikanischen Autoren Vertreter findet, ist wohl fast vollkommen fallen gelassen worden.

Eine operative Entfernung der intacten schwangeren Tube ist daher einer mehr palliativen und unsicheren Therapie unbedingt vorzuziehen. Es bleibt nur noch die Entscheidung zu treffen über den Weg, den man einschlagen will, ob vaginal, ob abdominell. Wiewohl ich gleich vorausschicken will, dass ich für die meisten Fälle von Extrauteringravidität die abdominelle Coeliotomie vorziehen möchte, worauf ich noch im Einzelnen zurückkommen werde, so muss ich doch gestehen, dass für Fälle supponirter früher Tubengravidität (besonders in den ersten 8-10 Wochen) bei vollkommen frei beweglicher Tube und weiter Vagina der vaginale Wog mir empfehlenswerth erscheint und zwar durch das hintere Scheidengewölbe. Man kann durch die gesetzte Oeffnung im Douglas mit Zeige- und Mittelfinger eingehen und sich unter Unterstützung der vom Abdomen her wirkenden äusseren Hand den Tubentumor herunterbolen.

Sollte nach Unterbindung und Abtragung der Adnexe, sowie Secundärligaturen der Gelässe doch noch eine Furcht vor Nachblutung bestehen, so kann man unbesorgt um spätere, daraus sich bildende Lageanomalien des Uterus, den Stumpf in die entsprechende Ecke der Douglaswunde einnähen, wie der weitere Verlauf des Falles XIV beweist, für den ich diesen Folgezustand fürchtete. Ich glaube auch nicht, dass im Falle einer neuen 
Schwangerschaft Störungen von Seite der Tubation des Uterus entstehen würden.

Man kann ja unter Umständen auch durch die Plica vesicouterina eingehen und in ähnlicher Weise operiren; ich bin aber dagegen, den Uterus principiell herauszustürzen, da dies nicht nothwendig ist und da man - und dies ist der. Hauptgrund - mit den am Fundus eingesetzten Häkchen oder Kugelzangen den sehr brüchigen Uterus leicht so sehr verletzt, dass man den Riss nicht mehr gnügend vernähen kann oder zum mindesten nach Repusition des Uterus eine Nachblutung aus der Nahtstelle befürchten muss. So musste ich im Falle XI, in dem ich allerdings wegen einer Haematocele operirte, aus diesem Grunde den Uterus exstirpiren und dadureh, wie ich glaube, die Frau unnütz verstümmeln. Oder es kann sich der Fall ereignen, dass es trotz der Stürzung des Uterus nicht gelingt, die Adnexe einzustellen und zu entwickeln, wie es Schmit) ereignete, sodass er die Totalexstirpation ausführen musste. (Der Uterus war faustgross und es hatte sich um einen completen Tubenabort in der 11. Woehe gehandelt, es bot also die Grösse des Tubentumors keinen Widerstand).

Gottschalk (l. c.) erlebte in einem Falle eine so starke Blutung aus der Stelle, wo er die Haken zum Stürzen des Uterus eingesetzt hatte, dass er sie durch Naht nicht stillen konnte; sondern das Cavum uterovesicale austamponiren musste.

Schon bald nach dem Aufkommen der Kolpotomia anterior hat A. Nartin2) empfohlen, sie awch zur Behandlung der Tubengravidität früherer Monate zu verwerthen, nachdem Dührssen ${ }^{3}$ ), Kossmann ${ }^{4}$ ) und Prochownik ${ }^{5}$ diesen Weg zuerst mit Erfolg. betreten hatten.

Aus der Schule Martin's wurde in letzter Zeit von Jung ${ }^{6}$ ) im Anschluss an die. Publication zweier in conservirender Weise aut raginalem Wege operirter Fälle wieder für die Bevorzugung

1) Mandl, Monatsschr. für Geb. n. Gyn. 1900. S. 209.

2) A. Martin, Die Kolpotomia anterior. Monatsschrift f. Geb. u. Gyn. Bd. II. S. 109 .

3) Dübrssen, Centralbl. für Gyn. 1898. No. 15. S. 385.

4) Kossmann, Verhandlungen 'der Berliner Ges. für Geb. und Gyn. 22. 3. 1895 .

5) Prochownik, Verhandlungen des VI, Gynäkologencongresses zuWien. 1895. S. 806.

6) Jung, Beitrag zur operativen Behandlung der Eileiterschwangerschaft. Centralbl. für Gyn. 1900. No. 22. S. 578. 
des vaginalen Weges eingetreten. In dieser wendet sich der Autor besonders gegen Madlener, der den vaginalen Weg auf Grund eigener Erfahrungen bei der Operation entzündlicher Adnextumoren in allen Fällen und der Tubenschwangersehaften bis auf die nach seiner Ansicht sehr selten zur Beobachtung gelangenden Fälle mit unversehrtem Fruchtsacke in den ersten Monaten verwarf ${ }^{1}$ ).

Martin zieht dabei wie viele andere nach Eröfinung der plica vesicouterina den Uterus ganz vor die Vulva.

Für den vaginalen Weg bei früher intacter Tubengravidität treten auch ein: Kreisch, Marsi, Beckmann, Boldt, Segond, Edgar, Haggard, Orthmann ete.

Finden wir eine Bauchhöhlengravidität, die in der zweiten Hälfte der Schwangerschaft in Bezug auf die Diagnose leichter ist als früher, da man schon die Kindestheile füblt, so ist auch unter allen Umständen eine möglichst baldige Operation angezeigt. Anzustreben ist, bei der abdominellen Koeliotomie den ganzen Fruchtsack zu entfernen. Ist dies aber in Folge von Verwachsungen, starker Blutung beim Exstirpationsversuch nicht möglich, so wird. die Frucht entfernt, der Fruchtsack in den Bauchdecken eingenäht, die Placenta in situ belassen und mit Jodoformgaze oder aseptischer Gaze (wir ziehen letztere wegen der Möglichkeit einer Jodoformintoxication vor) ausgestopft. Dann ist der Eingriff für die Patientin kein so schwerer. Ein ganz besonderes Unglück ist es aber, wenn man schon mit dem Bauchschnitt die an der vorderen Bauchwand sitzende Placenta durch den Schnitt trifft, wie wir es in einem Falle (l. e.) erlebten. Trotz rascher Umstechungen der Placenta mit Matratzennähten und Tamponade der Eihöhle gelang es nicht die Patientin zu retten. An ein Ausschälen des Sackes war bei den enormen Verwachsungen der Sackwand mit der Bauchwand und den Gedärmen gar nicht zu denken.

Bei nachgewiesener freier Blutung in die Bauchhöhle in Folge von Tubenruptur oder Tubenabort ist unbedingt ein möglichst rascher operativer Eingriff indicirt. Und wenn die Frau auch schon ganz pulslos, das Sensorium ganz benommen ist, so lange sie athmet, muss ein Rettungsversuch gemacht werden (Martin). Sobald als möglich sollen, wenn die Operation beschlossen ist, subcutane

1) Madlener, Vaginale Operation bei Extrauteringravidität. Monatsschrift für Geb. und Gyn. Bd. XI. S. $75 \%$. 
Kochsalztransfusionen und Kampherinjectionen gemacht werden. Ist man aber nicht in der Lage, bald zu operiren, halte ich Transfusionen nicht für geeignet, da dadurch der Blutdruck wieder gehoben wird und die Blutung, die vielleicht in Folge einer Anlage zur Hämatocelenbildung gestanden war, wieder angeregt werden kann.

Dagegen hat Albers-Sehönberg ${ }^{1}$ ) bei Collaps geradezu intravenöse Kochsalzinfusionen ohne Operation ausgeführt und will damit Erfolge gehabt haben.

In Fällen, in denen eine Operation aus äussern Gründen nicht möglich ist, hat Sippel²) die Beckenhochlagerung der Patientin angerathen in der Ueberlegung, dass sich das Blut nicht im Becken ansammeln könne, sondern zwischen die Gedärme fliesse und so wieder theilweise resorbirt werden könne. Doch glaube ich, dass diese Lage bei einem Fortbestehen einer freien Blutung in die Bauchhöhle in Bezug auf die Blutung nichts nützen wird, wohl wird sie gegen Ohnmachten günstig sein. Man könnte sich gerade umgekehrt vorstellen, dass es besser wäre, wenn das Blut in der Beckenhöhle bleiben würde, damit sich vielleicht doch eine Hämatosele bilde.

Wir haben wiederholt bei Laparotomieen, die nach starkem Blutverlust ausgeführt wurden (Cervixruptur bei Placenta praevia, Uterusatonie), sterile Kochsalzlösung in die Bauchböhle gebracht und haben sehr gute Erfolge davon gesehen. Der Puls war nach der Operation auffallend besser als vorher und einige Patientinnen erholten sich relativ rasch. In derselben Weise gingen wir in dem hochgradig ausgebluteten Fall No. I vor, bei dem es zweifelhaft war, ob die Patientin überhaupt lebend vom Tisch gebracht werden könnte. Auch in diesem Falle war der unmittelbare Erfolg ein vorzüglicher, indem der früher unfühlbare Radialpuls wieder gefunden werden konnte. In diesem Falle wurde auch das Blut in der Bauchhöhle gelassen. Zu unserm grossen Bedauern ging die Patientin nach 3 Wochen an Embolie zu Grunde. Obwohl es nicht 'wahrscheinlich ist, dachte ich daran, ob nicht das Zurücklassen von Blut und die Infusion in die Bauchhöhle an dem Auftreten der Thrombose mit Schuld tragen könnte. Doch scheint der gesunkene Blutdruck schon allein die Bildung einer Thrombose genügend zu

1) Albers-Schönberg, Ref. Centralbl. f. Gyn. 1896. S. 1001.

2) Sippel, Ref. Centralbl. für Gyn. 1896. S. 426. 
motiviren und ausserdem spricht der Bauchdeckenabscess sehr dafür, dass die Thrombose auf infectiöser Basis entstand. Jedenfalls sst nach einer so schweren inneren Blutung die Gefahr der Embolie an der scheinbar schon vollkommen gesunden Patientin nicht zu unterschätgen. In unserm Falle kam die Embolie um so überraschender, als gar kein Symptom bestimmt für das Yorhandensein einer Thrombose gesprochen hatte. Bemerkenswerth ist terner an unserm. Falle, dass sie trotz vollkommener Ruhelage der Patientin eingetreten ist, während doch gewöhnlich dieses traurige Ereigniss bei stärkeren Bewegungen oder bei den ersten Versuchen aufzustehen, eintritt.

So traurig dieser Fall auch war, so lehrreich war er für die Frage, was mit der ganzen grossen Blutmenge sammt Coagulis im Verlauf von 3 Wochen geschehen war. Es war von dem zurückgelassenen Blut nichts mehr zu finden als in der rechten Hälfte des Douglasischen Raumes ein etwa kleincitronengrosses; von einer zarten Membran eingehülltes Blutcoagulum, das mittelst der zarten Membran mit dem Uterus, dem rechten Ovarium und dem rechten lig. latum ziemlich innig verklebt war. Dieses Coagulum war im Centrum noch dunkelschwarzroth, in den peripheren Schichten rothbraun bis ockergelb. Das Peritoneum erschien bei der Section an einigen Stellen schwärzlichgrau gesprenkelt.

Bei Laparotomieen wegen freier Blutung in die Bauchhöhle sind manche Autoren dafür, das Blut zurückzulassen, um durch die Resorption desselben durch das Peritoneum auf den Organismus günstig cinzuwirken (Veit). Andere wieder stimmen für eine mehr weniger gründliche Entfernung desselben durch Austupfen der Bauchhöhle wegen der Gefahr, die darin bestehen soll, dass das zurückgelassene Blut einen guten Nährboden für etwa bei der abdominellen Koeliotomie eingebrachte Mikroorganismen abgebe. Da man das flüssige Blut, das sich zwischen den Darmschlingen befindet, ohnehin nicht gründlich entfernen kann, so halte ich den goldenen Mittelweg zwischen diesen Ansichten für den besten, die leicht zu erreichenden Coagula auszuräumen und dabei besonders auf den Douglas zu achten, das flüssige Blut zurückzulassen. Das wiederholte in die Tiefe Führen von gestielten Tupfern kann den Shock der Laparotomie vergrössern und das Peritoneum der Därme alteriren, wodurch ja auch eine Infectionsmöglichkeit gegeben ist oder die Resorptionskraft Jeiden kann. Ich habe in dem Fall IV die 
Coagula entfernt nnd auch die Bauchhöhle ausgetupft und muss gestehen, dass ich dies, wie ich glaube, unmotivirt unter dem Eindruck des Todesfalles an Embolie, in dem ich das Blut zurückgelassen hatte, ausführte. Ich unterliess leider auch eine Infusion von Kochsalzlösung in die Bauchhöhle, da der Puls vor der Operation und nach Meldung des Narcotiseurs auch während der Operation nicht schlecht war, und, da ich des Nachts in einem Sanatorium operirte, fürchtete ich, dass die Kochsalzlösung etwa nicht steril sein würde. Wenn dieser Fall zu Grunde ging, so kann ich den üblen Ausgang nicht so sehr dem Umstand zuschreiben, als vielmehr dem, dass so lange Zeit bis zur Operation verstrich und dass durch die wiederholten Transporte die Frau sehr gelitten haben musste. Ausserdem scheint mir nach der Krankengeschichte erwiesen, dass auch das Herz angegriffen war.

Ein längeres Zuwarten bei freier Blutung in die Bauchhöhle ist ja an und für sich für die Patientin wegen des grossen Blutverlustes höchst nachtheilig, um so schwerer muss sie ein langer und gar ein wiederholter Transport schädigen. Denn einmal kann die Shokwirkung erhöht werden, andererseits kann sich ein Blutcoagulum an der blutenden Stelle angelegt haben, das für einige Zeit die Blutung stillt, oder wenigstens in ihrer Vehemenz her absetzt; durch den Transport wird nun dieser Schutz leicht zerstört. Es wäre daher gewiss für die Patientinnen am vortheilhaftesten, wenn die Operation im Privathause vorgenommen werden könnte. Boldti) und Lyons $s^{2}$ ) haben daher vollkommen recht, wenn sie erklärten, nach Ruptur eines tubaren Fruchtsackes die Patientin nicht ins Krankenhaus schaffen zu lassen, sondern an Ort und Stelle zu operieren. - Leider wird es aus äusseren Gründen nur selten durchführbar sein, eine Laparotomie so unerwartet in einem Privathaus ausführen zu können.

Flata $u^{3}$ ) hat aber doch unter 20 Fällen von Extrauteringrávidität in 3 Fällen wegen hochgradigen Collapses im Hause der Patientin mit Glück operirt.

In unserm Falle V. wurde wieder ca. 1 Liter Kochsalzlösung

1) Bold̉, Med. News. April 1897. Ref. Centralblatt für Gyn. 1897. No. 85. S. 1069 .

2) Lyons, Centralbl. für Gyn. S. 1340.

3) Flatau. Diẻ Indication zur Operation bei Ruptur der schwangeren Tube. Mon. f. Geb. und Gyn. Bd. XII. H. 2. S. 194. 
in die Bauchhöhle gegossen und die Frau genas, obwohl sie ganz. enorm collabirt war. In den Fällen II und III war die Bauchhöhle ausgetupft und weder in die Bauchhöhle noch subcutan Kochsalzlösung transfundirt worden.

Nach unseren Erfahrungen möchte ich das Eingiessen von warmer, steriler Kochsalzlösung in die Bauchhöhle, wie sehon angedeutet, befürworten. Schon deshalb wäre bei freier Blutung in die Bauchhöhle der abdominelle Weg dem vaginalen vorzuziehen, da auf diese Weise besonders rasch der grosse Blutverlust theilweise ausgeglichen werden kann. Es sprechen aber auch eine Reihe. anderer, schwerwiegender Momente für den abdominellen und gegen den vaginalen Weg; durch ersteren finden wir die Quelle der Blutung sehr rasch, die Eröffnung der Bauchhöhle und das Hervorheben des Uterus zur Besichtigung der Adnexe oder zum mindesten das Abtasten der Adnexc ist eine Arbeit von der Dauer von Secunden, die Uebersicht ist eine viel leichtere; die Abtragung der geschwängerten Tube gelingt in der allerkürzesten Zeit und es kann nach Entfernung der grössten Blutcoagula die Bauchhöhlerasch wieder geschlossen werden, so dass die ganze Operation in kürzester Zeit vollendet sein kann. Auch ist allgemein anerkannt, dass der durch die Laparotomie hervorgerufene Shock um so geringer ist, je kürzer die Bauchhöhle eröffnet war. Ausserdem werden die Gedärme fast gar nicht insultirt, wenn sie in Beckenhochlagerung ordentlich geschützt werden und nicht gar zu viel ausgetupft wird. Manche Autoren, wie Bouilly, sind aber in solchen Fällen direct gegen die Beckenhochlagerung, weil das in die Bauchhöhle ergossene Blut gegen das Zwerchfell fällt und die Respiration verhindern kann, und weil das Blut in dieser Lage nicht genügend aus der Bauchhöhle entfernt werden kann. Die Laparotomie lässt sich bei sehr ausgebluteten Fällen unter Schleich's localer Anästhesirung ausführen, so dass das Herz nicht durch die Narcose unnütz angegriffen wird.

Durch die abdominelle Koeliotomie lässt sich mit grösserer Sicherheit conservativ operiren und man kann gleichzeitig Correcturen an den Adnexen der anderen Seite (Salpingotomie, Resection einer erkrankten Partie des Ovariums) gewiss leichter vornehmen, als auf dem vaginalen Wege. Unter Umständen kann man sogar gezwungen sein, bei Wahl letzteren Weges den Uterus unnützer Weise zu exstirpiren - wie ich schon an anderer Stelle besprochen habe. Ist die andere Tube auch schwer erkrankt, dann liegt aller- 
dings an der angeschlossen Totalexstirpation des Uterus nichts. Ist sie aber makroskopisch gesund, dann hat man die Frau unnütz verstümmelt. Man kann sich dann den schwachen Trost vorbalten, dass die Frau vielleicht doch noch in dieser Tube schwanger geworden wäre! Correct operirt hat man aber dann, wie ich meinen möchte, nicht. --

Diese ausgesprochene Ansicht bringt uns auf die Frage, ob bei Tubenschwangerschaft auf der einen Seite, unter allen $[\mathrm{T} m$ ständen auch die Adnexe der anderen Seite entlernt werden sollen in der Angst, dass sich in der Zukunft hier ei nEi ansiedeln könnte, eine Frage, die von den Autoren in diametraler Weise beantwortet wird. Nanche Autoren, [so Edgar ${ }^{1}$ ), Fergusson ${ }^{2}$ )] treten für die Entfernung des andern Eileiters ein, auch wenn er gesund ist, während andere Autoren, wie Fergusson, Sehauta, Bouilly, Legueu, Schwartz, Varnier ete. für die Erhaltung desselben. stimmen. Die meisten Gynäkologen werden wohl letzteren zustimmen, hat man ja doch auf die Inauguration Martin's hin die conservative Therapie so weit vervollständigt, dass sogar die Tube, in der das Schwangerschaftsproduct sitzt, durch Incision derselben, Entfernung des Schwangerschaftsproductes, Eies und Vernähung der Tubenwand. erhalten wird. Ferner hat $\mathrm{Martin}^{3}$ ) in einem Falle aus der Tube ein ca. $2 \mathrm{~cm}$ langes und $0,5 \mathrm{~cm}$ breites Ovulum durch Ausstreichen entfernt und nach vollkommener Entleerung die Tube, da keine weitere Blutung erfolgte, zurïckgebracht.

$\left.B a e r^{4}\right)$ hat gleichfalls in einem Falle, in dem die Adnexe der anderen Seite erkrankt waren, das Ovulum aus dem abdominellen Tubenende ausgedrückt und die erkrankten Adnexe der anderen Seite entfernt.

In gleicher Weise hat Bröse ${ }^{5}$ ) nach Kolpotomia posterior ein abgestorbenes Ei aus dem abdominellen Ende der Tube entfernt. $\mathrm{Da}$ es nach der Expression gar nicht aus der Tube blutete, wurde sie in die Bauchhöhle zurückgeschoben, doch scheint mir dieses Vorgehen wegen etwaiger Nachblutung nicht ungefährlich und nur bei ausgesprochener Molenbildung anwendbar.

Wenn auch manches Mal nach Exstirpation der erkrankten

1) Edgar, Edinb. med. Journ. July 1899. p. 35.

2) Fergusson, Am. journ. of obst. Vol. XXXIX. p. 551 .

3) Orthmann, Centralbl. für Gyn. 1899. S. 50.

4) Baer: Mon. f. Geb. u. Gyn. Bd. XIII. S. 273.

5) Brös e, Centralblatt für Gyo. 1901. S. 767. 
Tube Schwangerschaft in der zurückgebliebenen Tube beobachtet wird, so tritt doch viel häufiger eine irtrauterine Schwangerschaft ein. Pestalozzal) hat in letzter Zeit 108 derartige Fälle gesammelt und berechnet für operirte Frauen das Verhältniss von Wiederholung der extrauterinen zur normalen Schwangerschaft wie 1:4. Zu demselben Resultate kommen Sens ${ }^{2}$ ) und Varnier, sie fanden unter 177 wegen Extrauteringravidität operirten Frauen 17 weitere Schwangerschaften und davon 4 extrauterine.

Unter 53 an der Klinik Schauta einseitig operirten Extrauteringraviditäten waren in 31 F'ällen die Nachforschungen von Erfolg; unter diesen $\mathrm{kam}$ es $2 \mathrm{mal}$ zu einer neuerlichen Tubargravidität, und in 9 Fällen trat normale Gravidität ein, also anch in dieser für diese Frage kleineren Statistik das Verhältniss 1:4.

L. Funk-Brentan $0^{3}$ ) stellte 127 Fälle von Extrauteringravidität zusammen, in denen 188 mal Conception nach überstandener ektopischer Gravidität beobachtet wurde. Auf Grund seines Materials kommt er zu dem Schluss, dass jede erkannte Extrauteringravidität chirurgisch anzugreifen sei (Pinard); denn die normale Entwickelung einer reinen Schwangerschaft ist nahezu die Regel bei Frauen, die operirt worden waren, während bei conservativ behandelten Fällen das Gegentheil stattfindet; die häufigste Complikation ist bei diesen der Abort.

In zwei von unseren operirten Fällen trat wieder normale Schwangerschaft auf, Fall II und III; es hatte sich beide Male um freie Blutung in die Bauchhöhle gebandelt; im Falle No. II nach einer 7 jährigen Pause; es war in diesen Fällen die zurückgebliebene Tube bei der Laparotomie dem äusseren Aussehen nach gesund befunden worden. Ebenso trat in 3 Fällen, die conservativ behandelt wurden, eine uterine Gravidität ein und wurde die Frucht ausgetragen.

Es muss uns als durchaus nicht gerechtfertigt erscheinen, die anscheinend gesunde oder nur leicht erkrankte zweite Tube mit zu entfernen.

Bei der Anwendung des vaginalen Weges wird man die blutende

1) Pestalozza, Monatsschr. für Geb. und Gyn. Bd. XIII. S. 838.

2) Sens, Pariser Dissertationen. 1901. Ref. Centralbl. für Gyn. 1901. Seite 1152.

3) Funk-Brentano, Des grossesses utérines survenant après les grossesses extrauterines. Thèse de Paris. 1898. Centralblatt für Gyn. 1898. Seite 1399. 
Tubenstelle nicht so rasch auffinden, man wird durch das Gefühl nicht so rascb die Entscheidung treffen können und unter Umständen den Uterus gegen seine Absicht herausstülpen müssen, um die blutende Stelle zu Gesicht zu bekommen. Ferner wird man, wenn der Tubentumor nur etwas grosser ist, nicht so rasch die Entwickelung desselben bewerkstelligen können, als bei Vornahme der ventralen Koeliotomie. Ausserdem wirkt bei diesem Operationsweg das fortwährende Herausfliessen von Blut aus der Vaginalwunde recht störend, und wenn man auch den Tubenstumpf genau unterbunden hat und ihn dann reponirt, weiss man nicht, ob das herabfliessende Blut von der Bauchhöhle kommt oder vom Stumpf, denn es kann die Schnittfläche des Stumpfes, so lange er vorgezogen, ganz blass aussehen und nach dem Reponiren desselben in die Bauchhöhle wieder zu bluten anfangen. Allerdings kann man sich gegen diese Sorge durch Einnähen des Stumpfes in dio Vaginalwunde schützen.

Eine primäre vaginale Totalexstirpation des Uterus wird am wenigsten angezeigt sein; hauptsächlich spricht gegen diese Methode die vielleicht unnütze Verstümmelung der Patientin.

Gerade bei freier Blutung in die Bauchböhle ist das Abdomen gewöhnlich stark meteoristisch aufgetrieben und die Untersuchung, ob auch die Adnexe der andern Seite schwer krankhaft verändert sind, was eine Totalexstirpation rechtfertigen würde, nahezu unmöglich.

Dagegen ist Dührssen gerade in Fällen höchsten Collapses für die vaginale Totalexstirpation unter der Benutzung von Klemmen. Man könne auf diese Weise sehr rasch operiren und lässt sich eine Narkose leichter vermeiden.

Die Therapie der Hämatocele hat im Verlauf der Zeiten ihre Wandlungen durchgemacht. In der früheren Zeit, in der man Hämatocelen wohl diagnosticirte, in der man aber nicht wusste, dass sich nahezu alle Hämatocelen auf eine Tubenschwangerschaft zurïkführen lassen, wurde die nicht vereiterte Hämatocele conservativ behandelt. Es ist wohl auch die Annahme berechtigt, dass bei den damaligen ungenügenden Untersuchungsmethoden so manche Hämatocele als Parametritis behandelt wurde und dass also noch mehr Hämatocelen conservativ behandelt als diagnosticirt wurden.

Obwohl so manche Hämatocele übersehen worden sein dürfte, so ist doch nicht zu leugnen, dass die Anzahl der Beobachtungen von Hämatocele im Vergleiche zu der damaligen Zeit zugenommen hat, entsprechend der Zunahme der Extrauteringravidität, als deren 
Grund die Zunahme der Gonorrhoe in den grossen Städten angesehen werden kann. (Ahlfeld, Hegar, Fehling, Thorn.)

Als nun die Sturm- und Drangperiode in der Behandlung der Adnexaffectionen am Ende der $80 \mathrm{er}$ und Anfang der $90 \mathrm{er}$ Jahre eintrat, in der auch nicht sehr schwer erkrankte Adnexe exstirpirt wurden, war es natürlich, dass auch die Hämatocele operativ angegangen wurde, und gerade dieser Zeitepoche verdankt die Lehre über die Extrauteringravidität ganz ausserordentliche Fortschritte.

In der allerletzten Zeit hat sich wieder ein Umschwung zu Gunsten der conservativen Therapie der Hämatocele geltend gemacht und es haben einige der hervorragendsten gynäkologischen Operateure, die früher jedes Product einer Extrauteringravidität sofort exstirpirt wissen wollten, in Bezug auf die Behandlung ausgewählter Fälle, in denen die Indication zur Operation keine unbedingte ist, sich mehr conservativen Principien genähert.

So hatte Martin ${ }^{1}$ ) sich früher der Auffassung zugeneigt, dass jede Extrauteringravidität stricte als eine Indication zum Eingreifen anzusehen sei. Beobachtungen, wie die in dieser Abhandlung beschriebenen, könnten nach ihm wohl als ein Beweis für eine mehr zuwartende Therapie angeführt werden. Eine solche Schlussfolgerung: sei aber nur für solche Fälle als berechtigt anzuerkennen, in denen die Resorption eines abgestorbenen Eies klar diagnosticirt werden kann. Martin fürchtet, dass derartige Fälle schwer erkannt werden können und dass sich in der Regel Complicationen finden werden, welche die Diagnose erschweren oder mehr zu einem unmittelbaren Eingriffe drängen.

In der letzten Zeit liess Sehauta, der früher auch mehr für ein radicales Vorgehen bei jeder diagnosticirten Extrauteringravidität eingenommen war, durch Lindenthal seine Ansicht in der Weise formuliren, dass „principiell selbstverständlich alle Fälle, in welchen die Indication zur Operation keine unbedingte ist, eine Zeitlang bei absoluter Ruhe und symptomatischer Behandlung zu behandeln sein werden. Stellt sich nach einer gewissen Zeit ein bis zwei Wochen - heraus, dass das Allgemeinbefinden sich nicht bessert, die Blutungen nicht sistiren, die Beschwerden von Seiten der Nachbarorgane nicht nachlassen, oder dass eines dieser Symptome an Intensität zunimmt, die Geschwulst im Unterleibe

1) Martin, Zur Kenntniss der Tubensehwangerschaft. Monatsschrift $f$. Geb. and Gyn. 1897. H. 1. 
wächst oder Fieber eine Vereiterung anzeigt, so ist die Operation vorzunehmen."

In der Klinik Schauta besserten sich in 123 Fällen auf Bettruhe, Umschläge, Diät und Regelung des Stuhlganges bin dje Beschwerden, so dass von einer Operation Abstand genommen wurde. Die Patientinnen wurden mit der Weisung entlassen, sich von Zeit zu Zeit wieder vorzustellen und bei Eintritt eines unvorhergesehenen Ereignisses die Klinik wieder aufzusuchen. In 30 Fällen ergab die Beobachtung in einer Zeit von $1-3$ Wochen keine Linderung der Schmerzen, sondern Fortdauer der Blutung etc. und es wurde daher die Operation in diesen Fällen vorgenommen.

Thorn ${ }^{1}$ ) ist schon im Jahre 1895 für die conservative Behandlung der Haematocele eingetreten. Er hatte für 157 von ihm beobachtete Fälle, allerdings von Beckenhämatomen, eine Mortalilitätsziffer von $0,6 \%$. Nur in 6 Fällen wurden die Laparotomie ausgeführt.

Eine Arbeit, die wohl einen grossen Ausschlag bei der Verallgemeinerung der conservativen Riehtung in der Therapie der Haematoeele gegeben haben dürfte, ist die Fehling's ${ }^{2}$ ), in der er von dem übermässigen Operiren abräth und auch Kritik an einer Reihe seiner Operationen übt, die er nachträglich für nicht indicirt erklärt. Er theilte 91 Fälle von tubarem Abort mit Haematocele mit, die sämmtlich in klinischer Behandlung ausgeheilt sind.

$\checkmark$ eits) hebt dieses entschiedene Verdienst Fehling's auch besonders hervor und erklärt, dass er mit F. ganz übereinstimme, dass die abgestorbene Extrauteringravidität in früheren Monaten an sich nicht die Operation verlangt, er legt die Entscheidung in die Erscheinungen und die eventuelle Beobachtung der Patientin; damit reihe sich aber die Behandlung der abgestorbenen Tubenschwangerschaft von selbst den anderen Tubenkrankheiten an.

Chotzen kam nach einer Verwerthung der Statistik der Charité zum Schlusse, dass die ungünstigen Ausgange der Haematocele bei weitem seltener sind und dass die Prognose lange nicht so schlecht zu stellen ist als es bisher gesehah; er fand auf 194 Fälle von Haematocele der Charité nur 2 Todesfälle.

1) Thorn, Ueber Beckenhämatocele. Volkmann's Sammlung. Klin. Vorträge. No. 119-120, S. 327.

2) Fehling, Zeitschrift f. Gea, und Gyn. Bd. XXXVIII. Bd. 1.

3) Veit, 1. o. 
$\mathrm{Zu}$ einem gleichen Urtheile sind wir aus unseren Erfahrungen berechtigt.

Wir haben an der Klinik in den Jahren $92-98$ in 32 Fällen bei diagnosticirter Haematocele nicht operirt, viele davon in die Klinik aufgenommen und Wochen hindurch ruhig liegen lassen; wenn es sich zeigte, dass der Tumor kleiner wurde, und wenn die Blutungen aufgehört hatten, wurden die Patientinnen mit der Weisung entlassen, sich zu Hause zu Bett zu legen, zumindest aber keine schwere Arbeit zu verrichten.

Der beste Beweis dafür, dass eine Haematocele zurückgeht, liegt nach unsern Erfahrungen darin, dass sich die Gestalt der Geschwulst ändert und das der im Douglas getastete Tumor an verschiedenen Stellen eine versehiederie Consistenz annimmt, dass gleichsam Balken resistenteren Gewebes herausgetastet werden können. Gleichzeitig hören die Blutungen auf.

Bei den Patientinnen mit Haematocele, die nach längerer Beobachtung entlassen wurden, hat sich nach unserem Wissen kein übles Ereignis weiter zugetragen und wir haben der alten Ansicht gehuldigt, dass Haematocelen unter Einhalten von Ruhelage zu behandeln und zu beobachten seien und dass nur unter besonderen Indicationen eine Operation notwendig sei. Es wurden daher an unserer Klinik nur sehr wenig Haematocelen operirt. Die grösste Haematocele, die unter unserer Beobachtung zurückging, reichte bis nahe unter den Nabel.

Ausser den an der Klinik beobachteten Fällen habe ich in der Privatpraxis in 9 Fällen die Wahrscheinlichkeitsdiagnose auf Extrauteringravidität bezw. auf Haematocele gestellt and auch nach längerer Beobachtung, während welcher die Patientinnen vollkommene Ruhelage im Bette einhielten, aufrecht erhalten. Es werden gewiss von so manchen Aerzten etwas larvirte Fälle von Extrauteringravidität leicht übersehen; so wurde ich in zwei Fällen, in denen es sich sicher um eine Haematocele handelte, von den Collegen zur Vornahme einer Excochleation gerufen. Die Fälle von ausgebildeter Haematocele sind wohl nicht so leicht zu übersehen, als die Fälle von frühzeitigem Tubarabort im Stadium des vor sich gehenden Abortes. Es will mir, wie schon bemerkt, auch dünken, dass überhaupt so manche Fälle von Extrauteringravidität unbemerkt durch Tubarabort in früher Zeit endigen, eine Ansicht, die ja schon wiederholt ausgesprochen wurde. (Veit). Solche Fälle 
können besonders dann leicht übersehen oder schlecht gedeutet werden, wenn die Periode nicht ausgeblieben war.

In der kleinen Zahl von 9 in der Praxis beobachteten Fällen von Haematocele habe ich in der Folge 3 Graviditäten mit normalem Verlauf beobachtet, was der früher besprochenen Ansicht Funk's (l. c.) widerspricht.

In Bezug auf die Fötilität nach conservativer und nach operativer Therapie gehen die Ansichten auch auseinander. Während nach Prochownik's ${ }^{1}$ ) Statistik dem operativen Eingriffe für die spätere Fötilität der Vorrang zukommt (unter 29 radical operirten Fällen 21 mal, unter 40 expectativ behandelten Fällen 20 mal Befruchtung), ergiebt die Statistik Seanzoni's²) bessere Verhältnisse für die expectativ behandelten Fälle (37 pCt. unter 43 Fällen) als für die Laparotomirten 17 pCt. unter 29 Fällen.

Die Zeitdauer, die zur vollständigen Herstellung der Patientin bei der conservativen Therapie nöthig ist, hängt wohl wesentlich von der Grösse der Haematocele $a b$, und es ist sicher, dass sich die Patientin bei einer konservativen Behandlung auf eine Ruhelage von mehreren Worhen, ja vielleieht sogar einigen Monaten gefasst machen muss. Fehling hat für die Heilung eine Durchschnittsdauer von acht Wochen berechnet, welcher Ansicht ich mich bach meinen Erfahrungen durchaus anschliessen möchte. Es ist aber nicht nothwendig, die Patientinnen bis zur völligen Resorption der Geschwulst Bettruhe einbalten zu lassen; in der späteren Zeit, wenn. die Geschwulst sich schon auffallend verändert hat, kann man durch eine resorbirende Therapie die weitere Aufsaugung unter stützen.

Wenn in einem auf Extrauteringravidität verdächtigen Falle die Diagnose auch irrthümlich gestellt worden sein sollte, so bringt dies der Patientin beim Einhalten der conservativen Therapie durchaus keinen Schaden, sie hat höchstens durch Wochen umsonst im Bette gelegen. Da aber andrerseits ein Uebersehen einer solchen Erkrankung der Patientin schweren Schaden bringen und in vielen Fällen eine sichere Differentialdiagnose unmöglich gestellt werden kann, so ergiebt sich daraus die beherzigenswerthe Regel, lieber einen Fall von Adnexentumor zu viel irrthümlich unter der Diagnose der Haematocele conservativ zu behandeln, als einen zu wenig.

1) Krönig, Centrlbl. f. Gyn. 1901. S. 316.

2) Ibidem. 
Bei der Entschejdung über die Therapie der Haematocele, ob conservativ oder operativ, kommt eine Reihe von Umständen in Betracht. Es ist jedenfalls ein grosser Unterschied, ob man eine frische Haematocele diagnosticirt bald nach einem Tubenabort, oder ob man eine Haematocele constatirt, die, nach der Anamnese zu schliessen, schon vor Wochen sich gebildet hat.

Im ersteren Falle kann man jedenfalls eher eine Operationsindication begründen als im letzteren Falle, da es ja immerhin möglich ist, dass bei den dünnen Wandungen der Haematocele ein Platzen eintritt oder ein Nachschub der Blutung erfolgt.

Des ferneren spielt die sociale Stellung der Patientin eine bedeutende Rolle, und darin hat Küstner im Allgemeinen Recht, "dass es auch auf diesem Gebiete nahe liegt, einen Unterschied zwischen der armen und der reichen Frau zu machen, man mag darüber denken wie man will, der Unterschied besteht zu Recht!" Ich will damit nicht gesagt haben, dass man die unbemittelten Franen operiren und die bemittelten aber nicht, sondern ich glaube, dass man beiden die Verhältnisse wahrheitsgetreu auseinandersetzen soll und dass dann nur die Patientin ein Recht haben soll, zu entscheiden, ob sie sich operieren lassen und dann mit grösster Wahrscheinlichkeit in drei Wochen gesund und in sechs Wochen arbeitsfähig sein will, oder ob sie durch Jängere Ruhelage die Geschwalst zum Sehwinden bringen will. Die vermögende Patientin wird sich selbstverständlich für Jetztere entscheiden, wenn man ihr nicht die Gefahren der immerhin noch vorhandenen Möglichkeit eines Platzens der Haematocele zu grell malt. Trotz anderen Erfahrungen mancher Autoren hahe ich die Erfahrung gemacht, dass auch die armen Patientinnen die längere Ruhelage, die man ihnen in einem Krankenhause bietel, der Operation nicht selten vorzichen. Es ist ganz richtig, dass bei einer kinderreichen, armen Familie die Mutter sehr schwer so lange Zeit entbehrt werden kann, wie dies Küstner hervorhebt, und trotzdem habe ich die Erfahrung gemacht, dass, wenn man ibnen die Wahl der Therapie lässt, viele Frauen die conservative Therapie vorziehen. Ich bin bei der Stellung der Indication zur Operation bei einer rorhandenen Haematocele immer in dieser Weise vorgegangen.

Unter allen Umständen ist es erwünscht, wenn eine Haematocele diagnostirt wurde, die Patientin in derselben Stadt zu wissen; wenn man ganz vorsichtig sein will, so kann man die Patientin je nach den Verhältnissen in einem Sanatorium oder im Spitale inter- 
niren, damit sicher Ruhelage eingehalten werde. Ist eine Patientin weit entfernt oder befindet sie sich an einem Orte, an dem bei plötzlich eintretender Nothwendigkeit nicht sofort eine Operation ausgeführt werden kann, so wäre wohl auf einen Wechsel des Aufenthaltes der Patientin zu dringen, welcher die Möglichkeit raschen Eingreifens giebt, oder nach Wahl der Patientin die Operation sofort vorzunehmen. Bei ziemlich frischen Haematocelen ist aber ein Transport unbedingt zu vermeiden, da durch diesen gerade die noch dünne Wand der Haematocele zum Bersten gebracht werden kann und so eine innere Blutung eintritt, die dann zu einem raschen Eingreifen zwingen würde. In solchen Fällen steht man also vor einem unangenehmen Dilemma.

Die Verantwortung, die man bei der conservativen Therapie der Patientin gegenüber übernimmt, ist in gewisser Hinsicht eine grössere als bei den operativen. Platzt die Haematocele oder tritt eine freie Blutung in die Bauchböble ein, so operirt man sicher unter ungünstigeren Verhältnissen als bei intacter Haematocele, und hat andererseits ein gewiegter Operateur eine Haematocele entfernt, so kann er, wofern eine septische Infection bei der Operation ausgeschlossen ist, beruhigt sein.

Es sind allerdings die Statistiken derjenigen Operateure, welche (die meisten) sehr viele diagnosticirte Haematocelen operirt haben, sehr gute, so verlor Küstner von 72 Fällen von Haematocele nur einen Fall und Schauta von 81 Haematocelen zwei Fälle, von denen jedoch nach Lindenthal blos einer der Operation zur Last gelegt werden kann; aber wenn auch zugegeben werden muss, dass die Erfolge der operativen Therapie vorzügliche sind und auch die Dauererfolge vielleicht bessere sind als bei der conservativen Therapie und ferner, dass nach operativer Entfernung der Haematocele die Patientinnen rascher vollständig geheilt sind, so muss ich dennoch der Ueberzeugung Ausdruck geben, dass die conservative Therapie der operativen Therapie vorzuziehen ist, wenn wir durch erstere dasselbe oder nahezu dasselbe zu erreichen hoffen können wie durch Jetztere.

Es fragt sich nun, unter welchen Umständen eine operative Haematocele unbedingt angezeigt erscheint.

Erstens, wenn der Tumor zusehends wächst,

zweitens, weiterhin acute Nachschübe unter Collapserscheinungen auftreten (Fall $\mathrm{X}$ und XII), 
drittens, wenn die Haematocele sehr gross ist und die Patientin dadurch stärkere Beschwerden hat (unser Fall No. VIII) und viertens, wenn sich der Inhalt der Haematocele zersetzt oder verjaucht.

Vorübergehende Fiebertemperaturen auch höheren Grades dürfen nicht gleich als Verjauchungssymptome, der Haematocele aufgefasst werden, bestehen die hohen Temperaturen aber längere Zeit fort, so ist doch ejne Verjauchung anzunehmen, und es würde dann nur die vaginale Eröffnung der Haematocele erübrigen.

In Fällen der ersteren zwei Gruppen kommt wur die Exstirpation der Geschwulst in Betracht, in den Fällen der 3. Gruppe ist die abdominale Exstirpation naheliegend, man kann aber nicht daran denken eine vaginale Incision und darauffolgende Tamponade des Cavums vorzunehmen, in den Fällen der 4. Gruppe ist aber nur eine vaginale Incision am Platze.

Ein fraglicher Punkt bei der Indicationsstellung zur Operation bei Hämatocele ist die uterine Blutung, und auch die Vertreter der conservativen Richtung in der Behandlung der Hämatocele sprechen sich in der Weise aus, dass bei fortbestehendenBlutungen eine Operation ins Auge zu fassen ist. So sagt Veit $\left.{ }^{1}\right)$ : "Treten aber die Schmerzanfälle immer wieder trotz Ruhe etc. auf, hören die Blutungen nicht auf, so tritt die Frage der Operation an uns heran; sie ist bejahend zu beantworten, wenn Blutung oder Schmerz weiter bestehen bleibt, wenn bei wiederholter Untersuchung der Tumor nicht zurückgeht oder die Bildung einer Hämatocele nicht eintritt. Da hat man einen Process vor sich, der die Möglichkeit einer Ruptur noch in sich birgt uud jedesmal, wenn überhaupt, nur einen sehr langsamen Heilungsverlauf verspricht."

Es ist ja möglich, dass man wegen fortbestehender, hochgradiger uteriner Blutungen allein $z u$ einem operativen Eingriffe einmal gezwungen werden kann, da ja auch bei länger bestehender Hämatocele eine Excochleation unter allen Umständen verwerflich wäre; doch habe ich niemals einen solchen Fall gesehen, in welchem wir wegen der uterinen Blutung allein uns zu einer Operation bei der Hämatocele hätten entschliessen müssen. So habe ich in einem Falle [es ist dies derselbe Fall, in dem die Hämatocele fünf Wochen nach geschlossener Ehe eingetreten war] die Patientin wegen Fort-

1) Veit, Zur Behandlung früher Extrauterinschwangersehaften. S. 169. Zeitschrift für Geburtshülfe und Gynäkologie. Bd. 40. H. 1. 
bestehens von Blutungen geringeren oder höheren Grades drei Monate liegen lassen, obwohl es sich um eine kleine Hämatocele gehandelt hat. Gegen diese Blutungen wurden allerdings mit geringem Erfolge Ergotin-Präparate, Stypticin etc. nach dem ersten Monate verabreicht.

Ich glaube daher, dass der Zeitraum von 1 bis 3 Wochen, den man für die Sistirung der Blutung annimmt (vergl. Lindenthal l. c. p. 198), bevor eine Operation unternommen wird, ein viel zu kurzer ist.

Entschliesst man sich aber zu einem operativen Eingriffe, so bleibt wiederum die Entscheidung zu treflen zwischen dem abdominalen und dem vaginalen Wege. Für kleine Hämatocelen, die direct im Douglas liegen, ist der vaginale Weg und, wie ich glaube, durch das hintere Scheidengewölbe ganz angezeigt. In dieser Weise wurden unsere Fälle XIII und XIV operirt. Bei grösseren Hämatocelen (über gänseeigross) ist der abdominale Weg sicherer, und unter allen Umständen kann mit grösserer Bestimmtheit conservativ operirt werden.

Es hat schon Fehling, der mit Dührssen darin übereinstimmt, dass die vaginale Operation bei intactem Ei oder frischer Ruptur der Tube besser passt als bei Tubarabort, auf die Gefahren der vaginalen Operation bei unvollständigem Tubarabort mit grosser Hämatocele hingewiesen. Der Hochstand des Uterus bindert ein Herabziehen desselben; von einer klaren Lösung der kranken Tube könne daher keine Rede sein; das Ligamentum infundibulo-pelvicum șei stark infiltrirt und kurz, so dass es den Zug in die Vulva nicht gestatte. Die Schwierigkeit, dasselbe zu unterbinden, könne leicht von der vaginalen zur abdominalen Operation führen. Ferner weist er auf die grossen Gefahren von Durchreissung der Netz- und Darmverwachsungen im Dunklen hin, und es hat schon Dührssen darauf aufmerksam gemacht, wie zerreisslich die Adnexe sind, und Jeder, der solche vaginalen Operationen bei Extrauteringravidität ausgeführt hat, wird dies bestätigen können, dass man mit grosser Vorsicht die gelösten Adnexe nach abwärts zichen muss, um nicht eine Peritonealverletzung zu erzeugen und dadurch eine Blutung hervorzurufen, die vielleicht nur nach Totalexstirpation des Uterus oder durch eine angeschlossene abdominale Koeliotomie gestillt werden kann.

Es wurde an der Klinik Schauta unter 16 vaginal operirten Fällen 10 mal die Totalexstirpation ausgeführt, und in 4 von diesen 
Fällen war die Totalexstirpation nicht beabsichtigt, da die Veränderung der Adnexe der anderen Seite eine nur unbedeutende war und nur die Blutung zur Totalexstirpation gezwungen hatte. In zwei Fällen konnte die Operation überhaupt wegen heftiger Blutung, die das ganze Operationsterrain unsichtbar machte, nicht zu Ende geführt werden und musste die Laparotomie angeschlossen werden. Wir haben unter den drei vaginal operirten Fällen zweimal den Tubenstumpt zur sicheren Blutstillung in die Vaginalwunde genäht (Fall XIII, XIV); in einem Falle (XI) musste wegen Verletzung des Uterus die Totalexstirpation angeschlossen werden.

Was die vaginale Radicaloperation bei Hämatocele anbelangt, so ist sie nur dann stricte indicirt, wenn beide Adnexe erkrankt sind, wenn neben der Tubengravidität der einen Seite ein Pyosalpinx oder einc Cyste der anderen Seite besteht (Fehling, Schauta). Wie schon erwähnt, dürfte sich die Art der Erkrankung der Adnexe der anderen Seite häufig ante operationem nicht bestimmen lassen, da ja die Adnexe der anderen Seite mit der Hämatocele häufig zu einem Tumor verbacken sind und da diese Adnexe wegen der Verschiebung des Uterus fundus nach der Seite und nach oben dureh den den Douglas ausfüllenden Hämatocelentumor häufig gar nicht getastet werden können.

Es wird also das Gebiet der vaginalen Operationsmethode bei den Hämatocelen sehr eingeschränkt sein und auch die raginale Totalexstirpation nur in den seltensten Fällen nach stricter Indication ausgeführt werden können.

Demnach haben sich bei Hämatocele ohne wahrscheinliche Erkrankung der Adnexe der anderen Seite die meisten Operateure für den abdominellen Weg ausgesprochen (Fehling, Küstner, Schauta, Orthmann, Franz (Halle) etc.), ja sogar Dührssen und Martin halten den abdominellen Weg für den rationelleren. Dührssen hält den letzteren Weg für angezeigt, wenn der Tubentumor in Combination mit einer Hämatocele den Beckeneingang ubberragt, ferner in allen Fällen, wo bei grossem starren Uterus die Scheide enge und rigide ist.

Die einfache vaginale Incision der nicht vereiterten Hämatocele wurde unter Anderen von Piqué, Segond, Condamin, Henrotin, Elischer, Boule, Bouilly, K. A. Kelly als Behandlung emptohlen.

Segond giebt der vaginalen Incision vor der Koeliotomie den 
Vorzug. Bei eintretender starker Blutung oder Veränderung der Adnexe soll die Totalexstirpation ausgeschlossen werden.

H. A. Kelly ${ }^{1}$ ) befürwortet die vaginale Incision für mehr oder minder grosse Haematocelen, er stösst eine spitze Scheere in die sich am meisten nach der Vagina vorbeugende Stelle des Blutergusses, spreitzt ihre Branchen und zieht sie weitgeöfnet heraus. Dann wird die Oeffnung noch durch einen Uterusdilatator bis zu einer Oeffnung von $3,5 \mathrm{~cm}$ erweitert, mittelst der Finger Blutgerinnsel, Foetus und Placenta aus dem Sack entfernt und dieser, wenn er gegen die Peritonealhöhle abgeschlossen ist, mit physiologischer Kochsalzlösung ausgespült. Tamponade der Höhle mit Jodoformgaze. Doch sprechen seine Fälle IV. und VI durchaus nicht für diese Methode. (Im ersten Falle starke arterielle Blutung und daher sofortige Koeliotomie. Genesung. Im 2. Falle trat bei einer Ausspülung ein plötzlicher Collaps aus, Koeliotomie. Diffuse Peritonitis vorgefunden, langsame Genesung:)

v. $0 t^{2}$ ) kam in einem Falle von vaginaler Incision auf die Placenta, Tamponade, Drainage Heilung, erzählt aber von einem ähnlichen Fall eines Collegen, in dem sich die Frau verblutete.

Gottschalk ${ }^{8}$ ) hat einen unserm Falle. VIII ähnlichen schweren Fall beobachtet, er machte die vaginale Incision, liess die Jodoformgaze 5 Tage liegen, keine Ausspülungen, glatter Verlauf. Die Eröffnung hatte der Patientin eine grosse Erleichterung gewährt.

Nach Veit (l. c. pag. 157) hat sich trotz gegentheiliger Angabe Fehling's die langsame, eventuell nach Verlauf einiger Tage vorgenommere Ausräumung des Sackes mit nachfolgender Drainage als prognostisch sehr günstig erwiesen. Fritsch ${ }^{4}$ ) äusserte sich in dieser Frage folgendermaasen: Bei alter geplatzter Extrauteringravidität, die eine Haemacotele retrouterina bildet, also im Douglas liegt, ist der vaginale Weg ausschliesslich anzuwenden. Es ist nicht nöthig, in jedem Fall den Sack zu exstirpiren, wenn nur der ganze Inhalt sicher entlernt und die Oeffnung gross bleibt. Bei

1) H. A. Kelly, The treatement of extrauterin pregnancy in early months by rag. punction and drainage. The americ. gyn. and obst. journ. Vol. IX. H. 2.

2) v. Ott, Beiträge zur Kenntniss der ektopischen Schwangerschaft. 1895.

3) Gottsohalk, Zeitschr. für Geb. a. Gyn. Bd. XXXVIII. H. 2. S. 331.

4) Fritsch, Uebor vaginale Koeliotomie. Naturforscherversammlung in Aachen. Centralbl. f. Gyn. u. Geb. No. 40. S. 1040. 
frischer H., die Faustgrösse übersteigt, muss abdominell vorgegangen werden.

Regnier ${ }^{1}$ ) (Wien) veröffentlichte aus der Klinik Chrobak zwei Fälle von Incision bei Haematocele.

Im ersten Falle nach begonnener Laparotomie wegen intraligamentaeren Haematoms bei bestehendem Fieber von der Vagina aus. Im 2. Falle aber hatte es sich um eine Haematocele gehandelt, die nur möglicherweise extraperitoneal gelagert war. Wegen starker Verwachsungen wird bei der Laparotomie auf Exstirpation des Tumors żverzichtet, ein Theil der Tubenwand extraperitoneal in die Bauchwand eingenäht und der Tumor zweizeitig nach T'agen an dieser Stelle eröffnet und nach Verdrängen des Douglas durch eine Kornzange eine Gegenincision in der Vagina ausgeführt. Drainage mit einem Drain durch beide Incisionsöffnungen zur möglichst exacten Aus- und Durchspülung; ferner Tamponade der Höhle mit Jodoformdochten. Diesem Eingriffe folgten in den nächsten Tagen heftige Temperatursteigerungen bis $40^{\circ}$ mit hoher Pulssteigerung, Unruhe, Erbrechen und grosser Schmerzhaftigkeit des Abdomens. Nach Entfernung der Nähte am 4. Tage fiel die Temperatur $a b$ und war der Verlauf weiter normal.

Bei sehr grossen Hämatocelen, mit vielen Verwachsungen, könnte es wohl rathsam erscheinen, die Exstirpation des Tumors aufzugeben, wewn man nach Eröffnung der Bauchhöhle sich von der besonderen Schwierigkeit der Verhältnisse überzeugt hat. So hätte man auch in unserm Falle VIII eine vaginale Eröffnung in Erwägung ziehen können, doch wäre bei der tiefen Anheftung der Placenta im Douglas wahrscheinlich eine nicht stillbare Blutung eingetreten, hat sich ja dosh der früher citirte Fall an der Klinik Schauta ereignet, dass eine Patientin schon in Folge einer vaginalen Punction trotz angeschlossener Laparotomie zu Grunde ging.

Am meisten würde den chirurgischen Principien die doppelte Incision (zweizeitig von den Bauchdecken und von der Scheide her), wie sie Regnier im 2. Falle angewendet hat, entsprechen, doch war auch in diesem Falle der Verlauf keineswegs glatt.

Wegen der grossen Gefahr der Blutung, aber auch wegen der immer noch möglichen Vereiterung des Sackes haben sich viele Autoren gegen die vaginale Incision bei einer Hämatocele ausgesprochen (so Schauta, Fehling, Küstner, Chaput etc.), denen wir uns anschliessen möchten.

I. Tubenruptur in der 11. Woche. Das Ei noch in der Tube sitzend. Hochgradige freie Blutung in die Baucbhöhle.

1) Regnier, Beiträgø zur Kenntniss der Blutgeschwülste. Centralblatt für Gyn. 1893. S. 849 . 
Aeussere Ueberwanderung des Eies. Py osalpinx der anderen Seite. Laparotomie. Tod an Embolie am 19. Tage p. op.

Th. G., 24 Jahre alt, 3 Geburten am normalen Schwangerschaftsende mit angeblich normalem Puerperium. Keine Gonorrhoe, In der 11. Woche auf der Strasse plötzlich Bauchschmerz, Ohnmacht, dann Erholung. Am nächsten Tage dieselben Erscheinungen etwas heftiger, Erbrechen. Collaps. $1 / 211$ Uhr Nachts Transport auf die Klinik. Laparotomie. (R. Braun.) Geronnenes und flüssiges Blut in der Bauchhöhle. Die l. Tube am peripheren Ende kleinapfelgross. In der Mitte des Tumors eine $5 \mathrm{~cm}$ lange Continuitätstrennung, aus der das intacte Ei heranssieht. Exstirpation der Adnexe. Eingiessen von Kochsalzlösung in die Bauchhöhle. Die Wand des Fruchtsackes zeigt nur unregelmässige rissige Ränder und an verschiedenen Stellen verschiedene Dicke. Die dicksten Stellen vis-à-vis dem Risse $5 \mathrm{~mm}$. die dünnsten ca. $1 \mathrm{~mm}$ dick. Nach Eröffnung der Eihöhle entleert sich ein ca. $1 \mathrm{~cm}$ langer Gewebsfetzen. Zu ihm zieht von der vis-à-vis dem Riss an der dicksten Wandstelle befindlichen Placentarinsertionsstelle die ca. $2 \mathrm{~cm}$ lange Nabelschnur. Bis auf eine Nahteiterung im unteren Wundwinkel glatter Verlauf. Am 19. Tage Exitus letalis an Embolie.

II. Tubenruptur bei einer 14tägigen (?) Tubengravidität Freie arterielle Blutang in die Bauchhöhle. Laparotomie. Heilung.

Privatfall. J. St., 27 Jahre alt. Vor 4 Jahren Discision wegen dysmen. Beschwerden und Sterilität. Vor 2 Jahren normaler Partus und Puerperium. Kein Verdacht auf überstandene Gonorrhoe. Letzte Menses vor 25 Tagen. Patient hat keine Ahnung von bestehender Gravidität. Am 11. V. 1892 bei der morgendlichen Defaecation heftiger Schmerz im Bauche, dann Collaps. Transport in ein Sanatorium. $1 / 212$ Uhr Laparotomie (Hofrath G. v. Braun). Hochgradige Blutung in die Bauchhöhle. An der 1. Tube am isthmischen Theile knapp an der Uteruswand eine ca. haselnussgrosse Anschwellung, an deren Kuppe die Tubenwand perforirt ist. Die Oeffnung hat unregelmässige, lappige Ränder, die Höhle bis auf einen Belag an der Wand mit lockerem weichem Gewebe leer. Aus der Wand des kleinen Tubensackes spritzt eine kleine Arterie in relativ starkem Strahle. Keine interstitielle Gravidität. Abtragung der Tube, Entfernung des geronnenen and eines Theiles des flüssigen Blutes. Bauchnaht. Die Frau hat 1895 ein kräftig entwickeltes Kind geboren.

III. Incompleter Tubarabort, freie Blutung in die Bauchhöhle. Wiederholt wehenartige Schmerzanfälle im Verlauf von 5 Tagen. Laparotomie. Heilung.

Privatfall. M. T., 25 Jahre ait. 1. Partus ror 7 Jahren. Ausgangsforceps. Puerperium normal. Letzte Menses 7. IIT. 1897. Bis 24. IV. keine Beschwerden. Am 24. IV. den ganzen Tag wehenartige Schmerzen. Patientin glaubte zu abortiren. Schmerzen angeblich stäker als Wehen. 3 Tage Wohlbefinden bei Bettruhe. Am 28. IV. sehr starke Schmerzen, grosses Schwächegefühl. 29. IV. 1/24 Uhr Nachm. plötzlich sehr starke Schmerzen nnd Collaps. 1/25 Uhr sab ich Pat. zum ersten Mal, sie bot das Bild einer schweren inneren Blutung. 7 Uhr Abends Laparotomie (Operateur: Consiliarius Hofrath Chrobak). Viel geronnenes und flüssiges Blut, keine Haematocele. Abdominelles Tubenende aufgetrieben, stellt einen wallnussgrossen Tumor dar. Fimbrienende erweitert: aus demselben ragen Eihäute heraus and fliesst reichlich Blut. Exstirpation 
der Tube. Gewaue Toilette der Bauchhöhle. Afebriler Verlauf, Die Fral hat am 15. IX. 1901 nach normaler Schwangerschaft ein kräftig entwickeltes Kind innerhalb 2 Stunden geboren.

IV. Tubenruptur. Taubeneigrosses Ei noch in der Tube sitzend. Menses vor 3 Wochen - nur um einige Tage verspätet. Seither blutiger Ausfluss. Plötzlicher Eintritt der Ruptur. Transport vom Lande in die Stadtwohnung, 2. Transport ins Sanatorium. Laparotomie 12 Uhr nach erfolgter Ruptur. Tod an Inanition.

Privatfall. M. St., 35 Jahre. 1. Partus vor 15 Jahren mit normalem Puerperium. Vor 3 Jabren Peritonitis. Beim Spaziergang gelegentlich der Mictiou plötzlich Collaps, wiederholtes Erbrechen. Pat. ging nach Hause, wurde erst nach mehreren Stunden in die Stadtwohnung und wieder nach Stunden ins Sanatorium gebracht. Laparotomie. Grosse Mengen Blutes in der Bauchhöhle. Hühnereigrosser Tubentumor, darin das Ei. Tube an einer 2 Quadratcentimeter grossen Stelle usurirt. Aus der Lücke sehen die Zetten heraus und blutet es stark parenchymatös. Absetzen des Tubentumors und des vergrösserten degenerirten Ovariums, das ein Corpus luteum besitzt. Ausräumen der Coagula. Bauchnaht. Post op. relativ guter Puls. Später Autotransfusion, Kochsalzinfusion, Analeptica. 10 Uhr p. op. Tod an Herzschwäche. Nachträglich wurde ermittelt, dass Pat. in letzter Zeit eine übertriebene Entfettungscur durchgemacht, übertrieben dem Radfahrsporte huldigte und wiederholte Ohnmachtsanfälle ohne äussere Veranlassung hatte.

V. Tubenruptur mit Bildung einer kleinen Haematocele, die vor 5 Tagen von einem Fachmanne diagnostirt wurde. Perforation der Haematocele oder vielleicht weitere Durchwacherung des Tubensackes durch die Chorionzotten. Hochgradige Blutungen in die freie Bauchhöhle. Laparotomie. Heilung.

No. 479/1899. A. Sch., 32 Jahre. 1. Partus (1891): Forceps. 2. Partus: Abertus. Excochleation. Letzte Henses Anfangs December 1898. Vor 3 Wochen Blutung. Vor 8 Tagen von einem Fachmann erfolgter tubarer Abort diagnosticirt. Ruhelage. 19. II. 1899 nach Heben einer Schüssel Collaps. Muttermund geschlossen. Uterusfundus nach rechts verzogen. Hinter dem Uterus eine diffuse Schwellung. Laparotomie (Hofrath G. Braun). Viel geronnenes und fiüssiges Blut in der Bauchhöhle. Am ampulä̈ren Ende der $r$. Tube ein ca. eigrosses, durch Darm und Fibrinniederschläge abgelzapseltes Gebilde mit einer Perforation; die Tube sonst schlank. Abtragung des Tubentumors. Infusion von $1 \mathrm{l}$. Kochsalzlösung in die Bauchhöhle. Bauchnaht. Collaps nur schwer durch Analeptica behoben. Heilung.

Am gehärteten Präparat sieht man an dem Knickungswinkel der winklig abgeknickten Tube eine wallnussgrosse Anschwellung mit einer kreuzergrossen Oeffnung mit lappigen Rändern. Die Wand der Höhle mit Zottenresten besetzt. Der grösste Theil der Eihöhle ist von der Haftstelle getrennt und mit dem kuppenartigen Reste einer Haematocele innig verbunden. Dieser Rest weist an einer Stelle einen sichelförmigen Rand auf, an dem Chorionzotten hervortreten.

VI. No, 697/1898. K. R., 23 Jahre. April 1897 normaler Partus, Puerperium normal. Menses im August wieder aufgetreten. Anfangs Sept. und Oct. 3-4tägige Menses. November regelmässiger Eintritt der 
Menses. Mitte November heftige, periodisch auftretende Schmerzen im Unterbauch, dabei Blutabgang. Nach 6 Tagen beim Uriniren Abgang einer Haut. Schmerzen bis Ende Nov. Blutung bis Ende Nov., dann zeitweiliges Aussetzen, neuerliche Blutung im Dec. Danm 3 Wochen keine Blutung. Ende Jänner dreitägige Blutung. Seit Anfang Febr. andanernde Blutung. Laparptomie (12. III. 98). (G. Braun.) Kindskopfgrosse Haematocele hinter dem Uterus. Die r. Tube, die entfernt wurde, am uterinen Ende wenig verdickt, wird gegen das Fimbrienende zu dicker, ist geschlängelt; ihr Lumen stellenweise stark erweitert, in der Vitte auf Taubeneigrösse; das Fimbrienende schwach hühnereigross, enthält coagulirtes Blut. Von Fimbrienende fübrt ein kronengrosses Loch in den Haematocelensack, der am gehärteten Präparat Frauenfaustgrösse zeigt. Der Haematocelensack auf das innigste mit der exstirpirten Tube der anderen Seite verwachsen, so dass er sich am gehärteten Präparate von der gleichfalls schwer erkrankten Tube nicht trennen [ässt. Die 1. Tube verdickt, vielfach gewunden, die Windungen zu einem Tumor verbacken, das Fimbrienende zu einer bühnereigrossen Hydrosalpinx verwandelt.

VII. Tubenmole. Beiderseitige Hydrosalpinx. Trotz Verkleinerung des vermuthlich auf Extrauteringraviditat beruhenden Tumors auf Wunsch der Patientin Operation. Laparotomie. Heilung.

1340/1893. A. W., 29 Jahre. Stets gesund gewesen. Opara. Menses regelmässig. Verspätung der Menses um 1 Woche, unter heftigen Krämpfen geringe Blutung. Von da ab andauernder Schmerz, allmälige Steigerung der Blutung. Seit 1 Woche starke Schmerzen in der 1. Beckenhälfte beim Stuhl und Uriniren. 28. V. Aufnahme ins Spital. Portio virginal, nicht verfürbt, Uterus anteflectirt. Rechtsseitiger Adnextumor. Links hinter dem Uterus ein gänseeigrosser, wenig beweglicher, sich derb anfühlender Tumor. Auf eine Strecke von $2 \mathrm{~cm}$ lässt sich der uterine, wenig verdickte Antheil der Tube tasten, der in den Tumor übergeht. Conservative Therapie. Blutung und Schmerzen gehen zurück. Patientin zieht einen operativen Eingriff mit. rascher Genesung längerer Ruhelage ror, daher 28. VI. Laparotomie (G. Braun), obwohl der Tumor kleiner erschien. Das 1. Tubenende wallnussgross, verjüngt sich gegen den Uterus bis zu Fingerdicke. Im geschlängelten Tubenende ein Knollen coagulirten Blutes; mikroskopisch Chorionzotten nachgewiesen. Das Tubenende offen. Rechtsseitige Hydrosalpinx, Tube über fingerdick, geschlängelt. Beiderseitige SalpingoOophorektomie. Dieser Fall gehörte zu denen, in welchen man sich sehr. leicht vorstellen kann, dass bei conservativer Therapie eine vollständige Restitutio möglich ist.

VIII. Sehrgrosse Haematocele. Aeussere Ueberwanderung. des Eies. Pyosalpinx der anderen Seite. Sehr unklare Anamnese. Mumificirte, plattgedrückte Frucht von $4 \frac{1}{2}$ Monatell. Laparotomie. Exitus.

408/1898. A. G., 37 Jahre, Wittwe. Aufgenommen am 25. II. 1898. 6 Geburten mit normalem Wochenbett. Letzte Periode vor zwei Monaten. Seit ca. 6 Wochen Grössenzunahme des Bauches bemerkt. Seither blutigseröser, übelriechender Ausfiuss. Seit 4 Wochen Schmerzen im Abdomen; seit 14 Tagen keine Schmerzen im Abdomen; aber zunehmende Schwäche. Temp. normal. Sehr blasse Haut farbe, Herztöne schwach. Im Abdomen ein derb elastischer Tumor. 
der die untere Hälfte des Abdomens vorwölbt und in der Mittellinie Nabelhöhle erreicht. Portio in der Höhe des oberen Symphysenrandes, nach vorne gedrängt. Douglas durch eiren das Becken ganz ausfüllenden, weichelastischen Tumor ausgefüllt. Hintere Muttermundslippe ganz aufgebraucht. Cervix für 2 Finger durchgängig. Uterushöhle geräumig. Aus dem Uterus werden mit der Kornzange grosse Fetzen von Decidua entnommen. Laparotomie (Trende]enburg) am 25. II. (R. Braun.) Peritoneum mit Tumor innig verwachsen, ausgedehnte Adhaesionen des Netzes und Darms. Rechterseits sehr schwere Lösung; Flexura sigm. ganz nach rechts hinübergezogen, der Haematocelensack reisst beim weiteren Herauspräpariren ein, daher Ausräumen der Blutcoagula verschiedener Consistenz aus dem Douglas, wobei von einer nicht genau beobachteten Stelle der Foetus entwickelt wird. Coagula 1500 Gramm. Rechts an der hinteren Fläche des Lig. lat. Placentarinsertionsstelle, daraus schwere parenchymatöse Blutung, durch Aufnähen der Kapsel auf die hintere Fläche des Lig. lat. gestillt. Mikulicz. Bauchnaht. Weibliche, $20 \mathrm{~cm}$ lange Frucht mit Zeichen vorgeschrittener Mumification. Gesichtsskelett wenig, Schädel völlig plattgedrückt, so dass die Scheitelbeine aneinandergepresst sind. Mumificirte, $30 \mathrm{~cm}$ lange Nabelschnur. Nach 2 Tagen Exitus letalis an Herzschwäche. Sections b e f u d: Fettige Degeneration aller Organe. Myocard sehr morsch, gelbbraun. Keine Nachblutung. Linksseitige Pyosalpinx. Im linken Ovarium ein kirschkerngrosses Corpus luteum.

IX. Unklare Anamnese. Eigentbümliches Verhalten der Periode. Haematocele nach Tubarabort mit fortbestehender secundärer Abdominalgravidtat. Placenta im Douglas. Haematocelenantheile verschiedenen Datums. Laparotomie, H eilung.

2547/1896. M. R., 28 .Jahre. Vor 8 Jahren Haematemesis. 5. V. 1896 normale Geburt, Puerperium normal. Pat. verlässt am 2. Tage das Bett und arbeitet sehr schwer. 22. VI. normale Periode, ebenso am 20. VII. Dann unregelmässige Blutung bis 20. VIII., dann Wohlbefinden ohne Blutung. 15. IX beim Heben einer Last brennender Schmerz im Bauche, 20. IX. wieder Schmerzanfall; Uebelkeit, Erbrechen. Zeichen schwerster Anaemie. Operation, da Pat. in einem Gebirgsdorfe sich befindet, nicht ausführbar. Bei meiner Untersuchung Zeichen einer sich bildenden Haematocele. Nach 8 Tagen eigenmächtiges Verlassen des Bettes, Collaps. Nach weiteren 8 Tagen Ueberführung in die Klinik. $2^{1} / 2$ Std. Eisenbahnfahrt. Portio nach vorne gedrängt durch einen den Douglas breit herabdrängenden, das ganze Becken erfüllenden elastischen Tumor, der nach aufwärts bis in die Mitte zwischen Nabel und Symphyse reicht. Ca. $4^{1 / 2} \mathrm{~cm}$ oberhalb der Symphyse tastet man eine kuppenartige grössere Resistenz, die dem Fundus uteri entsprechen würde (die Operation bestätigte diese Annahme). Temp. 38, Puls 120. In der Zeit rom 20. X. bis 7. XI. Sobmerzanfalle und Blutungen. 7. XI. Laparotomie (R. Braun) (Trendelenburg): Adhaesionen von Netz und Darm. Linkerseits ziemlich frische Blutcoagula, die mit einer ganz zarten Membran überdacht sind. Schweres Abpräpariren der Därme. Entwickeln des Tumors und Absetzen desselben. Fritsch'sche Fächertamponade wegen parenchymatöser Blutungen. Der stark kindskopfgrosse Tumor besteht aus zwei Antheilen. Nach der Beurtheilung des Präparates hat es sich um einen Tubarabort im 1. Monate der Gra- 
vidität gehandelt mit Fortbestehen secundärer Abdominalgravidität und daneben bestehender Haematocele.

X. Typische Anamnese. Eine Ovarialcyste täuscht den extranterinen Tumor vor. Neben der Cyste in der Tube derselben Seite ein ektopisches Ei, einer sechswöchentlichen Gravidität entsprechend, mit abgestorbener Frucht. Flüssiges und geronnenes Blut in der Bauchhöhle, obwohl kein Collaps beobachtet worden war. Laparotomie. Heilung.

2393/1893. H. K., 30 Jahre alt. Normale Geburt von 6 Jahren. Nach 7wöchentlichem Sistiren der Menses, 4wöchentliche Blutung; Schmerzen auf der linken Seite. Links vom etwas vergrösserten, anteflectirten Uterus ein apfelgrosser, wenig beweglicher Tumor von elastischer Consistenz, der anscheinend von der Tube ausgeht.

30. IX. Laparotomie (Dr. Koffer). Der Tumor erweist sich als Ovarialeyste. Die 1. Tube am uterinen Ende normal, am abdominellen nussgross erweitert, verengt sich gegen das Fimbrienende zur Norm. In der Tuhe eine etwa 6 wöchentliche Gravidität mit seit längerer Zeit abgestorbener Frucht. Das r. kleincystisch degenerirte Ovarium wird mitentfernt. Normaler Verlauf.

XI. Aeussere Uberwanderung des Eies. Cyste im Ovarium derselben Seite. Tubenmole und in Rückbildung begriffene Haematocele. Vaginale Koeliotomie durch das vordere Scheidengewölbe. Wegen Verletzung des Uterus durch das Ausreissen dex Kugelzangen Totalextirpation, die nicht indicirtwar, da die zweite Tube anscheinend normal war. Heilung.

1443/1898. J. W., 30 Jahre. 3 normale Geburten, letzte vor 2 Jahren. 1897 Abortus. Jänner 1898 Excochleation, daruach regelmässige Periode. 23. IV. hettige Blutung. Seit 1. V. andauernde Blutung, Schmerzen im 1. Parametrium. Hinter dem vergrösserten anteflectirten Uterus ein circa eigrosser, höckeriger Tumor. 3. VI. Kolpotomia anterior (R. Braun). Im exstirpirten l. Ovarium kein Corpus lut. (daher äussere Ueberwanderung), aber eine kleine Cyste. Tube im Verlauf vou $3 \mathrm{~cm}$ normal, abdomivelles Ende offen, Fimbrien nicht aneinandergelegt; die Tube in der abdominellen Hälfte von Blutcoagalis bedeckt, die den Tubentumor mit dem Ovarium verbinden. In der grössten Anschwellung der auf der Sonde eröffneten Tube (2 cm vom Fimbrienende) ein taubeneigrosses Blutgerimnsel, in den äusseren Schichten mehr, in den inneren weniger organisirt. Auch hier kann man wie in Fall VII sich vorstellen, dass nach Resorption der Mole und der durch die Blutung um das Ovarium bedingten Adhaesionen Restitutio ad integrum hätte eintreten können.

XII. Haematocele. Wiederholte Nachschübe mit Collaps. Abgestorbenes $\mathrm{Ei}$ in einer Blutmole in der Ampalle. Die letzten Collapszustände trotz Rubelage und Eisbeutel. Laparotomie. Heilung.

Privatfall. A. W., 32 Jahre. 3 Geburten, letzte vor 3 Jahren. 2 Abortus, letzter August 1899. Letzte Menses 28. II. 1900. Patientin fühlt sich nicht gravid. 16. IV. bei der Arbeit plötzlich Krampf, Uebelkeit, Erbrechen, Blutabgang, Collaps. 1 Tag Ruhelage. Blutabgang bis 20. IV. Zweiter Collaps. Arzt, jetzt geholt, diagnosticirt Abortus und holt aus der Vagina einen Gewebsfetzen heraus. 21. IV. 
3. Collaps. Nach dem Sistiren der Krämpfe Oberkörper steif, Schmerzen in Axilla and Brust. Aerztl. Diagnose: Gelenkrhenmatismus. 24. IV. Vorm. 4. Collaps.

Nachm. Pat. collabịt, T. 38, P. 120. Muttermund etwas eröffnet, Uterus vergrössert, etwas elevirt, Fundus nach $r$. gedrängt durch einen links hinter ihm liegenden kleinkindskopfgrossen, den Douglas herabdrängenden Tumọ. Meine Diagnose: Haematocele. Bettruhe, Eisbeutel. 28. IV. Schmerzen, 5. Collaps. 5. V. 6. Collaps. Transport ins Sanatorium. Befund wesentlich geändert: Tumor mannskopfgross, reicht fast bis zum Nabel. Hinter dem Uterus eine in den Tumor übergehende Resistenz. 5. V. Laparotomie: zahlreiche Adhaesionen. Der Haematocelensack reisst ein. Nach Entfernung der Coagula wird ein orangengrosser Tumor emporgehoben. Adhaesionen der Flexur am Tumor und Ligament. Absetzen des Tumors. Mikulicz. Geheilt entlassen am 13. Tage p. op.

Präparat. Die anscheinend normale Tube gebt über in den Tumor. An $3 / 4$ der Peripherie eine der Tubenwand entsprechende Hülle des Tumors, an der restlichen Partie ist dieses den Tumor darstellende Blutcoagulum obne Hïlle. Im Centrum der Tube eine haselnussgrosse, plattgedrückte, von zarter Nembran ausgekleidete Höhle mit dünngallertartigem Inbalt. Es handelt sich um ein Blutcoagulum im Fimbrienende, das in sich das zerfallende Ei enthielt.

XIII. Alte, in Rückbildung begriffene Haematocele und Tubenmole. Vaginale Koeliotomie durch das hintere Scheidengewölbe. Heilung.

Privatfall. A. K., 35 Jahre. Opara. Letzte Menses 23. IV. 1900, 8 Tage zu früh; seither keine Blutung. 2. VI. plötzlich heftige, den menstruellen ähnliche Schmerzen, Abgang einiger Tropfen Blates. Blutung und Schmerzen durch 8 Tage. 11. VI. beim Stuhlgang kolikartige, von rechts her ausstrahlende Schmerzen. 12. VI. Abgang eines fleischartigen Klumpens aus der Vagina, Nachlassen der Schmerzen. Wegen der langdauernden Blutungen Excochleation rou anderer Seite, erfolglos. Pat. wird mit der Wahrscheinlichkeitsdiagnose "Myom" überwiesen. 26. VII. 1900: Portio nicht aufgelockert, Muttermund erweitert, Uterus kaum vergrössert. Hinter ihm, knapp anliegend, ein ca. eigrosser Tumor, deutlich beweglich ohne Mitbewegung des Uterus. Tubenabgang am Uterus deutlich constatirbar. Linke Adnexe normal. Douglas nicht herabgedrängt. Wahrscheinlichkeitsdiagnose; Graviditas extrauterina. 27. VII. Vag. Koeliotomie durch das hintere Scheidengewölbe. Tube im Verlaufe von $8 \mathrm{~cm}$ geschlängelt, vielfach knotig. aufgetrieben, abdominelles Ende geschlossen; eine taubeneigrosse Auftreibung im ampullaren Antheile, darin ein $31 / 2 \mathrm{~cm}$ langes, $1 / 2$ dickes Blutcoagulum. Das Lumen des uterinwärts gelegenen Tubenantheils stark erweitert, die Schleimhaut gewulstet und in Falten gelegt.

XIV. Tubenmole in alter Haematocele. Vaginale Koeliotomie durch das hintere Scheidengewölbe. Heilung.

Privatfall. B. S., 26 Jahre. 3 Geburten, 1 Abortus. Seit 2 Jahr. irreguläre Menses, letzte am 11. VI. 1899. Vom 14. VIII. an fortwährend unregelmässige Blutungen. 29. VIII. starke Schmerzen, besonders von der rechten Seite ausstrahlend. 9. IX. starke Blutang, Schmerzen, Ohnmachtsanfälle, Erbrechen. Tamponaden. 20. IX. eigene Untersuchung: Uterus vergrössert, sinistroponirt, rechts hinter ihm ein den Douglas herabdrängender, gänseeigrosser, nach aufwärts nicht deut- 
lich abgrenzbarer Tumor (Darmadhaesionen), In de r B ust viel C o lo s t r u m. Wahrscheinlichleitsdiagnose: Haematocele. 9tägige Ruhelage auf der Klinik. Entlassung auf eigenes Verlangen. 6. X. starke Blutungen, wehenartige Schmerzen auf der rechten Seite. Tastbefund wenig geändert. Die socialen Verbältnisse drängen zur Operation. (Pat. ist Kutschersgattin.) 10. X. Kolpotomia posterior. Einreissen der Tumorwand beim Herauspräparieren. Entwickelung des Tumorrestes (die in ihrem mittleren Antheile verdickte Tube nnd das Ovarium). Abtragung. Secundärligaturen. Einnähen des Stieles in die Laquearwunde. Drainage. Präparat: Am isthmischen Theile der Tube eine elliptische wallnussgrosse Auftreibung. Der ca, $5^{1 / 2} \mathrm{~cm}$ lange abdominelle Theil der Tube leicht geschlängelt, kleinfingerdick. Fimbrienenden frei. Am Durchschnitt der Auftreibung eine Blutmole. Im abdomin. Tubentheile gleichfalls congulirtes Blut.

Bei der Untersuchung nach mehreren Monaten war der Uterus in normaler Lage, beweglich; Pat. beschwerdenfrei. Auch hier kann man wie in den Fällen VII und IX wegen des Offenseins des Fimbrienendes eine Restitutio ad integrum bei conservativer Therapie sich leicht vorstellen.

XV. Vor dem Uterus allenthalben adhaerente Ovarialcyste mit blutigem Inhalt und verschiedenen Schichten organisirten Blutes an der Tumorwand in Folge von Stieltorsion, so dass der Eindruck der Haematocele anteuterina erweckt wird. Laparotomie. Heilung.

2645/1896. 'R. B., 32 Jahre. 4 Geburten, letzte 28. IV. 1896. Seither Bauch angeblich nicht kleiner geworden. Erste Menses p. p. 26. VI. von 2 tägiger Dauer. Nach 10 Tagen wieder blutiger Ausfluss unter Schmerzen in der rechten Seite. Damn regelmässige aber schmerzhafte Menses. Im vorgewölbten Abdomen eine ovale, $2 \mathrm{~cm}$ über den Nabel reichende, fluctuirende, wenig bewegliche Geschwulst von glatter Oberfläche. Uterus retroponirt. Unterer Geschwulstpol durch das vordere Laquear tastbar. Diagnose: Ovarialcyste vor dem Uterus. Laparotomie (R. Brann). Beim Tieferpräpariren gelangt man in die Wand des Tumors, der eine braunrothe, faserige Substanz darstelit. Dunkelrothe, theils flüssige, theils verdickte Blutmassen entleeren sich. Herauspräpariren der Sackwandung nach Verschluss der Incisionswunde. Adhaesionen an Netz und Darm. Herausschälen des Tumors aus der Plica resicouterina, daselbst starke parenchym. Blutung. Linke Tube normal. Im l. Ovarium eine kleimussgrosse Cyste, die beim Herausnehmen platzt, Resection des Ovariums, Naht (8 Suturen). Absetzen des Tumors, Versorgen des Stiels, Fritsch'sche Tamponade des Cavum vesicouterinum. Glatter Verlauf. Pat. seither beschwerdefrei, Pr äp a r a t (Prof. Kolisko): Manoskopfgrosse, cystische Geschwulst, am unteren Pole die Stelle des Stieles (intra op. hatte ich den Eindruck einer Stieldrehung) im Sinne des Torsionsgesetzes. Von der Absetzungsstelle des Stieles lässt sich die Tube in geradem Verlaufe durch $10 \mathrm{~cm}$ durch eine Sonde verfolgen. Am Ende dieses Kanales eine knopfartige, mit einer zarten Membran überzogene Erhabenheit, die beim vorsichtigen Sondiren dehiscirt, so dass eine Oeffunng entsteht (Fimbrienende). Von der Absetzungsstelle des Stieles auch ein 2. Abschnitt der Tube zu verfolgen, der ca. $6 \mathrm{~cm}$. lang ist und in einem Halbkreis verläuft. An der stellenweise mehr als $1 \mathrm{~cm}$ dicken Wand des Tumors verschiedene Schichten von organisirtem Blut, an anderen Stellen ist die Wand sehr 
dünn. Erst beim Durchschneiden des unteren Geschwulstabschnittes findet man den Bau eines glandulären, multiloculären Kystoms vor. Inhalt der einzelnen Cystchen colloide, blutigbraunrothe Flüssigkeit.

XVI. Pyosalpinx, eine Haematocele vortäuschend. Collaps er Patientin bei vorsichtiger Untersuchung, täuscht eine nnere Blutung vor. Laparotomie. Drainage. Heilung.

602/1896. E. Th., 28 Jahre. 4 Geburten, letzte im October 1894. Letzte Menses schwächer als sonst begonnen am 19. II. 1896. Seit 8 Tagen Schmerzen im l. Parametrium. Seit 1 Monat Magenbeschwerden. 27. II. Portio lacerirt, etwas aufgelockert, leicht verfärbt. Uterus etwas vergrössert, Fundus nach $r$. verdrängt, wenig beweglich. Links hinter ihm eine frauenfaustgrosse, elastische, in manchen Partien weichere Geschwulst. Uterus dagegen verschieblich. Uterines Tubenende verdickt. Colostrum in den Brüsten. Untersuchung sehr schmerzbaft. Haematocele retrouterina (?). 6. III. Nach einer vorsichtigen Untersuchung Collaps, Dyspnoe, Erbrechen, leicht unterdrückbarer Puls. Diagnose einer inneren Blutung, Laparotomie (R. Braun): Darmadhaesionen; nach deren Lösung steigt Eiter empor. Rechte Adnexe nach rückwärts geschlagen, mit den linken zu dem getasteten Adnexentumor vereint. Pyosalpinx bilateralis und perisalpingitische Abscesse. Abtragung des Tumors, Drainage nach Fritsch. Afebriler Verlauf, Heilung. Mikroskopisch keine Mikroorganismen nachweisbar.

XVII. Pyosalpinx profluens mit Bildung einer abgekapselten Eiterhöhle im Douglas (Pyocele), eine Haematocele mit Nachsehüben vortäuschend. Laparotomie. Heilung.

2695/1898. A. W., 30 Jahre. Vor 4 Jahren Partus, manaelle Placentalösung. 2 Tage nach dem Auftreten der letzten etwas stärkeren Menses brauner Ausfluss. 3. X. Nachm. plötzliches Unwohlsein, Mattigkeit, Schwindel. Ohnmacbt. Gleichzeitig krampfartige Schmerzen im Bauch, die Nachts sich steigerten. Patientin war Anfangs September in einem Spitale mit Retroflexio uteri in Behandlung und wurde massirt. 4. X. eigene Untersuchung: Patientin blass, Augen halonirt. Puls 140. Kein Erbrechen, Bauch weich, rechts Druckschmerzhaftigkeit. Portio deutlich aufgelockert. Aensserer Muttermund offen. Uterus vergrössert, sinistrovertirt, rechts und hinter ihm ein gänseeigrosser, weicher Tumor, gegen den der Fundus uteri deutlich abgrenzbar ist. Linke Adnexe nicht zu tasten. Starke uterine Blutung. Ruhelage, Eisbeutel. Besserung der Schmerzen. 6. X. neuerliche Schmerzen. 9. X. plötzlich schwerer Collaps mit Bewusstseinsverlust. 10. X. Pat. verfallen, Puls leicht unterdrückbar, Temp. 39,6. Transport ins Spital. Der Tumor schien bei der innerlichen Untersuchung grösser. Diagnose: Haematocele mit Nachschüben. 9 Uhr Abds. Laparotomie (R. Braun): Starke Darmverwachsungen. Nach dem ersten Lösungsversuch stei gt Eiter aus der Tiefe. Exstirpation der erkrankten Adnexe. Der Douglas bedeckt mit ca. $2 \mathrm{~mm}$ dicken pyogenen Membranen. Fritsch'sche Tamponade. Heilung.

Präparat: An den r. Adnexen findet man eine Tube, die nahe dem uterinen Ende normale Dicke aufweist, gegen das abdominelle Ende bis zu Daumendicke anschwillt. Peritoneum der Tube und Fimbrien stark injicirt. Das Fimbrienende ist vollständig frei, scbön trichterförmig, so dass auf Druck aus dem TubenIumen Eiter berausquillt. Schleimhaut der Tube enorm gewulstet. Orarium vergrössert, cystisch degenerirt. Befund an den l. Adnexen ähnlich, 
nur entleert die Tube auf Druck mehr Eiter als rechterseits, Fimbrienende einen breiten offenen Trichter darstellend, auch das Ovarium cystisch degenerirt. Die Tuben und Ovarien sind nicht durch perimetritische Stränge verbunden, sondern nur von Eiter umgeben. Bakteriologische Untersuchung negativ. Resumirend möchte ich die Erscheinungen bedingt halten durch einen Pyolalpix profluens mit Bildung einer Pyocele, wenn ich per analogiam mit der Haematocele dieses Wort gebrauchen darf. Auffällig ist, dass erst nach mehrtägiger Beobachtung Fieber auftrat. Es darf nicht übersehen werden, dass Pat. vor einigen Wochen wegen Retroflexio in einem Frauenspitale massirt wurde, und es erscheint daher ausgeschlossen, dass damals der rechtsseitige Tumor schon vorhanden war. Es scheint daher die Entstehung des Tumors mit den von Collapsanfällen begleiteten Schmerzanfällen in aetiologischem Zusammenhang zu stehen. Ich vermuthe daher, dass diese Schmerzanfälle durch das Profluiren von Eiter aus den erkrankten Salpinges erregt wurden und der Tumor in der Weise entstand, dass um den in die Bauchböhle ergossenen Eiter durch Verlöthung der Gedärme sich eine Kapsel gebildet hat. Da der Gatte der Patientin, während sie im Spitale lag, an einer Epididymitis (nach seiner Angabe infolge von Trauma) erkrankt sein soll, ist ein gonorrhoischer Ursprung der Erkrankung nicht ausgeschlossen.

Zum Schlusse erfülle ich eine angenehme Pflicht, wenn ich meinem verehrten Lehrer und ehemaligen Chef Herrn Hofrath G. v. Braun für die Ueberlassung der verwendeten klinischen Fälle und des Privatfalles II zur Publikation meinen ergebenen Dank ausspreche. 